\title{
A utilização de modelos geoidais e altimetria por satélite no estudo das variabilidades no nível do mar e correntes geostróficas no Atlântico Sul e região da Confluência Brasil Malvinas
}

\begin{abstract}
Tese apresentada ao Instituto Oceanográfico da Universidade de São Paulo, como parte dos requisitos para obtenção do título de Doutor em Ciências, área de Oceanografia Física.
\end{abstract}

Orientador: Prof. Dr. Joseph Harari 


\title{
UNIVERSIDADE DE SÃO PAULO
}

INSTITUTO OCEANOGRÁFICO

\begin{abstract}
A utilização de modelos geoidais e altimetria por satélite no estudo das variabilidades no nível do mar e correntes geostróficas no Atlântico Sul e região da Confluência Brasil Malvinas
\end{abstract}

Alexandre Bernardino Lopes

JULGADA EM POR:

Prof. Dr:

conceito

Prof. Dr:

conceito

Prof. Dr:

conceito

Prof. Dr:

conceito

Prof. Dr:

conceito 

Que seja denso enquanto dure. 


\section{Sumário}

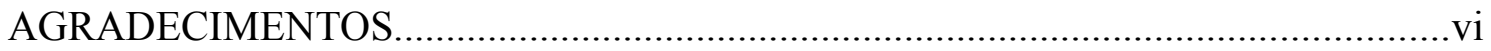

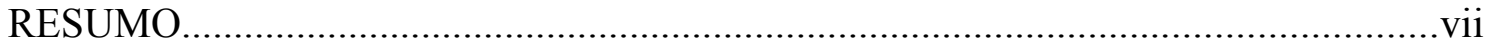

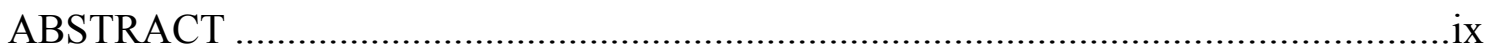

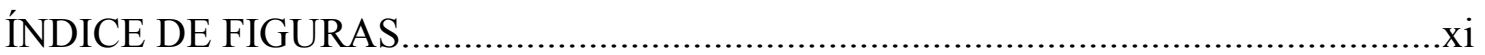

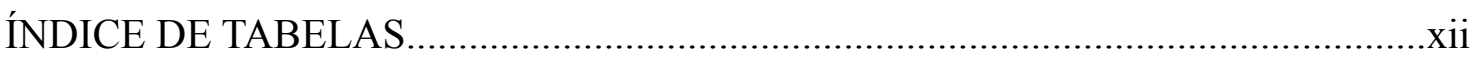

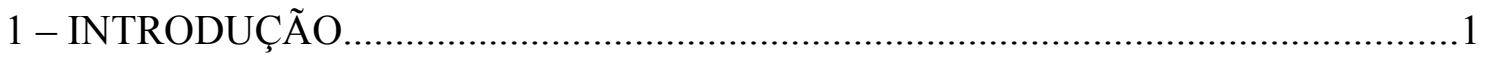

1.1 - As regiões de estudo ...............................................................................

1.3 - Método direto e método combinado .................................................................

1.4 - Hipóteses.........................................................................................

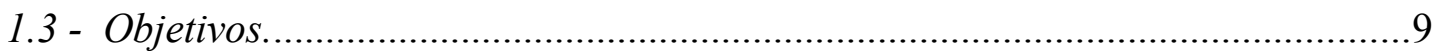

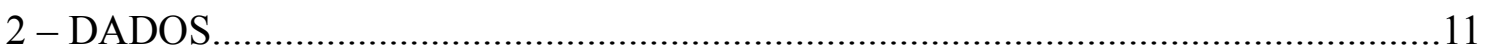

2.1 - O campo da gravidade terrestre e suas aplicações............................................11

2.2 - Altimetria por satélite, dados do TOPEX/POSEIDON e JASON …………........21

2.3-O modelo de nivel médio do mar DNSC08......................................................24

2.4 - O modelo numérico HYCOM......................................................................24

2.5 - Dados AVISO: Topografia dinâmica absoluta e correntes geostróficas.............26

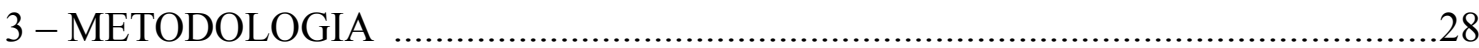

3-1 - Processamentos dos dados do TOPEX/Poseidon e Jason 1...............................28

3.2 - Determinação dos modelos geoidais estáticos.................................................29

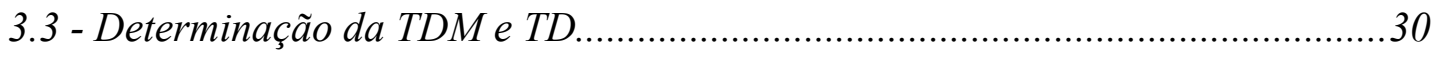

3.4 - Os métodos estatísticos de Filtragem …………………………………….....

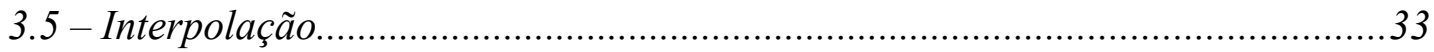

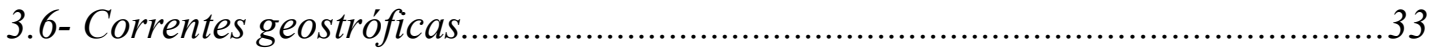

3.7 - Análise da TDM e correntes geostróficas médias no Atlântico Sul.....................34

3.8 - Comparação e análise das TDs e correntes geostróficas absolutas na região da

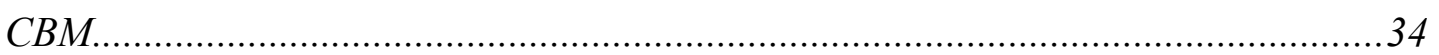

3.8 - Análise das correntes geostróficas................................................................

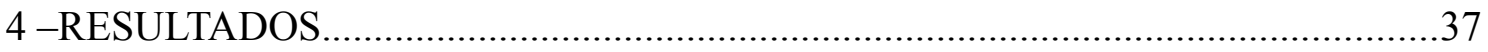

4.1 - Os modelos geoidais e respectivas aplicações na determinação da TDM.........37 
4.2 - Aplicação do filtro SSA e comparação com o filtro gaussiano. 39

4.3 - Correntes geostróficas médias resultantes. 44

4.4 - Variação temporal da TD na região da CBM e comparação dos resultados de diferentes modelos. 49

4.5 - Correlação temporal entre as TDs na região da CBM...... 65 4.6 - Corrente geostróficas na região da CBM e sua comparação com os produtos do modelo numérico HYCOM. .66

4.7 - Variabilidade temporal das componentes barotrópicas da Corrente do Brasil, Corrente das Malvinas e Corrente do Atlântico Sul........ .78 4.8 - Análise da Corrente do Brasil e Corrente das Malvinas através do método direto, para o período de 1992 a 2005. .83 4.9 - Correlações entre as correntes geostróficas obtidas com modelos geoidais as correntes geostróficas do modelo numérico HYCOM.. 86 5 - DISCUSSÕES

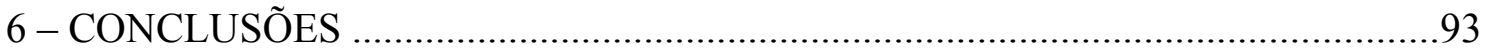

7 - SUGESTÕES PARA TRABALHOS FUTUROS...................................................95 


\section{AGRADECIMENTOS}

Ao Professor Dr. Joseph Harari pela orientação e por ter compartilhado todos os momentos difíceis ao longo da jornada;

Ao Professor Ilson da Silveira pela amizade e por ter acreditado na concretização do trabalho;

A todos os professores do IO, cuja disciplinas oferecidas foram de grande proveito;

Ao CNPq pela bolsa concedida, que foi de grande auxílio;

Aos funcionários do IO, pelo apoio técnico;

A todos meus colegas do IO, por compartilhar o conhecimento e pelo apoio;

A Ana Paula, minha companheira durante todo o tempo em que estive envolvido com este projeto;

Aos meus pais João B. Lopes e Maria Nelina F. Lopes e meus irmãos Agnaldo F. Lopes, Rodrigo F. Lopes e Álvaro F. Lopes, por todo apoio em todos os momentos;

A Luiz Tadeu Lopes, pela convivência durante todo o tempo que estive em São Paulo;

A Isaac Ramos e pela amizade e por ter oferecido a oportunidade de trabalhar em um ambiente que sempre apoiou meu projeto de pesquisa e ao companheiro de trabalho Cícero A . Teixeira, pela amizade e confiança;

Aos mestres Everton e André, pelas densas manifestações;

A todos os amigos $3^{\circ}$ Oficial de Registro de Imóveis, em especial a Sandra, Lívia, André, Fernando, Victor, João, Fabiano e ao Dr. George Takeda por serem compreensivos nas horas em que tive que me ausentar do trabalho para dedicar a concretização desta tese. 


\section{RESUMO}

A variação do nível do mar em relação ao geóide é conhecida como Topografia Dinâmica do oceano, cuja determinação é importante no estudo da circulação geostrófica, vórtices e outros fenômenos. O sinal do geóide predomina na definição da topografia dinâmica em todos os comprimentos de onda, ou seja, o nível do mar está intimamente ligado ao campo geopotencial. Os modelos geoidais globais anteriores ao GRACE eram precisos para comprimentos de onda com centenas de quilômetros, já em curtos comprimentos de onda (menores que $100 \mathrm{~km}$ ) esses modelos não possuíam resolução suficiente, prejudicando assim a determinação da TD e, conseqüentemente, o estudo de fenômenos com comprimentos de ondas na faixa de 100 a $200 \mathrm{~km}$. No desenvolvimento do modelo EGM96, foram inseridos novos dados gravimétricos de superfície, além de dados de órbitas de satélites e altimetria, obtendo-se assim melhora considerável em relação ao modelo OSO91A (incorporado aos dados do TOPEX/Poseidon); ainda sim, o modelo EGM96 possui erro de aproximadamente 18 $\mathrm{cm}$, que é considerado alto para várias aplicações oceanográficas. Recentemente, foram divulgados os modelos globais do campo de gravidade EIGEN-5C (obtido através dos dados do GRACE) e EGM2008, completos para grau e ordem 360 e 2159 em termos de coeficientes harmônicos esféricos, respectivamente; estes modelos possibilitaram a estimativa de correntes com resolução e precisão superior ao modelo EGM96. No presente trabalho, os modelos geoidais citados acima, juntamente com o modelo de nível médio do mar DNSC08, foram usados na determinação da topografia dinâmica média e das correntes geostróficas absolutas médias (no período de 2003 a 2008) utilizando o método de filtragem SSA no Atlântico $\mathrm{Sul}\left(20^{\circ} \mathrm{N}\right.$ a $55^{\circ} \mathrm{S}, 80^{\circ} \mathrm{W}$ a $\left.20^{\circ} \mathrm{E}\right)$. Os resultados foram comparados com produtos do modelo numérico HYCOM, demonstrando que os modelos geoidais recentes (EIGEN-5C e EGM2008) apresentaram resultados satisfatórios na determinação da TDM e correntes, com a plena identificação das principais feições de grande e meso escala, o que não ocorre com a TDM do EGM96. A Corrente do Brasil, entre $20^{\circ} \mathrm{S}$ e $30^{\circ} \mathrm{S}$, na isóbata de $200 \mathrm{~m}$, apresentou velocidades resultantes médias de aproximadamente $0.20 \mathrm{~m} / \mathrm{s}$ (desvio padrão de 0.09 $\mathrm{m} / \mathrm{s}$ ) quando determinada com a TDM-EGM2008, $0.22 \mathrm{~m} / \mathrm{s}$ (desvio padrão de $0.12 \mathrm{~m} / \mathrm{s}$ ) 
utilizando a TDM-EIGEN-5C, embora os ruídos interfiram na estimativa, e $0.30 \mathrm{~m} / \mathrm{s}$ (desvio padrão de $0.17 \mathrm{~m} / \mathrm{s}$ ) considerando a TDM-EGM96; o modelo numérico HYCOM forneceu velocidade de $0.25 \mathrm{~m} / \mathrm{s}$ (desvio padrão de $0.13 \mathrm{~m} / \mathrm{s}$ ) na mesma região. Estatisticamente, as correntes do modelo TDM-EGM08 possuem maior correlação espacial com o modelo numérico HYCOM, 0.7 para $u$ (componente EW) e 0.69 para $v$ (componente NS); por outro lado, as correntes oriundas da TDM-EIGEN-5C apresentaram uma correlação de 0.62 para $u$ e 0.64 para $v$, enquanto que as correntes do modelo TDM-EGM96 apresentaram uma correlação de 0.10 para $u$ e 0.11 para $v$. Uma alternativa no uso de dados de altimetria de satélites (Jason, por exemplo) se encontra em dados de altimetria multi-satélites combinados com resultados de medições in-situ, submetidos a análise objetiva (são portanto dados combinados, MERGED, fornecidos pela AVISO); com esses dados se tem significativo aumento de precisão e resolução dos dados de altimetria, da topografia dinâmica e das correntes geostróficas. $\mathrm{Na}$ região que engloba a Confluência Brasil Malvinas $\left(50^{\circ} \mathrm{S}\right.$ a $20^{\circ} \mathrm{S}, 70^{\circ} \mathrm{W}$ a $\left.30^{\circ} \mathrm{W}\right)$ foram analisadas as variações temporais da topografia dinâmica e correntes oriundas de altimetria e do modelo geoidal EGM2008. Na análise específica desta região, verificouse que, apesar das principais feições terem sido identificadas, os dados de altimetria ainda carecem de resolução necessária no estudo das mesmas. O modelo EGM2008 apresentou os melhores resultados que os outros modelos (comparando com o modelo HYCOM e dados combinados de AVISO), devido à sua resolução espacial. 


\section{ABSTRACT}

The variations of sea level relative to the geoid are known as Dynamic Ocean Topography (DOT), whose determination is important in studies of the geostrophic circulation, eddies and other phenomena. The sign of the geoid predominates in the definition of dynamic topography at all wavelengths, ie, sea level is closely linked to the geopotential field. Global geoid models prior to GRACE were precise for wavelengths of hundreds of kilometers, but in short wavelengths (less than $100 \mathrm{~km}$ ) these models did not have enough resolution, thus impairing the determination of DOT and therefore the study of phenomena with wavelengths in the range of 100-200 km. In developing the EGM96, new surface gravity data were incorporated into the modeling, from satellite orbits and altimetry, resulting in a considerable improvement over the previous OSO91A (incorporated to TOPEX / Poseidon data); still EGM96 had a standard deviation of about $18 \mathrm{~cm}$, considered too high for many oceanographic applications. Recently, global models of the gravity field were published, EIGEN-5C (obtained from GRACE data) and EGM2008, complete to degree and order 360 and 2159 in terms of spherical harmonic coefficients, respectively; these models allowed the estimation of currents with resolution and accuracy better than model EGM96. In this work, the geoid models mentioned above, along with models of mean sea level such as DNSC08, were used in the determination of DOT and absolute geostrophic currents (in 2003-2008) using the filtering method SSA (Singular Spectrum Analysis) in South Atlantic $\left(20^{\circ} \mathrm{N}\right.$ $\left.55^{\circ} \mathrm{S}, 80^{\circ} \mathrm{W}-20^{\circ} \mathrm{E}\right)$. The results were compared with products from HYCOM hydrodynamic numerical model and show that recent geoid models (EIGEN-5C and EGM2008) lead to satisfactory results in determining the Average Dynamic Topography (ADT) and currents, with full identification of the main features of large and meso scales, which does not occur with ADT_EGM96. The Brazil Current $\left(20^{\circ} \mathrm{S}-30^{\circ} \mathrm{S}\right)$, in the $200 \mathrm{~m}$ isobath, had average speed results of approximately $0.20 \mathrm{~m} / \mathrm{s}$ (standard deviation $0.09 \mathrm{~m} / \mathrm{s}$ ) when computed with ADT-EGM2008, $0.22 \mathrm{~m} / \mathrm{s}$ (standard deviation $0.12 \mathrm{~m} / \mathrm{s}$ ) by using ADT_EIGEN-5C, despite noise interference with the estimate, and $0.30 \mathrm{~m} / \mathrm{s}$ (standard deviation $0.17 \mathrm{~m} / \mathrm{s}$ ) considering the ADT_EGM96; the numerical model HYCOM provided speed of $0.25 \mathrm{~m} / \mathrm{s}$ (standard deviation $0.13 \mathrm{~m} / \mathrm{s}$ ) in the same region. Statistically, the currents based on model ADT_EGM08 have higher correlation with the 
numerical model HYCOM, 0.70 for u (EW component) and 0.69 for v (NS component); on the other hand, the currents computed with ADT_EIGEN-5C had correlations of 0.62 for $\mathrm{u}$ and 0.64 for $\mathrm{v}$, while currents estimated from ADT_EGM96 showed correlations of 0.10 for $\mathrm{u}$ and 0.11 for $\mathrm{v}$. An alternative in the use altimetry data (Jason, for example) is found in altimetry multi-satellites data combined with results of measurements in-situ, submitted to objective analysis; with these data, a significant increase of precision and resolution is reached for the altimetry data, dynamic topography and geostrophyc currents. In the region encompassing the Brazil Malvinas Confluence $\left(50^{\circ} \mathrm{S}-20^{\circ} \mathrm{S}, 70^{\circ} \mathrm{W}-30^{\circ} \mathrm{W}\right)$ were analyzed temporal variations of DOT and currents derived from altimetry and geoid model EGM2008. In the specific analysis of this region, it was found that although the main features have been identified, the altimetry data still lacks resolution to study them. The model EGM2008 showed the best results (comparing with the HYCOM model and combined data of AVISO), due to their spatial resolutions. 


\section{ÍNDICE DE FIGURAS}

Figura 1.1: Representação esquemática da Circulação no Atlântico Sul. (fonte:

CIRANO et al. (2006), adaptado de PETERSON \& STRAMMA (1991))........................5

Figura 1.2: Batimetria da região de estudo Região do Atlântico Sul...............................6

Figura 1.3: Batimetria da região de estudo no Sudoeste do Atlântico Sul......................8

Figura 2.1: Modelo geoidal EGM2008, referenciado ao elipsóide utilizado pelo

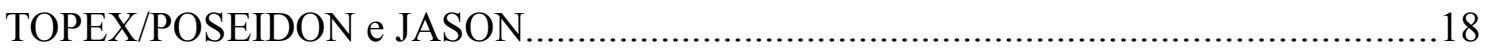

Figura 2.2: Amplitudes dos coeficientes harmônicos......................................................19

Figura 2.3: Relações entre os erros dos coeficientes e os coeficientes, em função dos

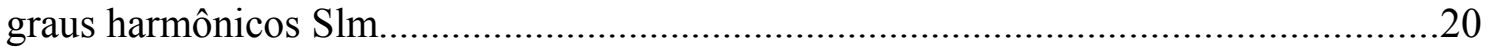

Figura 2.5: Passagens do TOPEX/POSEIDON para o Atlântico Sul..............................24

Figura 2.6: Velocidades médias na superfície do modelo numérico HYCOM................25

Figura 2.7 - Método de determinação da Topografia Dinâmica Combinada .................27

Figura 3.1: Sistema de referência da TD................................................................... 31

Figura 3.2: Localização dos pontos em que foi analisada a topografia dinâmica............36

Figura 3.3: Localização dos pontos em que foram analisadas e comparadas as correntes .

Figura 4.1: Topografia Dinâmica determinada com o modelo geoidal EGM2008 truncado em grau e ordem 2159

Figura 4.2: Topografia Dinâmica determinada com o modelo geoidal EGM2008

truncado em grau e ordem 360 .

Figura 4.3: Topografia Dinâmica determinada com o modelo geoidal EGM2008

truncado em grau e ordem 120.

Figura 4.4: Perfil longitudinal da TDM filtrada e não filtrada na longitude $20^{\circ} \mathrm{W} . . . . . .39$

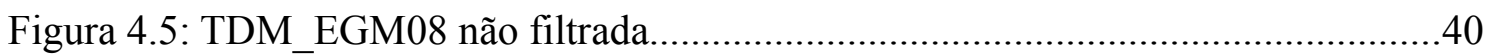

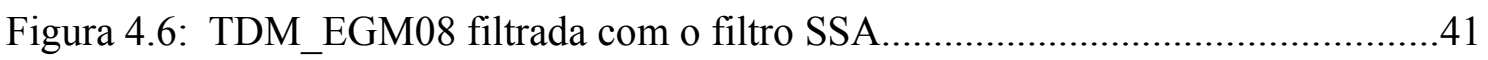

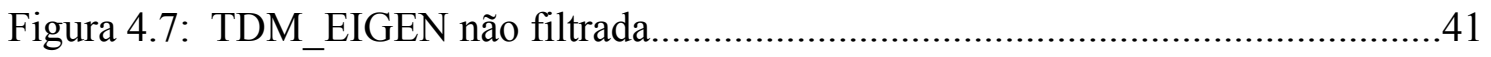

Figura 4.8: TDM_EIGEN filtrada com o filtro SSA ..................................................42

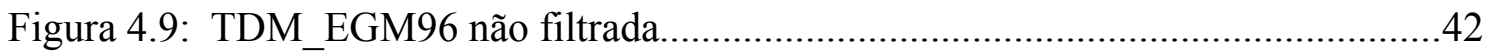

Figura 4.10: TDM_EGM96 filtrada com o filtro SSA................................................43

Figura 4.11: MDT_EIGEN filtrada com o filtro gaussiano...........................................43 
Figura 4.12: Corrente geostrófica determinada a partir da TDM_EGM08...................45

Figura 4.13: Corrente geostrófica determinada a partir da TDM_EIGEN-5C..............45

Figura 4.14: Corrente geostrófica determinada a partir da TDM_EGM96...................46

Figura 4.15: Corrente geostrófica média do modelo numérico HYCOM.....................46

Figura 4.16: Correntes geostróficas médias na região da CBM, a partir da

TDM_EGM08

Figura 4.18: Correntes geostróficas médias na região da CBM, a partir da

TDM EGM96. 48

Figura 4.20: TDA (altimetria - geóide) do verão de 2004 (em cm)..............................50

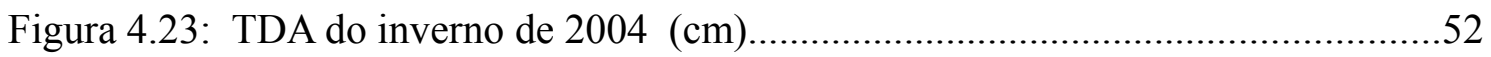

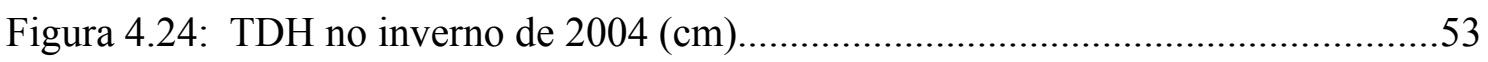

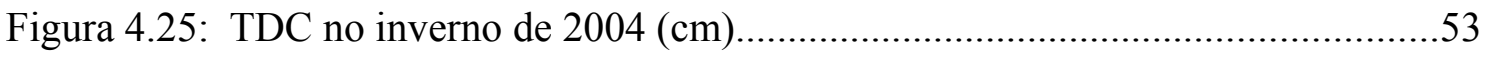

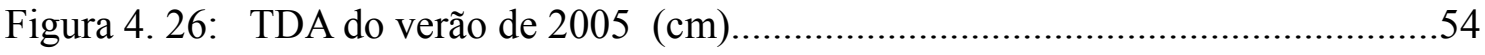

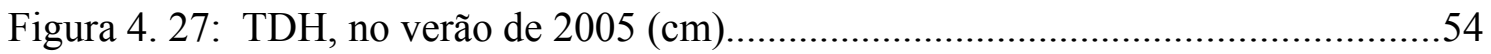

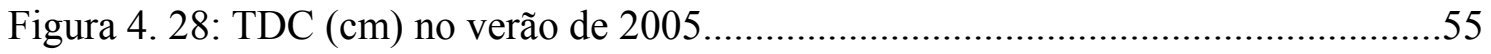

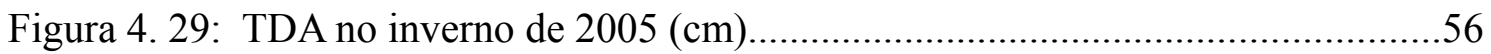

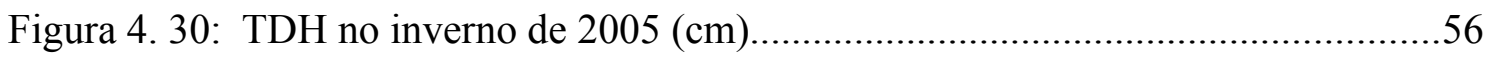

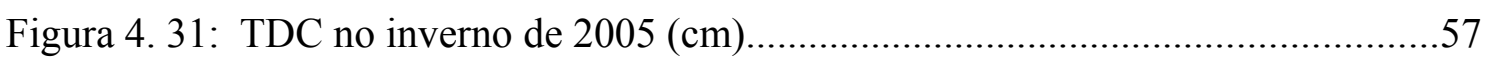

Figura 4. 32: Anomalia do nível do mar em janeiro de 1993 ........................................58

Figura 4.33: Temperatura da superfície do mar calculada pelo modelo ECCO em janeiro de 2004 .

Figura 4.34: Temperatura da superfície do mar calculada pelo modelo ECCO em julho de 2004

Figura 4.35: Comparação entre TDA, TDH e TDC em 54o W e 37o S (superior) e seus espectros (inferior).

Figura 4.36: Comparação entre TDA, TDH e TDC em 52o W e 37o S (superior) e seus espectros (inferior).

Figura 4. 37: Comparação entre TDA, TDH e TDC em 50o W e 37o S (superior) e seus espectros (inferior).

Figura 4. 38: Comparação entre TDA, TDH e TDC em 54o W e 39o S (superior) e seus espectros (inferior). .61

Figura 4.39: Comparação entre TDA, TDH e TDC em 52o W e 39o S (superior) e seus 
espectros (inferior)

Figura 4.40: Comparação entre TDA, TDH e TDC em 50o W e 39o S (superior) e seus espectros (inferior).

Figura 4.41: Comparação entre TDA, TDH e TDC em 54o W e 41o S (superior) e seus espectros (inferior).

Figura 4.42: Comparação entre TDA, TDH e TDC em 52o W e 41o S (superior) e seus espectros (inferior).

Figura 4.43: Comparação entre TDA, TDH e TDC em 50o W e 41o S (superior) e seus espectros (inferior).

Figura4. 44: Correlação temporal e significância entre a TDH e TDA na região da CBM.

Figura4. 45: Correlação temporal e significância entre a TDH e TDC na região da $\mathrm{CBM}$

Figura4. 46: Circulação determinada com a anomalia do nível médio do mar em janeiro de 2004

Figura 4. 47: Correntes geostróficas determinadas com dados altimétricos e o modelo geoidal EGM08 (CGA) no verão de 2004.

Figura 4.48: Correntes geostróficas determinadas com dados do modelo numérico HYCOM (CGH) no verão de 2004.

Figura4. 49: Correntes geostróficas determinada com dados combinados (CGC) no verão de 2004.

Figura 4.50: Correntes geostróficas determinadas com dados altimétricos e o modelo geoidal EGM2008(CGA) no inverno de 2004

Figura 4.51: Correntes geostróficas determinadas com dados do modelo numérico HYCOM (CGH) no inverno de 2004.

Figura 4.52: Correntes geostróficas determinadas com dados combinados (CGC) no inverno de 2004.

Figura 4.53: Correntes geostróficas determinadas com dados altimétricos e o modelo geoidal EGM08 (CGA) no verão de 2005.

Figura 4.54: Correntes geostróficas determinadas com dados do modelo numérico HYCOM (CGH) no verão de 2005. 
Figura4. 55: Correntes geostróficas determinadas com dados combinados (CGC) no verão de 2005 .

Figura 4.56: Correntes geostróficas determinadas com dados altimétricos e o modelo geoidal EGM08 (CGA) no inverno de 2005

Figura 4. 57: Correntes geostróficas determinadas com dados do modelo numérico

HYCOM (CGH) no inverno de 2005.

Figura 4. 58: Correntes geostróficas determinadas com dados combinados (CGC) no inverno de 2005 .

Figura 4.59: Comparação das médias de u e v, sendo MUH38/MVH38 as correntes fornecidas pelo modelo HYCOM (componente barotrópica e baroclínica), MUGH38/MVGH38 as correntes geostróficas determinadas com a TDH e MUT38/MVT38 as correntes geostróficas com a TDA, na latitude de 38o S.

Figura 4.60: Comparação das médias de u e v, sendo MUH39/MVH39 as correntes fornecidas pelo modelo HYCOM (componente barotrópica e baroclínica), MUGH39/MVGH39 as correntes geostróficas determinadas com a TDH e MUT39/MVT39 as correntes geostróficas com a TDA, na latitude de 39o S

Figura 4.61: Comparação das médias de u e v, sendo MUH40/MVH40 as correntes fornecidas pelo modelo HYCOM (componente barotrópica e baroclínica), MUGH40/MVGH40 as correntes geostróficas determinadas com a TDH e MUT40/MVT40 as correntes geostróficas com a TDA, na latitude de 40o S

Figura4. 62: Comparação das médias de u e v, sendo MUH41/MVH41 as correntes fornecidas pelo modelo HYCOM (componente barotrópica e baroclínica), MUGH41/MVGH41 as correntes geostróficas determinadas com a TDH e MUT41/MVT41 as correntes geostróficas com a TDA, na latitude de 41o S

Figura 4.63: Valores de u e v da CB em 31o S e 48o W, sendo U/Vcbme (azul) valores das correntes dos dados combinados, U/Vcbto (vermelho) valores das correntes oriundas de altimetria - geóide e U/Vcbgh (verde) valores da correntes geostróficas do HYCOM.

Figura 4.64: Valores de u e v da CM (46o S e 59o W), sendo U/Vcmme (azul) valores das correntes dos dados combinados, U/Vemto (vermelho) valores das correntes oriundas de altimetria - geóide e U/Vcmgh (verde) valores da correntes geostróficas do HYCOM. 
Figura 4.65: Valores de u e v da CAS (39.5o S e 48o W) sendo U/Vcsame (azul) valores das correntes dos dados combinados, U/Vcsato (vermelho) valores das correntes oriundas de altimetria - geóide e U/Vcsagh (verde) valores da correntes geostróficas do HYCOM

Figura 4.66: Valores de u e v da CAS (41o S e 48o W), sendo U/Vcsame (azul) valores das correntes dos dados combinados, U/Vcsato (vermelho) valores das correntes oriundas de altimetria geóide e U/Vcsagh (verde) valores da correntes geostróficas do HYCOM.

Figura 4.67: Valores da componente de corrente zonal u e seu histograma, para a componente barotrópica da CB, no período de 1992 a 2005

Figura 4.68: Valores da componente de corrente meridional v e seu histograma, para a componente barotrópica da CB, no período de 1992 a 2005

Figura 4.69: Valores da componente de corrente zonal u e seu histograma para a componente barotrópica da CM, no período de 1992 a 2005.

Figura 4.70: Valores da componente de corrente meridional $\mathrm{v}$ e seu histograma para a componente barotrópica da CM, no período de 1992 a 2005.

Figura 4.71: Correlação (esquerda) e significância (direita) da corrente zonal u entre CGH e CGA.

Figura 4.72: Correlação (esquerda) e significância (direita) da corrente meridional v entre $\mathrm{CGH}$ e CGA.

Figura 4.73: Correlação (esquerda) e significância (direita) da corrente zonal u entre a

$\mathrm{CGH}$ e $\mathrm{CGC}$ .88

Figura 4.74: Correlação (direita) e significância (esquerda) da corrente meridional v entre a $\mathrm{CGH}$ e $\mathrm{CGC}$ 


\section{Índice de Tabelas}

Tabela 4.1 - Comparação estatística (médias de todos os pontos de grade) entre as correntes $(\mathrm{U}$ e $\mathrm{V}$ ) do modelo numérico HYCOM e dos modelos geoidais.

Tabela 4.2 - Valores médios da TD (e respectivos desvios padrão STD) para latitudes de 37o S, 39o S, 41o S na latitude de 50o W......

Tabela 4.3 - Valores médios, desvios padrão, máximos e mínimos da componente barotrópica da CB $(\mathrm{u})$ em 31 o S e $480 \mathrm{~W}(\mathrm{em} \mathrm{m} / \mathrm{s})$

Tabela 4.4 - Valores médios, desvios padrão, máximos e mínimos da componente barotrópica da CB (v) em 31o S e 48o W (em m/s).

Tabela 4.5 - Valores médios, desvios padrão, máximos e mínimos da componente barotrópica da CM (u) em 46o S e 59o W (em m/s)...

Tabela 4.6 - Valores médios componente barotrópica da CM (v) em 46o S e 59o W (em $\mathrm{m} / \mathrm{s})$

Tabela 4.7 - Valores médios, desvios padrão, máximos e mínimos da componente barotrópica da CSA (u) em $39.50 \mathrm{~S}$ e $480 \mathrm{~W}(\mathrm{em} \mathrm{m} / \mathrm{s})$

Tabela 4.8 - Valores médios, desvios padrão, máximos e mínimos da componente barotrópica da CSA (v) em 39.5o S e 48o W (em m/s)......

Tabela 4.9 - Valores médios, desvios padrão, máximos e mínimos da componente barotrópica da CSA (u) em 41o S e 48o W (em m/s).

Tabela 4.10 - Valores médios, desvios padrão, máximos e mínimos da componente barotrópica da CSA (v) em 41o S e 48o W (em m/s). 


\section{1 - INTRODUÇÃO}

O nível do mar varia com a posição geográfica e o tempo, em várias escalas espaço-temporais, na horizontal desde alguns metros até milhares de $\mathrm{km}$, e no tempo desde segundos até vários anos. A variação do nível do mar em relação ao geóide é conhecida como Topografia Dinâmica do oceano (TD), cuja determinação é importante no estudo da circulação geostrófica, vórtices e outros fenômenos. Teoricamente, a superfície do oceano média a longo prazo deveria coincidir com o geóide, conseqüentemente a topografia dinâmica deveria ser zero; entretanto, ventos e flutuações (provocadas por fontes de calor e água doce, por exemplo) levam a uma topografia oceânica diferente de zero e uma correspondente circulação do oceano, o que explica a utilização da TD no estudo circulação oceânica; assim, este trabalho tem como finalidade utilizar dados de satélites gravimétricos e altimétricos para estudar a Topografia Dinâmica Média (TDM) e correntes absolutas médias na região do Atlântico Sul e variações temporais da TD e correntes na região da Confluência Brasil Malvinas (CBM).

Até o presente, a assimilação de alturas geoidais nos estudos dos oceanos foi feita somente em poucos casos, devido à baixa acurácia e resolução dos modelos geoidais. O sinal do geóide predomina na definição da topografia dinâmica em todos os comprimentos de onda, ou seja, o nível do mar está intimamente ligado ao campo geopotencial. Os modelos geoidais globais anteriores ao Gravity Recovery and Climate Experiment (GRACE) eram precisos para comprimentos de onda com centenas de quilômetros, já em curtos comprimentos de onda (menores que $100 \mathrm{~km}$ ) esses modelos não possuíam resolução suficiente, prejudicando assim a determinação da TD e, conseqüentemente, o estudo de fenômenos com comprimentos de ondas na faixa de 100 a $200 \mathrm{~km}$.

Os primeiros modelos do geopotencial surgiram com o lançamento dos primeiros satélites artificiais em 1957, onde as observações precisas dos movimentos dos satélites permitiram determinar os coeficientes de baixo grau do desenvolvimento em série do geopotencial (determinação de longos comprimentos de onda). A partir desta data, os modelos geoidais vem sendo aprimorados de modo a resolver os curtos comprimentos de onda. 
O modelo geopotencial OSO91A (Rapp et al. 1991), desenvolvido pela Ohio State University (OSU), a partir de dados de gravimetria terrestre e observações de satélites, é expandido até grau 360; este modelo foi incorporado aos dados do TOPEX/Poseidon, porém sua precisão (erro de aproximadamente $26 \mathrm{~cm}$ ) não é satisfatória. No desenvolvimento do modelo Earth Gravitational Model 1996 (EGM96), foram incorporados novos dados gravimétricos de superfície, além de dados de órbitas de satélites e altimetria, obtendo-se assim melhora considerável em relação ao modelo OSO91A. O modelo EGM96 foi incorporado aos dados do satélite altimétrico Jason, porém o seu erro (desvio padrão de aproximadamente $18 \mathrm{~cm}$, segundo Lemoine et al. 1998) ainda é alto para várias aplicações oceanográficas.

Recentemente, foram divulgados os modelos globais do campo de gravidade EIGEN-5C (Förste et al. 2008) e EGM2008 (Pavlis et al. 2008). O EIGEN-5C, completo para grau e ordem 360, é resultado do sistema GRACE, do Laser Geodynamics Satellite (LAGEOS) e dados de superfície. O EGM2008 foi publicado recentemente pela U.S. National Geospatial-Intelligence Agency (NGA) e é completo para grau e ordem 2159 em termos de coeficientes harmônicos esféricos. Estes dois modelos, juntamente com o modelo de Nível Médio do Mar (NMM) DNSC08 (Andersen and Knudsen, 2008), foram utilizados e avaliados neste trabalho.

Em março de 2009, foi lançado o sistema Ocean Circulation Explorer (GOCE), que deve melhorar significativamente a precisão $(1 \mathrm{a} 2 \mathrm{~cm})$ do sistema de referência definido pelos modelos geoidais e, conseqüentemente, auxiliar em diversos estudos oceanográficos, como os de correntes oceânicas e transporte de calor. Segundo Vossepoel (2007), o problema da baixa resolução dos modelos geoidais serão definitivamente sanados com os modelos provindos do GOCE, que deverá reduzir os erros dos modelos geoidais em escalas menores que $100 \mathrm{~km}$.

De fato, o pobre conhecimento do geóide tem sido um obstáculo para oceanógrafos explorar de forma satisfatória dados de altimetria, de modo que as aplicações tem se concentrado no estudo de anomalias, deixando de lado o estudo de correntes absolutas. Inúmeros trabalhos foram desenvolvidos para estimar a Topografia Dinâmica Média (TDM), independentemente do conhecimento de feições de pequena escala do geóide, como citam Castruccio et al. (2008); no entanto, nenhuma das soluções foi satisfatória e erros significativos permanecem; Parent et al. (2003) 
explicam que isto se deve basicamente a diferenças no referencial dos dois tipos de dados.

A utilização de uma superfície de referência como a média do nível do mar pode ser questionada, pois estudos recentes mostram a eficácia dos modelos geoidais obtidos com a missão GRACE (Tapley et al. 2005), que possibilitou uma considerável melhora na utilização de sinais exclusivamente de satélites em aplicações oceanográficas (Gourdeau et al. 2003).

A combinação de geóide com altimetria apresenta vantagens em relação às escalas espaciais, quando comparadas a medidas in situ. Outra vantagem é a rapidez que as técnicas por sensoriamento remoto apresentam no estudo de correntes. Para oceanógrafos, a importância da determinação da TD está relacionada ao fato de que suas estimativas são baseadas em dados observados de forma homogênea espacialmente. Ademais, as correntes geostróficas derivadas são absolutas e, assim, aplicáveis na estimativa de correntes em regiões onde as correntes barotrópicas predominam (Vianna and Menezes, 2010).

Os primeiros resultados a nível global com modelos geoidais provindos do GRACE foram desenvolvidos por Chambers et al. (2004), Tapley et al. (2004), Tapley et al. (2003), Rio and Hernandez (2004) e Vossepoel (2007).

O primeiro trabalho relevante no Atlântico Sul foi desenvolvido por Vianna et al. (2007), que utilizou o modelo geoidal GGM02C (modelo geoidal do sistema GRACE) e o modelo de NMM GSFCMSS00, na determinação da TDM e corrente geostrófica média absoluta; neste trabalho foram discutidos os problemas referentes aos ruídos e ao uso do filtro Singular Spectrum Analises (SSA) na determinação da TDM, o qual mostrou-se eficiente quando comparado com os filtros utilizados em Rio and Hernandez (2004).

A grande vantagem do modelo EGM2008 é a ausência de ruídos que os modelos do GRACE apresentavam ao longo de sua trajetória, assim o EGM08 oferece uma atrativa possibilidade de determinar uma TD precisa em curtos comprimentos de onda.

O padrão de circulação média e as principais feições dinâmicas na região compreendida entre $55^{\circ} \mathrm{S}-20^{\circ} \mathrm{N}$ e $70^{\circ} \mathrm{W}-20^{\circ}$ E serão estudados utilizando diferentes modelos geoidais (EGM96, EIGEN5C e EGM2008) e o nível médio do mar DNSC08; 
este estudo tem como objetivo verificar qual modelo melhor representa as correntes e feições mencionadas por Stramma and England (1999) e pelo modelo numérico HYCOM, bem como mostrar a utilidade das recentes evoluções dos modelos geoidais para aplicações oceanográficas.

\section{1 - As regiões de estudo}

\subsection{1-O Atlântico Sul.}

As correntes de contorno oeste são caracterizadas por fluxos intensos, estreitos e bem definidos ao longo das margens continentais, como no trabalho clássico feito por Stramma and England (1999) em estudo qualitativo do padrão de circulação no Atlântico Sul (Figura 1.1); neste estudo as principais feições e correntes desta área foram bem definidas: nos primeiros 100 metros de profundidade se tem a Corrente Sul Equatorial, limitando o giro Subtropical ao Norte, a seguir a Corrente do Brasil (CB) flui para sul no sudoeste do Brasil e se separa da costa nas proximidades de $38^{\circ} \mathrm{S}$, na região da Confluência Brasil Malvinas ( $\mathrm{CBM})$, onde ocorre o encontro da $\mathrm{CB}$ com a Corrente das Malvinas (CM); a seguir, a Corrente do Atlântico Sul limita o giro subtropical ao sul, depois a Corrente de Benguela flui rumo a norte, se tem o giro de Angola e novamente a Corrente Sul Equatorial (CSE). A Corrente do Atlântico Sul (CAS) também é mostrada flui para leste na latitude aproximada de $40^{\circ} \mathrm{S}$. 


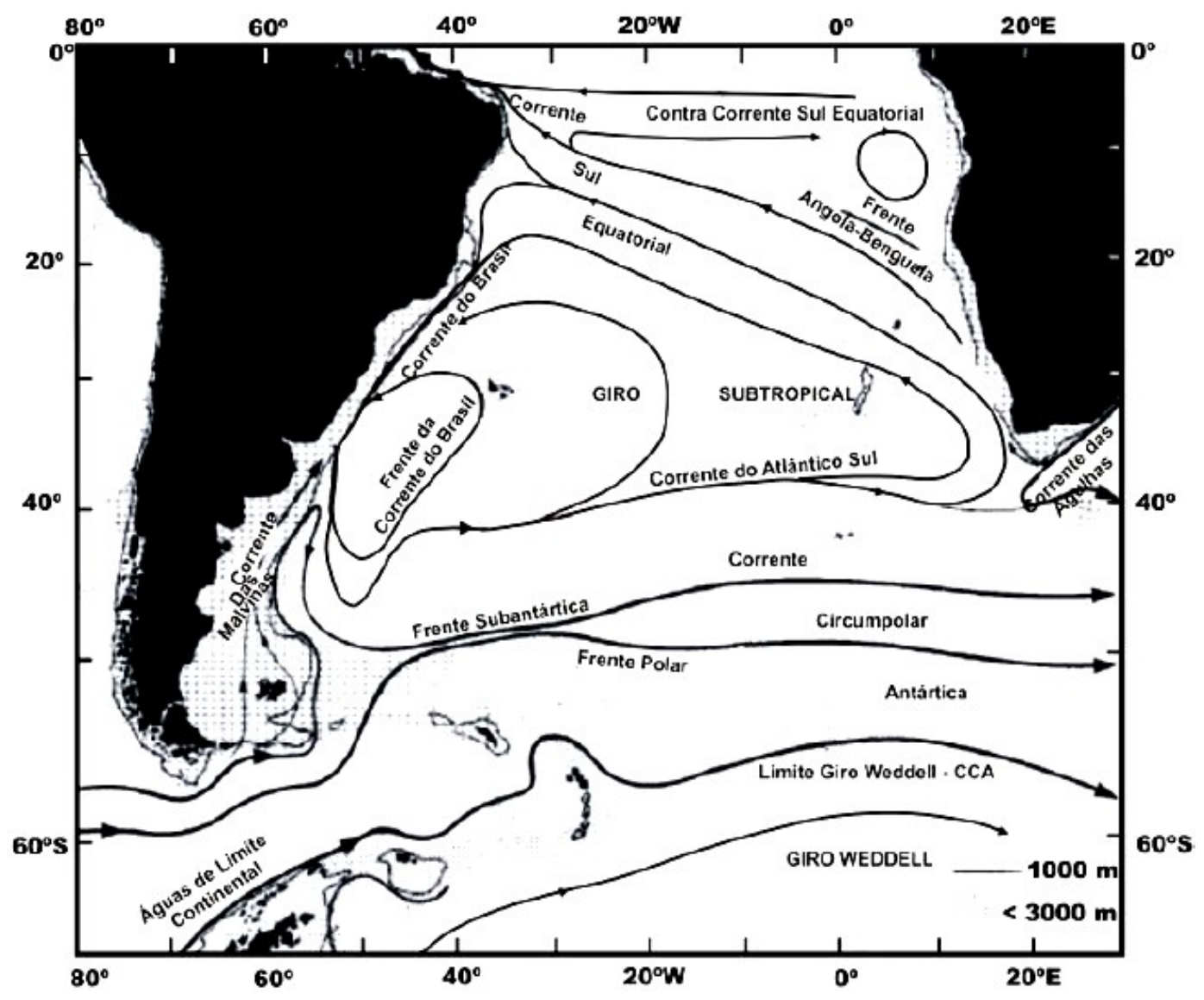

Figura 1.1: Representação esquemática da Circulação no Atlântico Sul. (fonte:

CIRANO et al. (2006), adaptado de PETERSON \& STRAMMA (1991)). 
A Figura 1.2 ilustra a região do Atlântico Sul que será estudada no presente trabalho.
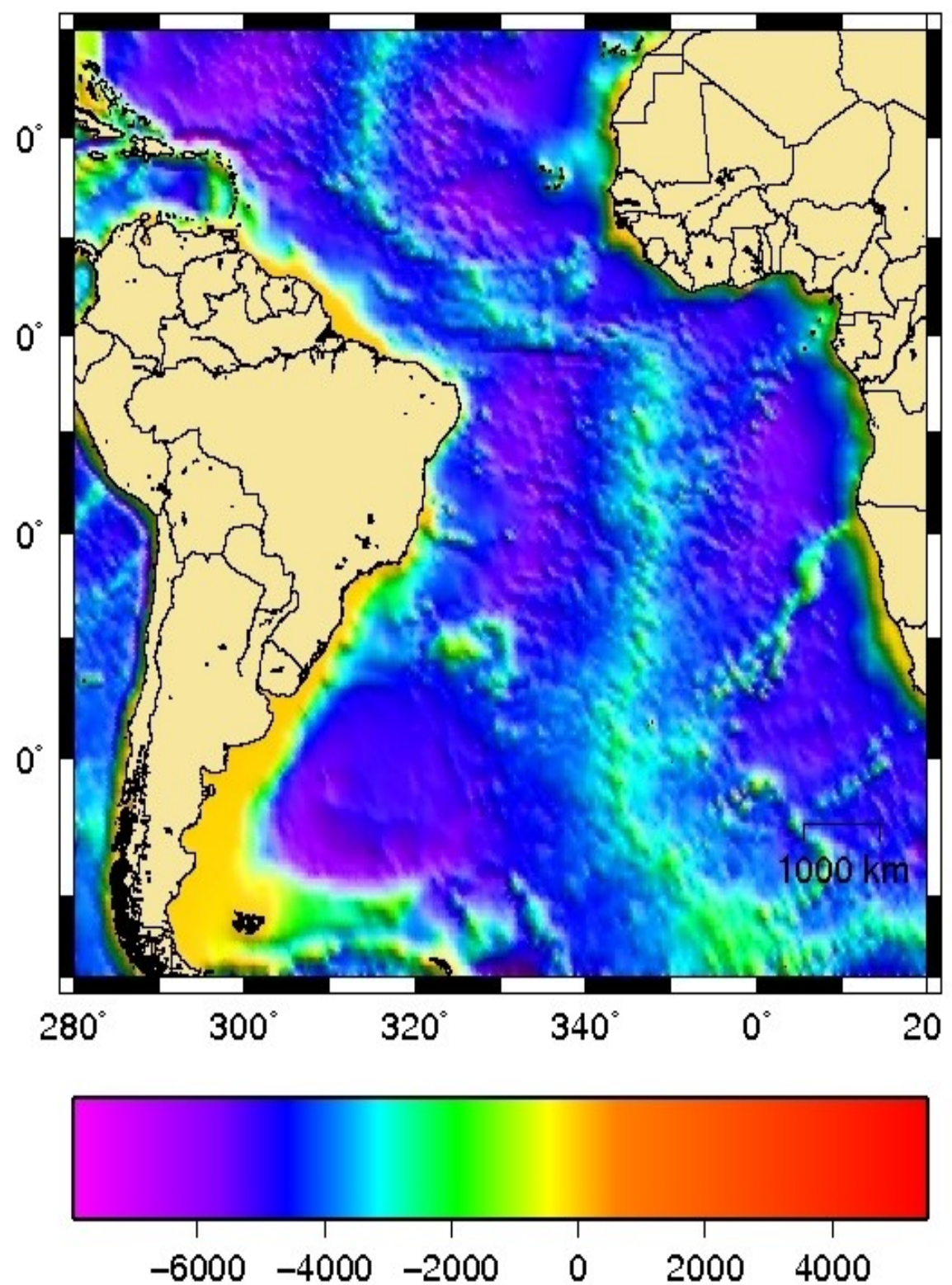

$\mathrm{m}$

Figura 1.2: Batimetria da região de estudo Região do Atlântico Sul.

\subsection{2 - Sudoeste do Atlântico Sul.}

$\mathrm{Na}$ região sudoeste do Atlântico Sul, delimitada por $25^{\circ} \mathrm{S}-50^{\circ} \mathrm{S}$ e $70^{\circ} \mathrm{W}-$ $20^{\circ}$ E (Figura 1.3), serão estudadas as variabilidades de nível do mar e correntes, utilizando o modelo geoidal que apresentar melhor resultado na representação da 
feições médias no Atlântico Sul.

A cerca de $15^{\circ} \mathrm{S}$ a Corrente Sul Equatorial bifurca, formando a Corrente Norte do Brasil (CNB) para Noroeste e a Corrente do Brasil (CB) para Sul, a qual segue até a Confluência Brasil - Malvinas (CBM), onde se separa da costa. Considerando as latitudes entre $10^{\circ} \mathrm{S}$ e $31^{\circ} \mathrm{S}$, Silveira et al. (2000b) apresentaram um quadro de velocidades determinadas por diferentes autores, sendo que a velocidade máxima é de $0.8 \mathrm{~m} / \mathrm{s}$ na latitude de $31^{\circ} \mathrm{S}$ e velocidade mínima de $0.16 \mathrm{~m} / \mathrm{s}$ na latitude de $15^{\circ} \mathrm{S}$. Em relação à Corrente do Golfo, nas baixas latitudes a $\mathrm{CB}$ é menos intensa, pois a componente termohalina tem sentido oposto à componente gerada pelo vento (Stommel, 1965).

A CM é formada a partir da Corrente Circumpolar Antártida (CCA) e flui para o norte ao longo da corta argentina até encontrar a CB, separando-se da costa na latitude de $39^{\circ} \mathrm{S}$ (Olson et al. 1998 ; Francisco, 2007); em relação à CB, ela é caracterizada por baixas salinidade e temperatura e é fortemente barotrópica.

$\mathrm{O}$ encontro da $\mathrm{CB}$ com a $\mathrm{CM}$ caracteriza a $\mathrm{CBM}$, que é uma região onde encontram-se muitos vórtices e meandros, com comprimentos de onda de 400 a $500 \mathrm{~km}$ (Olson el al. 1998), e ocorre a separação destas correntes da costa; a intensa atividade turbilhonar pode ser atribuída ao encontro de correntes de características dinamicamente diferentes; quando a CB se separa da costa, juntamente com a CM, se forma a Corrente do Atlântico Sul (CAS), que flui rumo a leste.

$\mathrm{Na}$ região da $\mathrm{CBM}$, a $\mathrm{CB}$ divide-se em dois ramos, o primeiro forma uma célula de recirculação anticiclônica e o segundo continua a fluir para o sul, e posteriormente desvia-se para nordeste, formando a Corrente do Atlântico Sul (CAS) (Francisco, 2007).

Goni et al. (1996) utilizaram dados de altimetria e dados in situ no estudo da dinâmica da CBM, em trabalho onde é discutido o regime na CBM, caracterizado pelo encontro da $\mathrm{CB}$, uma corrente fraca e relativamente quente que flui rumo ao Sul, e a $\mathrm{CM}$, uma corrente forte, de águas frias e menos salinas que flui para o norte; nesta região existe uma grande variabilidade na espessura da camada superior, confirmando a complexidade da dinâmica na região.

A separação da $\mathrm{CB}$ da costa foi investigada pela localização da $\mathrm{CB}$ na trajetória ascendente do T/P a323 por Goni and Wainer (2001). Resultados mostraram 
que a latitude média da separação é $38.54^{\circ} \mathrm{S}$, com desvio padrão de $0,8^{\circ}$, sendo que a separação da costa desloca-se para o norte durante os meses de inverno e primavera e para o sul durante os meses de meses de verão; na análise espectral foram observados picos de 6 a 12 meses, ou seja, a variabilidade da posição possui uma forte assinatura semi-anual e anual. Estudos feitos com Advanced Very High Resolution Radiometer (AVHRR) detectaram oscilações de 2 meses, provavelmente relacionadas com movimentos norte-sul da CB, e oscilações de 12 meses relacionadas com a penetração da CM. No geral, variações do vento, que é o principal mecanismo forçante da circulação de superfície, devem ser consideradas na investigação das variações dos movimentos da $\mathrm{CB}$.

Resultados de modelagem numérica também confirmam que a variabilidade da confluência está parcialmente ligada às mudanças de transporte da $\mathrm{CM}$ e CB (Matano et al. 1993); neste estudo, concluiu-se que a CB se intensifica enquanto a CM enfraquece durante o verão austral, provocando o deslocamento da confluência para sul, e a situação inverte durante o inverno austral.

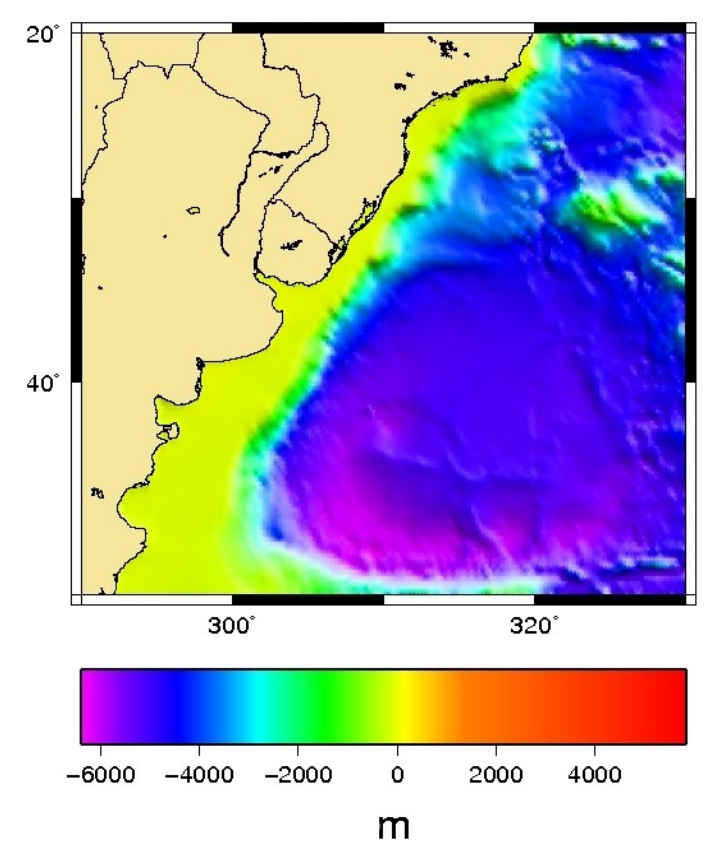

Figura 1.3: Batimetria da região de estudo no Sudoeste do Atlântico Sul. 


\section{3 - Método direto e método combinado.}

Existem várias ferramentas no estudo das variabilidades do nível médio do mar e correntes (modelagem, aquisição de dados in situ, etc ), entretanto, quando se utiliza dados de satélites altimétricos pode-se definir dois métodos:

1. Método direto - Determinação de TD e correntes geostróficas utilizando apenas dados de altimetria e de modelos geoidais, ou seja, a TD é determinada como a diferença entre o nível do mar e o modelo geoidal adotado;

2. Método combinado - Utilização de dados de altimetria e dados in situ, com análise objetiva, na determinação das variáveis de interesse; atualmente, a AVISO disponibiliza a TD e correntes com resolução temporal de 1 dia e resolução espacial de $1 / 3^{\circ}$ a nível global, como será visto no Capítulo 2 .

\section{4 - Hipóteses}

As hipóteses básicas do presente estudo são:

1. As feições de circulação de grande e meso escala podem ser identificadas com a TDM oriunda de modelos geoidais recentes e modelos do nível médio do mar;

2. As TDs e correntes geostróficas na região da CBM possuem variabilidades que podem ser identificadas com a utilização de modelos geoidais recentes e altimetria, mas o método direto possui limitações (de resolução), havendo necessidade de outros dados, de modo que o método combinado conduz a resultados de melhor qualidade.

\section{3 - Objetivos.}

O objetivo central deste trabalho é investigar o uso dos modelos geoidais na determinação da Topografia Dinâmica Média (TDM) e da circulação média no Atlântico Sul, bem como suas potencialidades no estudo das variações temporais da TD e correntes na região da CBM. Os objetivos específicos são: 
- Estimar e filtrar a TDM (Topografia Dinâmica Média), e correspondentes correntes geostróficas médias no Atlântico Sul, a partir do nível médio do mar e modelos geoidais estáticos recentes, analisar o padrão de circulação e comparar os respectivos resultados com dados do modelo numérico HYCOM.

- Estimar e filtrar as superfícies de TD com dados do TOPEX/Poseidon e Jason 1 na CBM no período de 2003-2005, considerando o modelo geoidal mais adequado, e analisar suas variabilidades

- Estimar a corrente geostrófica na CBM através do método direto (altimetria e modelo geoidal) e analisar as variabilidades da CB e CM no período de 20032005, comparando os resultados obtidos com dados do HYCOM e dados combinados (MERGED) disponibilizados pela AVISO.

- Avaliar a aplicabilidade dos modelos geoidais combinados com dados altimétricos no estudo da TD e correntes geostróficas. 


\section{2 - DADOS}

Este capítulo tem como objetivo discutir os dados utilizados e suas origens. Será feita uma introdução na teoria do campo de gravidade e posteriormente uma descrição dos modelos geoidais que foram utilizados na determinação da topografia dinâmica e correntes, bem como do modelo de nível médio do mar e dos dados de altimetria.

\section{1 - O campo da gravidade terrestre e suas aplicações.}

A representação do campo de gravidade é fundamental para a Geodésia e outras ciências, pois está diretamente relacionado com a forma e os processos dinâmicos que ocorrem no interior da Terra. Em Oceanografia, o estudo da forma da Terra tem um papel fundamental na determinação da topografia dinâmica e determinação de correntes geostróficas.

Neste Capítulo, serão apresentados alguns aspectos conceituais básicos do campo de gravidade, e sua relação com os modelos geoidais, com o objetivo de auxiliar na compreensão dos capítulos posteriores e na definição dos respectivos modelos.

\subsection{1-Geopotencial}

O campo de gravidade é expresso em termos do geopotencial por

$$
g=\operatorname{grad} W
$$

onde $W$ é o geopotencial, composto pelo potencial gravitacional $V$, decorrente da atração gravitacional das massas, e o potencial centrífugo $\Phi$, decorrente da rotação da Terra 


$$
W(\mathrm{r}, \varphi, \lambda)=V(\mathrm{r}, \varphi, \lambda)-\Phi(\mathrm{r}, \varphi, \lambda)
$$

onde $r, \varphi, \lambda$ são as coordenadas geocêntricas (raio, latitude e longitude).

No exterior das massas atrativas, o geopotencial reduz-se ao potencial gravitacional que, por ser uma função harmônica, satisfaz a equação de Laplace.

$$
\nabla^{2} V(\mathrm{r}, \varphi, \lambda)=0
$$

Assim, o geopotencial pode ser expresso em harmônicos esféricos na forma (Heiskanen \& Moritz, 1967):

$$
V(\mathrm{r}, \varphi, \lambda)=\sum_{n=0}^{\infty} \frac{1}{r^{n+1}} \sum_{m=0}^{n}\left(A_{n m} \cos m \lambda+B_{n m} \operatorname{sinm} \lambda\right) P_{n m}(\cos \varphi)
$$

onde $(r, \varphi, \lambda)$ são as coordenadas geocêntricas, $A_{n m}$ e $B_{n m}$ são coeficientes obtidos a partir de elementos conhecidos do campo de gravidade, e $P_{n m}(\cos \varphi)$ representa os polinômios de Legendre associados de grau $n$ e ordem $m$.

O potencial centrífugo não pode ser representado em harmônicos esféricos por não ser uma função harmônica.

As superfícies equipotenciais do campo de gravidade real satisfazem a condição

$$
W=\text { cons } \tan t e
$$

Entre essas superfícies, a que coincide com o nível médio dos mares não perturbados é denominada superfície geoidal.

\subsection{2 - Esferopotencial}

Do ponto de vista geométrico, o modelo mais adequado, para a aproximação da forma e dimensões da Terra, é o modelo elipsoidal. Esse modelo tem a forma de um 
elipsóide de revolução, com a mesma massa e velocidade da Terra real. O campo de gravidade gerado por esse modelo pode ser expresso por

$$
\gamma=\operatorname{grad} U
$$

O esferopotencial $(U)$, é constituído pelo potencial gravitacional normal e pelo potencial centrífugo.

$$
U(\mathrm{r}, \varphi, \lambda)=\mathrm{V}^{\prime}(\mathrm{r}, \varphi, \lambda)+\Phi^{\prime}(\mathrm{r}, \varphi, \lambda)
$$

onde $V^{\prime}$ é o potencial gravitacional e $\Phi^{`}$ é o potencial centrífugo.

A superfície limitante deste modelo é equipotencial, ou seja, satisfaz a condição

$$
U(\mathrm{r}, \varphi, \lambda)=\text { constante }
$$

\subsection{3 - Potencial anômalo e a altura geoidal}

A diferença entre o geopotencial e o esferopotencial no mesmo ponto é chamado potencial anômalo $(\mathrm{T})$, o qual descreve variações de grandezas físicas e geométricas da Terra real em relação à terra normal. Essas variações são decorrentes da distribuição heterogênea de massa da Terra. O potencial anômalo independe do potencial centrífugo, que se cancela por se tratar do mesmo ponto. Assim, o potencial anômalo tem a forma.

$$
T(\mathrm{r}, \varphi, \lambda)=W(r, \varphi, \lambda)-U(r, \varphi, \lambda)
$$

O potencial anômalo externo é uma função harmônica, que pode ser expressa em harmônicos esféricos por (Heiskanen \& Moritz, 1967)

$$
T(r, \varphi, \lambda)=\sum_{n=0}^{\infty}\left(\frac{R}{r}\right)^{n+1} T_{n}(\varphi, \lambda)
$$


Utilizando a aproximação esférica, a expressão (2.10) assume a forma:

$$
T(r, \varphi, \lambda)=\sum_{n=0}^{\infty} T_{n}(\varphi, \lambda)
$$

então em o potencial anômalo pode ser expresso em harmônicos esféricos por:

$$
T(r, \varphi, \lambda)=\frac{K M}{R} \sum_{n=2}^{n} \sum_{m=0}^{n}\left(\bar{C}_{n m} \cos m \lambda+\left(\bar{S}_{n m} \operatorname{sen} m \lambda\right) \bar{P}_{n m}(\cos \varphi)\right.
$$

onde $T_{n}(\varphi, \lambda)$ representa os harmônicos esféricos de superfície, $R$ é o raio terrestre médio, $r$ é o raio vetor do ponto de coordenadas geográficas $(\varphi, \lambda)$ e $K M$ representa a constante gravitacional geocêntrica, oriunda do geopotencial e esferopotencial.

Os coeficientes e polinômios de Legendre totalmente normalizados são dados pelas expressões:

$$
\begin{aligned}
& \bar{C}_{n m}=\sqrt{\frac{(n+m) !}{K(2 \mathrm{n}+1)(n-m) !}} C_{n m} \\
& \bar{S}_{n m}=\sqrt{\frac{(n+m) !}{K(2 \mathrm{n}+1)(n-m) !}} S_{n m} \\
& \bar{P}_{n m}(\cos \varphi)=\sqrt{\frac{K(2 \mathrm{n}+1)(n-m) !}{(n-m) !}} P_{n m}(\cos \varphi)
\end{aligned}
$$

$\operatorname{com} \mathrm{K}=1$ se $\mathrm{m}=0$ e $\mathrm{K}=2$ se $\mathrm{m} \neq 0$.

onde $C_{n m}$ e $S_{n m}$ são coeficientes determinados a partir de dados associados ao campo de gravidade terrestre e $P_{n m} \cos (\varphi)$ representa os polinômios de Legendre.

As relações entre a altura geoidal e a anomalia gravimétrica, com o potencial anômalo, tem aplicações práticas importantes, sendo dadas pela fórmula de Bruns e pela equação fundamental da Geodésia Física, respectivamente (Heiskanen \& Moritz, 1967). 


$$
N=\frac{T}{\gamma}
$$

onde $\gamma$ é a aceleração de gravidade normal.

$$
N=\frac{1}{\gamma} \sum_{n=0}^{\infty} T_{n}(\varphi, \lambda)
$$

Considerando a esfera como uma aproximação da forma da Terra pode-se definir $\gamma$ :

$$
\gamma=\frac{K M}{R^{2}}
$$

Substituindo (2.12) e (2.18) em (2.17), e levando em consideração os coeficientes harmônicos normalizados, se define a altura geoidal expandida como a soma de harmônicos esféricos:

$$
N(\theta, \varphi)=R \sum_{n=2}^{\infty} \sum_{m=0}^{n} \tilde{P}_{n m}(\cos \theta)\left(C_{n m} \cos (m \varphi)+S_{n m} \operatorname{sen}(m \varphi)\right)
$$

onde $R$ é o raio da Terra, $\theta$ é a co-latitude, $\varphi$ é a longitude, $C_{n m}$ e $S_{n m}$ são os coeficientes do desenvolvimento, $\tilde{P}_{n m}(\cos (\theta)$ são as funções associadas de Legendre de grau $n$ e ordem $m$. A expressão (2.19) será usada na determinação dos modelos geoidais utilizados neste trabalho.

\subsection{4 - Avanços na representação do campo de gravidade}

As técnicas espaciais e os recursos computacionais revolucionaram a metodologia para representação do campo de gravidade. Até o início da década de 60 , os modelos do geopotencial eram determinados usando apenas dados gravimétricos terrestres. 
Nessa época, os modelos globais do potencial gravitacional expresso em harmônicos esféricos eram representados até o grau 4. Na década de 90, os dados de satélites, combinados com outros, possibilitaram a representação do campo de gravidade terrestre até o grau 1800 (Wenzel, 1999).

Com o sucesso do experimento realizado com o SKYLAB, a altimetria por satélite justificou as missões seguintes Geodynamics Experiment Ocean Satellite (GEOS-3), SEASAT, Geodetic Satellite (GEOSAT), International Earth Rotation Service (IERS), entre outros, as quais forneceram dados para a representação do campo de gravidade e da topografia do fundo oceânico com alta resolução.

O modelo geopotencial OSO91A (Rapp et al. 1991), desenvolvido pela Ohio State University (OSU) e expandido até o grau e a ordem 360, foi desenvolvido visando aplicações geodésicas. Os dados utilizados nesse modelo foram dados de Gravimetria terrestre e dados de observações de satélites, incluindo satélites altimétricos (Nerem, 1995).

No desenvolvimento do modelo Earth Gravitational Model 1996 (EGM96) (Lemoine et al. 1998), foram incorporados novos dados gravimétricos de superfície, além de dados de órbitas de satélite e altimetria, obtendo-se assim melhora considerável em relação ao modelo OSO91A.

O modelo geoidal EGM96 utilizou dados gravitacionais de inúmeros satélites, dados de elevação de 27 fontes e dados de altimetria por satélite na região marinha (ERS-1 e do GEOSAT), possibilitando uma acurácia do geóide entre $\pm 0,5$ e $\pm 1 \mathrm{~m}$ RMS (erro médio quadrático) em todo o planeta.

Recentemente, foram divulgados os modelos do campo de gravidade EIGEN5C e EGM2008, que resultaram da combinação de dados do campo de gravidade terrestres, oceânicos e derivados da altimetria por satélite, com os coletados nas missões Challenging Minisatellite Payload (CHAMP) e GRACE; estes modelos apresentaram melhorias significativas no estudo de correntes no oceano; segundo Tapley et al. (2004) o erro na altura do geóide para o grau e ordem 40 é somente $0.004 \mathrm{~m}$ (erro calculado a partir de 111 dias de dados).

O máximo de dados possível foi requerido para auxiliar o desenvolvimento do modelo EGM2008; dentre as principais fontes de dados destaca-se a missão GRACE, que foi desenvolvida especificamente para levantar dados do campo gravitacional 
terrestre; outras fonte de dados foram as missões TOPEX/POSEIDON, JASON-1, ERS1/2, GEOSAT, ENVISAT, GFO e ICESAT.

O sistema GOCE promete revolucionar o estudo da dinâmica do oceano, pois tem como meta resolver os problemas de pequena escala e ruídos que interferem na determinação do geóide e, conseqüentemente, de correntes marítimas.

\subsection{4 - Os modelos geoidais estáticos.}

Três modelos geoidais serão utilizados neste trabalho: EGM96, EIGEN-5C e EGM2008; a partir destes modelos serão determinadas as respectivas circulações médias; ao comparar os resultados de correntes com os de modelo numérico hidrodinâmico (HYCOM) será adotado o modelo que melhor representar as feições de correntes no Atlântico Sul, para análise das variabilidades do nível do mar e correntes na região da CBM.

O modelo EGM96 foi incorporado aos dados do satélite altimétrico Jason, porém o seu erro (desvio padrão de aproximadamente $18 \mathrm{~cm}$, segundo Lemoine et al. 1998) ainda é alto para várias aplicações oceanográficas; o modelo é completo para grau e ordem 360, com resolução espacial de $110 \mathrm{~km}$ aproximadamente. Os dados do modelo geoidal EGM96 são obtidos no site:

ftp://cddis.gsfc.nasa.gov/pub/egm96/general-info/egm96-to360.ascii

O modelo EIGEN-5C é o modelo estático mais recente do sistema GRACE e é completo para grau e ordem 360 em termos de coeficientes harmônicos esféricos; sua resolução espacial é de $110 \mathrm{~km}$. Os coeficientes harmônicos do modelo são obtidos no site: http://op.gfz-potsdam.de/grace/results/grav/g005-eigen-5c-coef .

O modelo EGM2008 foi publicado recentemente pela U.S. National Geospatial-Intelligence Agency (NGA). O modelo é completo para grau e ordem 2159 em termos de coeficientes harmônicos esféricos (Pavlis et al. 2008) proporcionando uma resolução teórica de $10 \mathrm{~km}$ aproximadamente. $\mathrm{O}$ acesso aos coeficientes, bem como aos programas que calculam o modelo geoidal, são disponíveis no site:

\section{http://earth-info.nga.mil/GandG/wgs84/gravitymod/egm2008/index.html}

A Figura 2.1 ilustra o modelo geoidal global EGM2008. 


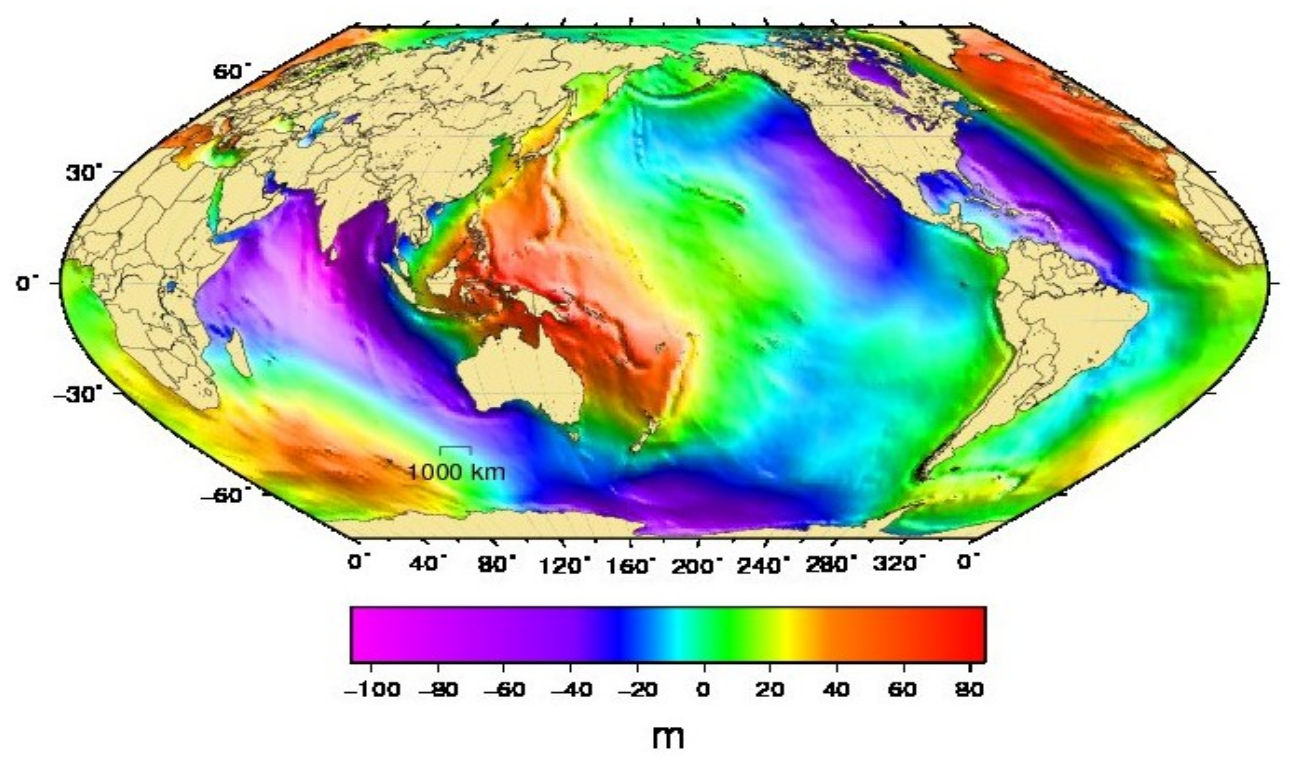

Figura 2.1: Modelo geoidal EGM2008, referenciado ao elipsóide utilizado pelo TOPEX/POSEIDON e JASON

\subsection{5 - Os coeficientes harmônicos.}

Os coeficientes harmônicos dos modelos geoidais citados acima são fornecidos conforme exemplo abaixo (coeficientes do modelo EGM2008):

$\begin{array}{ccccccc}\text { grau } & \text { ordem } & \text { Coeficiente C } & \text { Coeficiente S } & \text { Erro C } & \text { Erro S } \\ \mathrm{N} & \mathrm{M} & \mathrm{C} & \mathrm{S} & \text { sigma C } & \text { sigma S } \\ 1 & 1 & 0.000000000000 \mathrm{D}+00 & 0.000000000000 \mathrm{D}+00 & 0.0000 \mathrm{D}+00 & 0.0000 \mathrm{D}+00 \\ 2 & 1 & -.255214998162 \mathrm{D}-09 & 0.144095058328 \mathrm{D}-08 & 0.1618 \mathrm{D}-10 & 0.1624 \mathrm{D}-10 \\ 3 & 1 & 0.203045404686 \mathrm{D}-05 & 0.248204888962 \mathrm{D}-06 & 0.1566 \mathrm{D}-10 & 0.1565 \mathrm{D}-10 \\ 4 & 1 & -.536143384738 \mathrm{D}-06 & -.473563815490 \mathrm{D}-06 & 0.4803 \mathrm{D}-11 & 0.4800 \mathrm{D}-11 \\ 5 & 1 & -.629233735827 \mathrm{D}-07 & -.943668736898 \mathrm{D}-07 & 0.2966 \mathrm{D}-11 & 0.2965 \mathrm{D}-11 \\ 6 & 1 & -.759215565053 \mathrm{D}-07 & 0.265095835194 \mathrm{D}-07 & 0.2088 \mathrm{D}-11 & 0.2088 \mathrm{D}-11 \\ 7 & 1 & 0.280885396331 \mathrm{D}-06 & 0.951208792928 \mathrm{D}-07 & 0.1602 \mathrm{D}-11 & 0.1601 \mathrm{D}-11 \\ 8 & 1 & 0.231656416318 \mathrm{D}-07 & 0.588913572962 \mathrm{D}-07 & 0.1290 \mathrm{D}-11 & 0.1290 \mathrm{D}-11 \\ 9 & 1 & 0.142149973286 \mathrm{D}-06 & 0.214021468050 \mathrm{D}-07 & 0.1081 \mathrm{D}-11 & 0.1081 \mathrm{D}-11\end{array}$

A Figura 2.2 ilustra amplitudes dos coeficientes harmônicos do modelo 
geoidal EGM2008 em função do grau e ordem, para l = m.

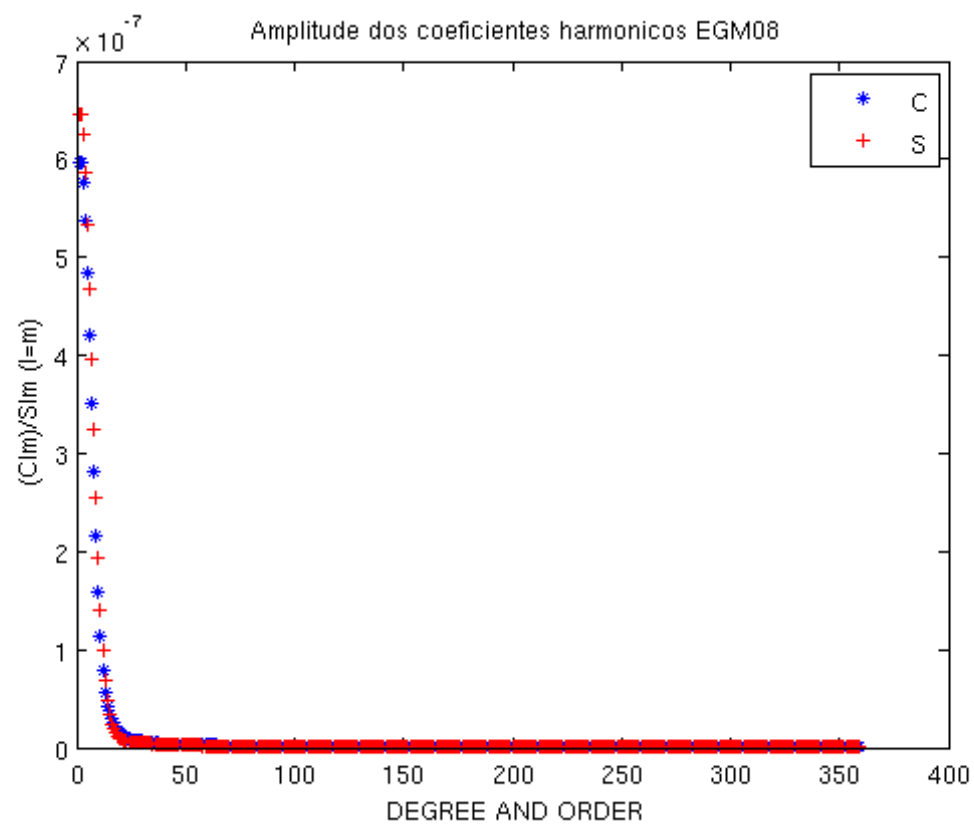

Figura 2.2: Amplitudes dos coeficientes harmônicos

A precisão dos coeficientes harmônicos reflete diretamente na precisão dos modelos geoidais, assim modelos geoidais com grau e ordem elevados apresentam ruídos que devem ser removidos adequadamente. Em longos comprimentos de onda os modelos geoidais são precisos, no entanto possuem baixa resolução.

A resolução aproximada de um modelo geoidal equivale a $20000 \mathrm{~km} / \mathrm{l}_{\max }$, onde $l_{\max }$ é o grau máximo do modelo (Swenson \& Warh, 2002). Desta forma, o modelo com maior resolução é o EGM2008 (9 km). Pela expressão fornecida, os modelos EGM96 e EIGEN-5C possuem resolução de aproximadamente $55 \mathrm{~km}$ que, no entanto, na prática, depende também da distribuição e qualidade dos dados gravimétricos utilizados na sua determinação. Apesar da resolução do EIGEN-5C ser igual à do EGM96, deve-se observar a precisão dos coeficientes harmônicos, pois estes dependem da distribuição e qualidade dos dados gravimétricos.

A relação entre o erro e o coeficiente é diretamente proporcional ao grau e ordem do modelo, por outro lado, os coeficientes de grau e ordem maiores que 50 possuem amplitude de ordem 1e-10, o que torna o erro maior que o coeficiente em alguns casos. As Figuras 2.3 e 2.4 mostram as relações entre os erros dos coeficientes e 
os coeficientes harmônicos, para $l=m$.

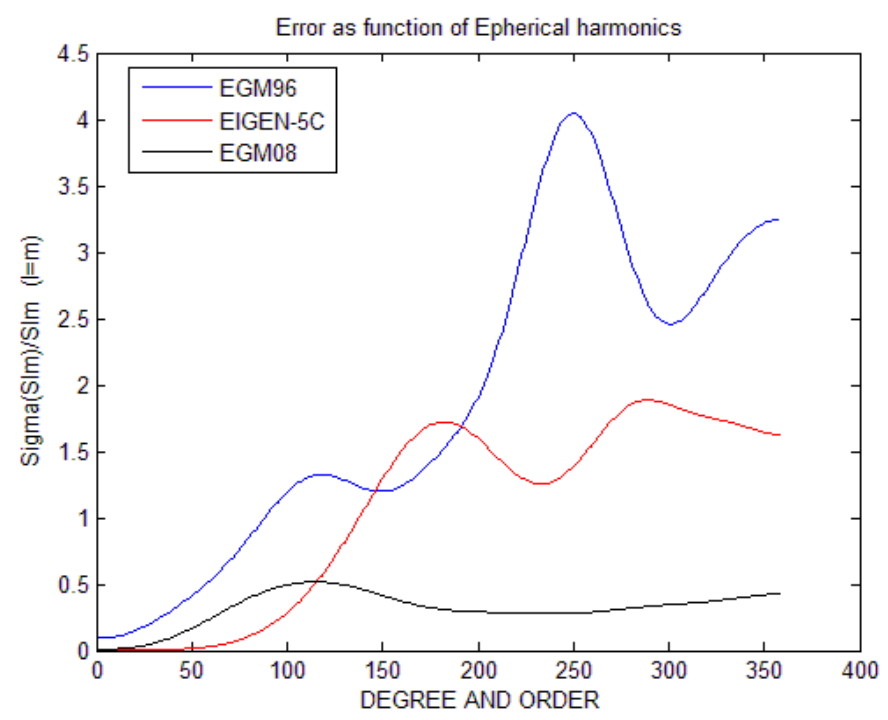

Figura 2.3: Relações entre os erros dos coeficientes e os coeficientes, em função dos graus harmônicos $\mathrm{S}_{\mathrm{lm}}$

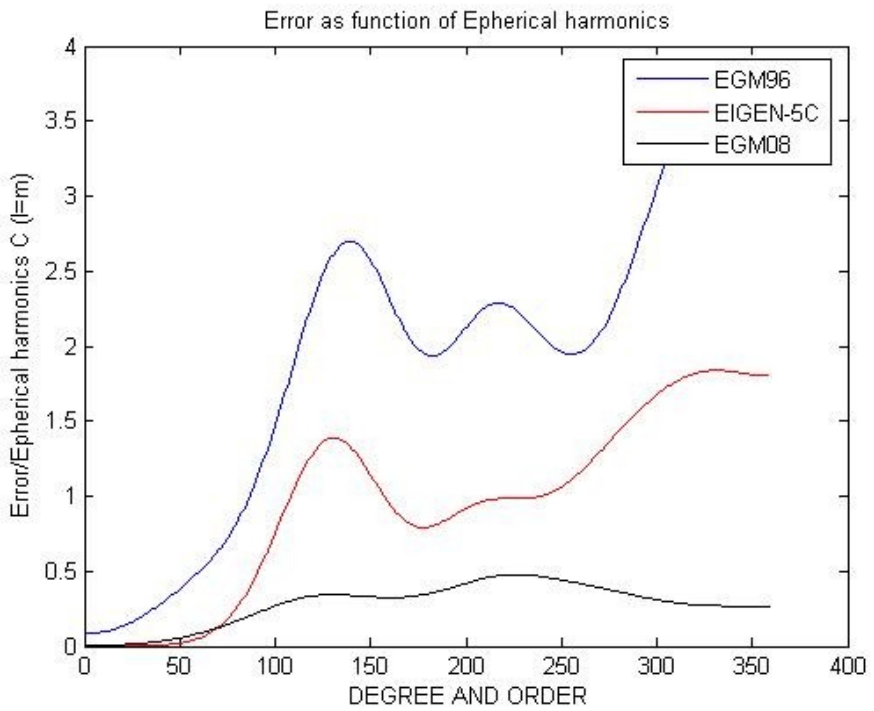

Figura 2.4: Relações entre os erros dos coeficientes e os coeficientes, em função dos graus harmônicos $\mathrm{C}_{\mathrm{lm}}$

Como foi mostrado nas figuras acima, o modelo EGM2008, truncado em grau e ordem 360, apresenta erros relativos menores que o EIGEN-5C e o EGM96, entretanto os cálculos do modelo em grau e ordem elevados podem apresentar ruídos prejudiciais à determinação de correntes geostróficas absolutas. 


\section{2 - Altimetria por satélite, dados do TOPEX/POSEIDON e JASON.}

Os dados de altimetria do TOPEX / POSEIDON que foram utilizados neste trabalho são do tipo MGDR geração B (MGB) e estão disponíveis no site: ftp://podaac.jpl.nasa.gov/pub/sea-surface-height/topex-poseidon/mgdrb/data/.

Os dados estão divididos em 481 pastas, sendo que cada pasta contém um ciclo (que corresponde a aproximadamente 10 dias).

A precisão da altura do nível do mar depende das correções aplicadas aos dados. No processamento dos dados MGDR deve-se atentar para todas as correções ambientais e geofísicas a considerar nos dados brutos. Para exemplificar a importância da correção, Polito and Sato, (2004) citaram o caso das marés, que no geral são muito maiores que o sinal da anomalia de altura. Como a remoção desta grandeza é feita a partir de modelos numéricos, é importante que o usuário tenha conhecimento das limitações dos mesmos, pois estes modelos são falhos em profundidades menores que 1000 metros devido à influência topográfica nas marés, o que chega ao ponto de invalidar as medidas altimétricas; no caso de estimativas de correntes, os erros na correção das marés provocam erros da ordem de alguns $\mathrm{m} / \mathrm{s}$.

Cada arquivo de dados possui um cabeçalho (MGBccc.HDR) contendo informações sobre os dados de cada passagem. As informações contidas neste arquivo orientam o usuário sobre as características dos dados, por exemplo, geração do produto, confiança sobre os dados, etc.

Os arquivos de dados científicos possuem uma série de informações e correções que devem ser lidas e posteriormente aplicadas às variáveis de interesse. Cada registro pode ser dividido em 12 grupos (AVISO, 1996):

- Tempo;

- Localização;

- Altitude;

- Atitude - Posição;

- Range do altímetro;

- Correções ambientais;

- Altura significativa das ondas; 
- Backscatter Coefficients ;

- Medidas geofísicas;

- Temperatura de brilho;

- Flags;

- Reserva (Spares).

- As principais correções que são aplicadas aos dados dos altímetros são explicadas e formuladas em Robinson (1985):

- Correção da troposfera seca;

- Correção da troposfera úmida;

- Correção ionosférica;

- Correção do estado do mar (ondas).

Além das correções ambientais, há correções geofísicas que devem ser aplicadas de acordo com o interesse do estudo (os modelos utilizados são descritos em AVISO, 1996).

No calculo da TD será utilizado o SSHTC (Sea Surface Height Tide Corrected), que é dado por:

$$
S S H T C=\text { ALTITUDE }-R C-C G
$$

onde ALTITUDE é a altitude do satélite em relação ao elipsóide de referência, RC é o range corrigido e CG contém contribuições geofísicas a serem consideradas neste estudo específico.

$$
R C=R A N G E+D D R Y+D W E T+D I O N O+D E M B I A S
$$

onde $D D R Y$ é correção da troposfera seca, $D W E T$ é a correção da troposfera úmida, $D I O N O$ é a correção da ionosfera e DEMBIAS são correções do estado do mar (ondas).

$$
C G=H \_S E T-H \_E O T-H \_P O L
$$

onde H_SET é a correção da maré terrestre, H_EOT é a correção da maré oceânica e H_POL é a correção da maré do pólo. Os modelos utilizados para as correções 
ambientais e geofísicas são descritos em AVISO (1996). A amostragem espacial dos dados é ilustrada na Figura 2.5, que mostra as passagens do TOPEX/POSEIDON na região do Atlântico Sul; no equador o espaçamento é de aproximadamente $315 \mathrm{~km}$ e os dados consecutivos ao longo de uma passagem possuem espaçamento de $7 \mathrm{~km}$. Apesar de todos os dados terem sido interpolados em grade de $0.5^{\circ} \times 0.5^{\circ}$ as determinações da TD e das correntes podem ser prejudicadas por causa do espaçamento e possíveis falhas dos dados originais.

Os dados do Jason foram considerados até julho de 2005 e estão disponíveis no site:

$\mathrm{ftp} / /$ podaac.jpl.nasa.gov/pub/sea_surface_height/jason/gdr/data/

Todas as correções aplicadas aos dados do TOPEX são também aplicadas aos dados do Jason, sendo que as diferenças se encontram nos modelos dos dados auxiliares utilizados nos dois casos (modelos geoidais e de maré, por exemplo). As unidades das variáveis foram todas padronizadas.

Assim como nos dados do TOPEX, os arquivos do Jason possuem cabeçalhos contendo informações sobre os dados de cada passagem. Os arquivos científicos possuem aproximadamente 3360 registros (cada passagem equivale a meia revolução ou 3360 segundos, resultando em aproximadamente um registro por segundo). Cada registro é obtido a partir da média de 10 medições altimétricas e possui 96 campos de informações, que são agrupados de forma similar aos do TOPEX / Poseidon.

Todos os elementos dos cabeçalho, registros científicos e modelos utilizados são descritos em Desai et al. (2003) e AVISO (2008).

As precisões dos altímetros a bordo dos satélites T/P e Jason, para medições do nível do mar, correspondem a $0.03 \mathrm{~m}$ e $0.025 \mathrm{~m}$, respectivamente (Polito and Sato, 2004). 


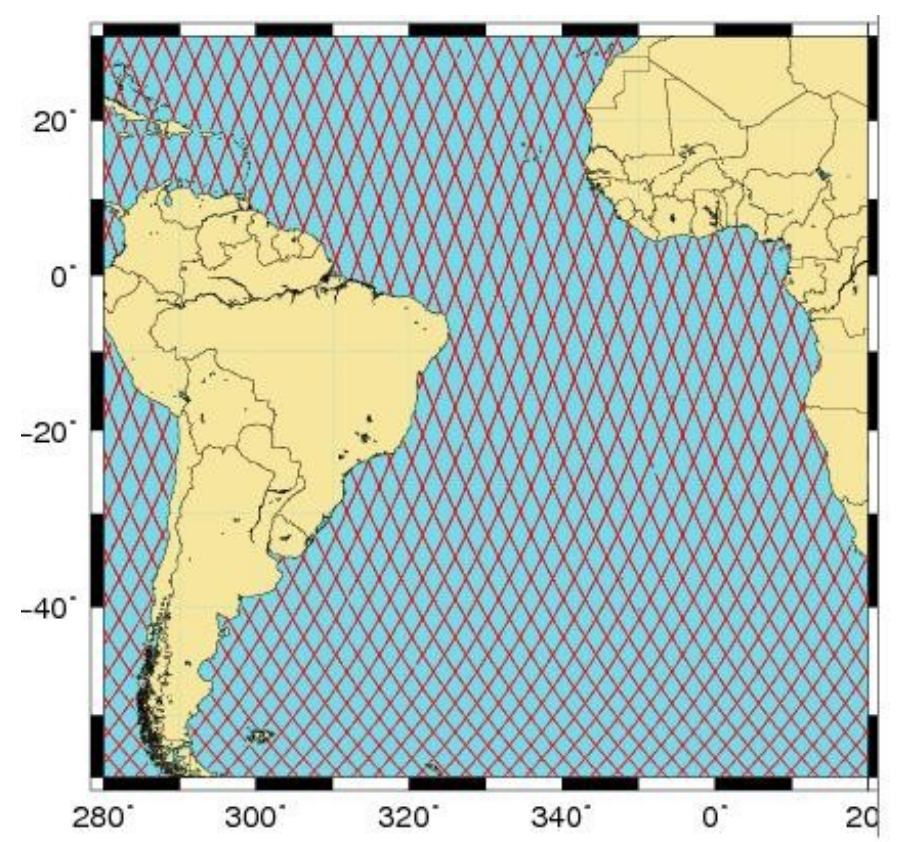

Figura 2.5: Passagens do TOPEX/POSEIDON para o Atlântico Sul

\section{3- O modelo de nível médio do mar DNSC08.}

O modelo The Danish National Space Center (DNSC08) é o mais recente modelo de nível médio do mar. Este modelo utiliza a combinação de 12 anos de dados (1993-2004) de oito satélites altimétricos diferentes. O DNSC08 foi desenvolvido para auxiliar a determinação da TDM juntamente com o modelo geoidal EGM08; sua resolução espacial é de 1 minuto (Andersen and Knudsen, 2008) e será usado na determinação das TDMs juntamente com os modelos geoidais EGM08, EIGEN-5C e EGM96.

\section{4 - O modelo numérico HYCOM.}

Os avanços em recursos computacionais e na arquitetura dos modelos numéricos proporcionam grades com resolução cada vez maior. Outro fator importante na evolução dos modelos foi a incorporação de dados de batimetria de alta resolução e a utilização de dados observacionais como forçantes do modelo também em alta resolução. 
$\mathrm{Na}$ avaliação da qualidade dos dados oriundos de altimetria e modelos geoidais foram utilizados produtos do HYCOM, de Bleck (2002); o HYCOM é um modelo numérico baseado em coordenadas isopicnais no oceano aberto e estratificado, revertendo suavemente para coordenadas sigma em regiões de plataforma e costeiras, e para coordenadas lineares em regiões muito rasas ou homogêneas. O modelo HYCOM apresenta um sistema de coordenadas verticais otimizadas, representando assim um avanço sobre os demais modelos.

Os dados de correntes médias (no tempo) estão disponíveis no site:

ftp://ftp.hycom.org/datasets/GLBa0.08/mean-std/data/ em formato netcdf, tendo sido desenvolvidas rotinas para leitura e interpolação. Os dados médios diários produzidos com resultados do HYCOM possuem resolução de $1 / 12^{\circ}$ e são disponíveis no site: ftp://ftp.hycom.org/datasets/GLBa0.08/expt-90.3/data/. A Figura 2.6 ilustra as velocidades geostróficas médias obtidas com a TD do modelo HYCOM para o Atlântico Sul.

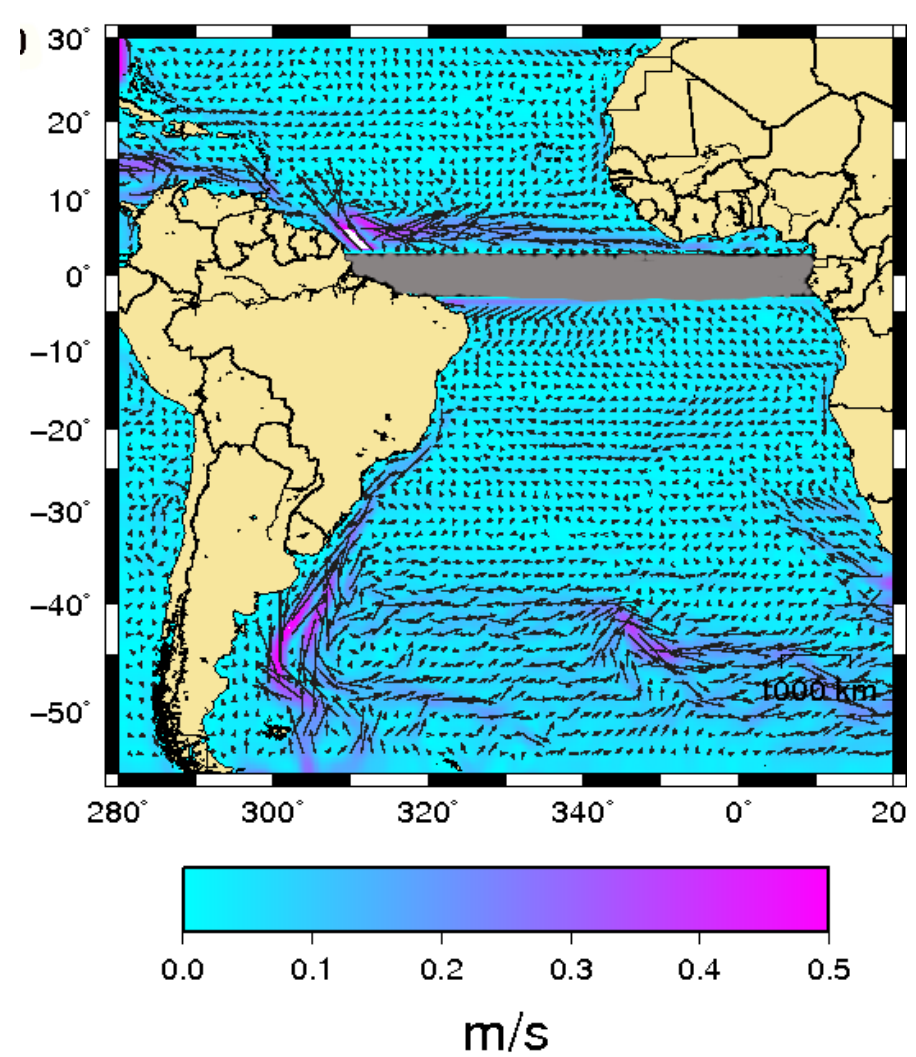

Figura 2.6: Velocidades médias na superfície do modelo numérico HYCOM 
Vale ressaltar que os dados do HYCOM usados neste trabalho são fornecidos diretamente no site mostrado acima, ou seja, o modelo não foi processado no presente trabalho para a obtenção da TD e correntes.

As correntes geostróficas do modelo HYCOM foram obtidas a partir da topografia dinâmica do modelo, utilizando as expressões (3.6).

\section{5 - Dados AVISO: Topografia dinâmica absoluta e correntes geostróficas.}

A AVISO fornece dados de Topografia Dinâmica Combinada (TDC) e corrente a cada 3 dias ou menos; conforme será visto posteriormente, estes dados são de boa qualidade e serão usados na comparação com a TD calculada através do método direto.

A TDC fornecida pela AVISO é dada por (AVISO, 2010):

$$
T D C=A N M+T D C M
$$

onde ANM é a anomalia do nível do mar (multi-satélite) e TDCM é a Topografia Dinâmica Combinada Média, cuja metodologia de processamento será discutida a seguir.

A TDC disponibilizada pela AVISO através do site http://atoll-motu.aviso.oceanobs.com/?action=listcatalog\&service=AvisoNRT é uma combinação de vários dados (Rio and Hernandez, 2004), a saber:

- Dados multisatélites: TOPEX/Poseidon, Jason 1, Jason 2;

- Modelo do nível médio do mar Collecte localisation Satellites 2001 (CLS01);

- Modelo geoidal EIGEN-GRGS. RL02, baseado em 4,5 anos de dados do GRACE;

- Dados de bóias (apenas componente barotrópica) Atlantic Oceanographic and Meteorological Laboratory (AOML);

- A Topografia Dinâmica Combinada Média (TDCM) foi determinada com a seguinte metodologia (Figura 2. 7);

1. Método direto: consiste em subtrair o modelo geoidal do nível médio do mar e filtrar os resultados; 
2. Método sintético: consiste em determinar a componente barotrópica média da corrente através dos dados in situ e da corrente anômala determinada por altimetria.

3. Determinar a TDCM através de análise objetiva.

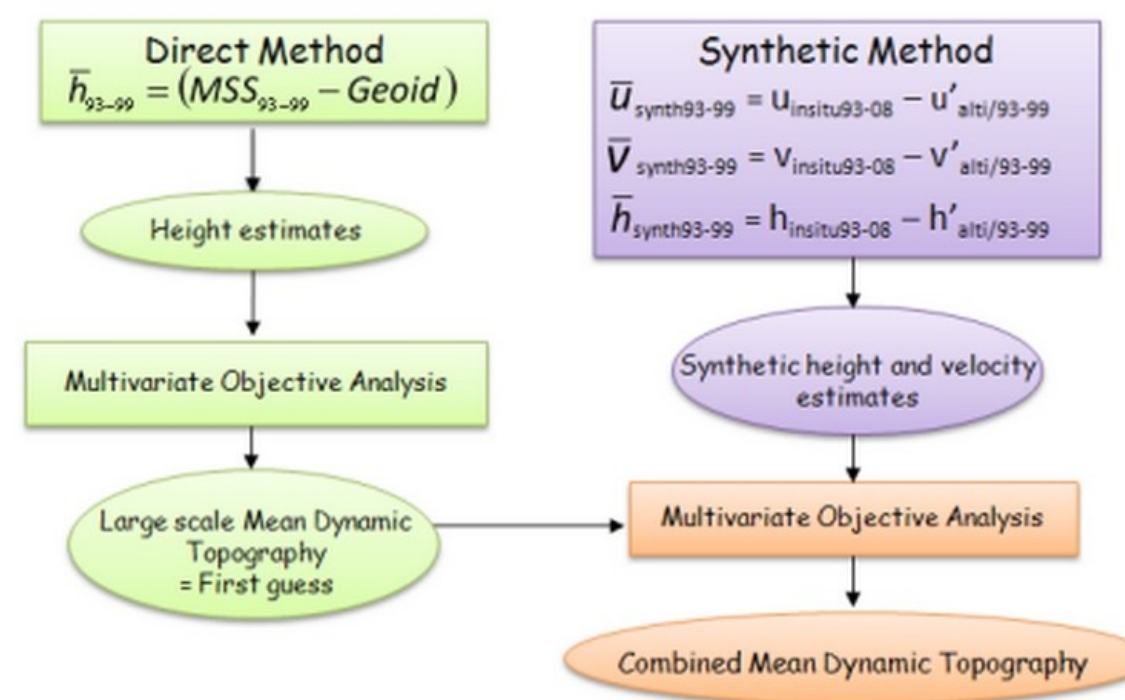

Figura 2.7 - Método de determinação da Topografia Dinâmica Combinada

(Fonte: http://www.aviso.oceanobs.com/en/data/products/auxiliaryproducts/mdt/description/index.html)

Após a determinação da TDC, as correntes são determinadas conforme (3.6). Como foi descrito acima, os dados fornecidos dependem de dados in situ, o que não ocorre com o método direto. 


\section{3 - METODOLOGIA}

A metodologia a ser aplicada no presente estudo consiste em:

- Processar os dados dos satélites altimétricos TOPEX/Poseidon e Jason1

- Determinar os modelos geoidais estáticos, a partir dos coeficientes harmônicos dos modelos EGM96, ENGEN-5C e EGM2008, com os mesmos parâmetros utilizados nos satélites altimétricos;

- Determinar e filtrar as topografias dinâmicas médias (TDM) do Atlântico Sul para diferentes modelos geoidais, bem como as correspondentes correntes geostróficas;

- Processar dados do modelo numérico hidrodinâmico HYCOM, de modo a representá-los na mesma grade dos dados de altimetria;

- Selecionar um modelo geoidal em função da comparação das TDMs provenientes de diferentes modelos geoidais com resultados do modelo numérico hidrodinâmico HYCOM;

- Determinar e filtrar a TD (altimetria-geóide) no Sudoeste do Atlântico Sul, com ênfase na região da CBM, considerando o modelo geoidal selecionado;

- Comparar os resultados obtidos no item anterior com os dados do modelo numérico HYCOM e dados disponibilizados pela AVISO e analisar suas variabilidades.

\section{3-1 - Processamentos dos dados do TOPEX/Poseidon e Jason 1}

$\mathrm{Na}$ leitura dos dados do TOPEX/Poseidon e Jason 1 foi utilizado o mesmo método, ou seja, foram consideradas as mesmas variáveis com as correções pertinentes.

Os programas utilizados foram desenvolvidos no Laboratório de Simulação e Previsão Numérica Hidrodinâmica (LabSIP) e Laboratório de Marés (MAPTOLAB).

As variáveis geradas são: Tempo (s); Latitude $\left(^{\circ}\right)$; Longitude $\left(^{\circ}\right)$; Flag; SSH $(\mathrm{cm})$ - Nível do mar não corrigido para a maré; SSHTC $(\mathrm{cm})$ - Nível do mar corrigido para a maré; Patm (hPA) - Pressão Atmosférica; Geóide $(\mathrm{cm})$ - O modelo geoidal OSU91 A no caso do TOPEX/Poseidon e EGM96 no caso do Jason 1; MSS (cm) nível médio do mar; Dep (m) - Batimetria; SWH (cm) - Altura significativa das ondas; 
WS (m/s) - Velocidade dos ventos.

É comum um ciclo não conter as 254 passagens do satélite; neste caso, torna-se necessário processar o ciclo separadamente, levando-se em conta as falhas do arquivo. No caso dos programas utilizados para a leitura dos dados do TOPEX, é necessário modificar o arquivo MGBCCC.HDR, que indica as passagens inicial e final a serem lidas, possibilitando ignorar as falhas do arquivo.

Das variáveis descritas acima foram utilizadas, no presente trabalho: tempo, Latitude, Longitude, SSHTC e MSS, cobrindo o período de 1992 a 2005.

\section{2 - Determinação dos modelos geoidais estáticos.}

Os modelos geoidais são estimados com os coeficientes harmônicos esféricos disponibilizados na Internet. Na determinação dos modelos estáticos EGM2008, EIGEN-5C e EGM96 foram utilizados e adaptados programas que foram previamente desenvolvidos por Tscherning (1976).

A altura geoidal, expandida como a soma de harmônicos esféricos, é dada pela expressão (2.19). Um modelo geoidal obtido através de dados de satélite consiste na obtenção dos valores de $C_{l m}$ e $S_{l m}$ (estes coeficientes são fornecidos gratuitamente, como discutido anteriormente) e das definições dos parâmetros geodésicos.

Neste trabalho, os modelos geoidais EIGEN-5C e EGM96 foram calculados em grau e ordem 360 e o EGM2008 foi determinado em grau e ordem 120, 360 e 2159, respectivamente (este modelo foi truncado em grau e ordem diferentes para verificar o quanto o truncamento de grau e ordem influencia na determinação da TD e respectivas correntes).

Todos os modelos referem-se ao mean tide system; neste sistema, são mantidos os valores médios das deformações da crosta da Terra e do seu efeito sobre o potencial da gravidade associado à maré permanente (Heck, 2004).

Os coeficientes harmônicos não definem um modelo geoidal específico, ou seja, na definição de uma superfície determinada pelo modelo geoidal é necessário, além dos coeficientes, os parâmetros geodésicos: semi eixo maior, semi eixo menor, achatamento e a constante gravitacional geocêntrica. 
Foi adotado o elipsóide de referência do TOPEX/POSEIDON, como será discutido a seguir.

\section{3 - Determinação da TDM e TD}

Após o processamento dos dados de altimetria e a obtenção dos modelos geoidais, foi determinada a TDM na região ilustrada na Figura 1.2 e a TD (com resolução temporal de 9.9156 dias) na região ilustrada na Figura 1.3. Todas as unidades das variáveis usadas foram padronizadas em $\mathrm{cm}$. Matematicamente, a TDM e a TD podem ser escritas, respectivamente, por:

$$
\begin{aligned}
& T D M=N M M-N \\
& T D=S S H T C-N
\end{aligned}
$$

onde NMM é o nível médio do mar DNSC08, SSHTC (determinado a partir dos dados fornecidos pelo TOPEX/POSEIDON ) é o nível do mar (subtraindo as marés), relativo ao elipsóide de referência, e $\mathrm{N}$ é a altura geoidal.

O elipsóide de referência do modelo geoidal e dos dados altimétricos deve ser único; os parâmetros foram os utilizados pelo TOPEX/POSEIDON (AVISO, 1996):

$\mathrm{a}=6378.1363 \mathrm{~km}$ (semi eixo maior);

$f=(a-b) / a=1 / 298.257$ (achatamento, onde b é o semi eixo menor).

$\mathrm{GM}=398600.4415^{*} 10^{9} \mathrm{~m}^{3} / \mathrm{s}^{2}$ (constante gravitacional geocêntrica)

Os parâmetros citados acima foram portanto utilizados na determinação dos modelos geoidais; a Figura. 3.1 ilustra o referencial do modelo geoidal e dos dados altimétricos. 


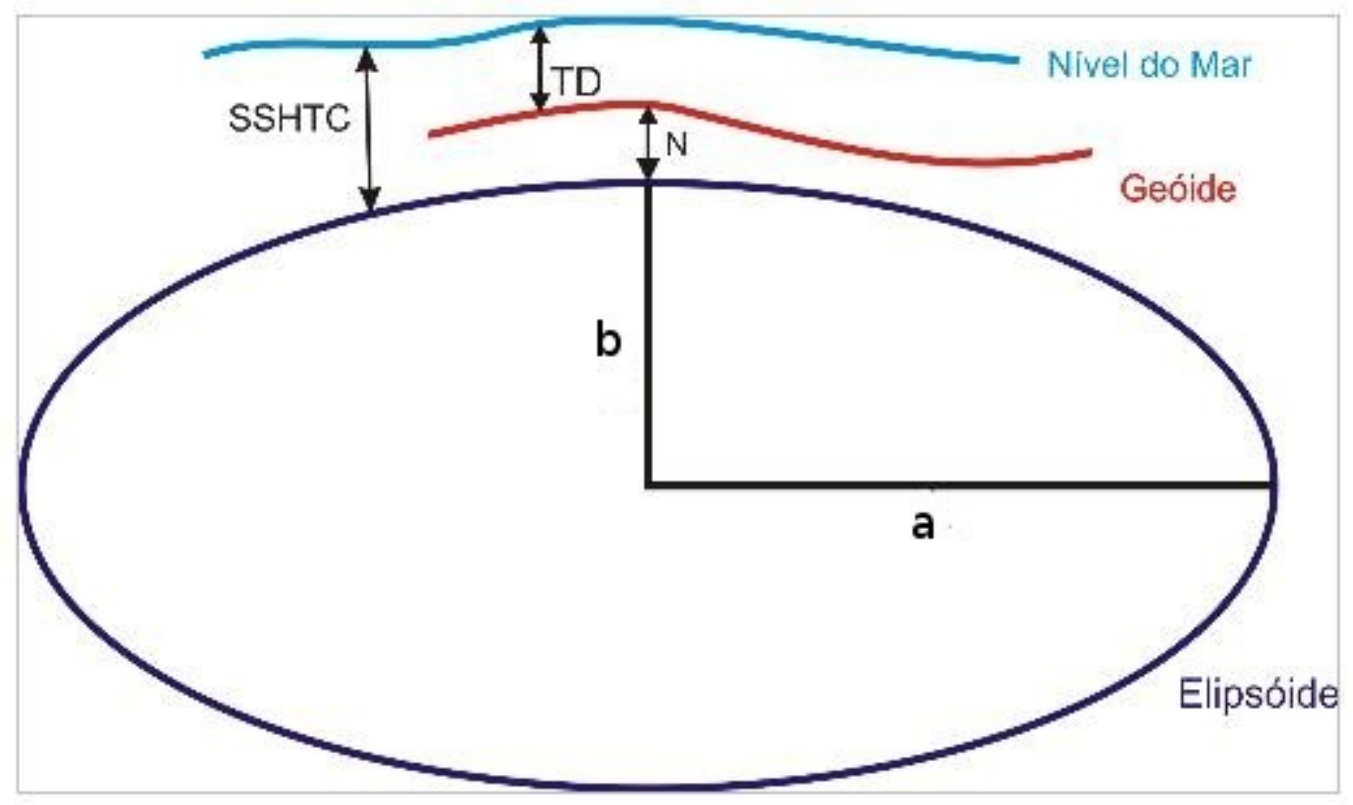

Figura 3.1: Sistema de referência da TD

A TDM foi determinada da seguinte forma:

- Na região mostrada na Figura 1.2 foi utilizado o modelo do nível médio do mar DNSC08 e os modelos geoidais descritos anteriormente.

A TD foi determinada da seguinte forma:

- Na região mostrada na Figura 1.3 foram utilizados os dados de altimetria do nível do mar, corrigido de maré, com resolução temporal de 9.156 dias, e o modelo geoidal que melhor representou as feições de circulação na região da Figura 1.2.

\section{4 - Os métodos estatísticos de Filtragem}

Um dos grandes problemas da utilização dos modelos geoidais existentes na determinação da TD são os inúmeros ruídos presentes, principalmente quando se trata de modelos expandidos em grau e ordem elevados. Vianna et al. (2007) propuseram uma técnica eficiente para resolver o problema. O trabalho em questão utilizou um filtro para determinar a topografia dinâmica em alta resolução $\left(0.25^{\circ} \times 0.25^{\circ}\right)$, o filtro SSA, que foi utilizado na presente pesquisa, para a determinação da TD no Atlântico Sul e nas 
regiões da CBM.

A SSA é um caso particular da EOF e é muito utilizada em reconstituições de séries temporais e preenchimento de lacunas devidas à falta de informações. Matematicamente a matriz covariância utilizada na SSA é dada por (Vianna et al. 2007):

$$
c_{i j}=\frac{1}{N-|i-j|} \sum_{j=1}^{N-|i-j|} X_{l} X_{l+|i-j|} \quad 0 \leq i, j \leq M-1
$$

onde, $X_{l}$ é uma latitude constante (longitude) na seqüência de $N$ pontos e $M$ é um parâmetro livre, que mostra a informação máxima da dimensão da matriz. Os autovalores $\lambda_{k}$ e os auto-vetores $E_{j}^{k}$ desta matriz são obtidos e ordenados em ordem decrescente de energia $\lambda_{k}$, com $j, k$ variando de 1 a $M$. As $k$ componentes principais $p^{k}$ são obtidas por:

$$
p_{i}^{k}=\sum_{j=1}^{M} X_{i+j} E_{j}^{k} \quad 0 \leq i, j \leq N-M
$$

As componentes reconstruídas $R_{i}^{k}$ são dadas por:

$$
\begin{array}{ll}
R_{i}^{k}=\frac{1}{M} \sum_{j=1}^{M} p_{i-j}^{k} E_{j}^{k} & M \leq i \leq N-M+1 \\
R_{i}^{k}=\frac{1}{i} \sum_{j=1}^{i} p_{i-j}^{k} E_{j}^{k} & 1 \leq i \leq M-1 \\
R_{i}^{k}=\frac{1}{N-i+1} \sum_{j+i-N+M}^{i} p_{i-j}^{k} E_{j}^{k} & N-M+2 \leq i \leq N
\end{array}
$$

As componentes reconstituídas constituem as versões filtradas do sinal, sendo que cada uma das componentes é caracterizada por um comprimento de onda dominante. O filtro é a soma parcial das componentes reconstituídas, que são escolhidas por seus comprimentos de onda dominantes. 
No caso da TD, o procedimento de filtragem consiste em 2 passos: primeiro removem-se os ruídos meridionais e depois removem-se os outros ruídos, a partir dos dados filtrados no passo 1 . Nos dois passos utiliza-se a mesma origem do filtro descrito acima.

Apesar de Vianna et al. (2007) comprovar as melhorias do filtro SSA no estudo de correntes, o mesmo foi comparado com um filtro gaussiano para análise dos resultados.

\section{5 - Interpolação}

Todos os dados foram interpolados em grade de $0.5^{\circ} \times 0.5^{\circ}$. Foram testados inúmeros interpoladores, no entanto o método da curvatura mínima apresentou melhores resultados. O método consiste na solução da equação abaixo para cada ponto (z) :

$$
(1-T) \nabla_{(z)}^{4}+T \nabla_{(z)}^{2}=0
$$

onde $T e ́$ a tensão, compreendida entre 0 e 1, 0 resulta em curvatura mínima. Estudos realizados mostraram que o valor de 0.25 apresenta melhores resultados (Smith and Wessel, 1990). Para se obter melhores resultados, os dados devem ser bem distribuídos, de forma homogênea; esta solução foi adotada em todos os dados com recursos do The Generic Mapping Tools (GMT).

O critério de interpolação acima foi comparado com outros métodos (triangulação, vizinho próximo, gaussiano), entretanto, a utilização da curvatura mínima apresenta melhores resultados no caso dos dados de altimetria, onde comumente ocorrem falhas em seqüências de dados.

\section{6- Correntes geostróficas}

De posse da TDM e TD, se pode facilmente estimar as correntes geostróficas 
absolutas (componentes u - EW e v - NS) por:

$$
\begin{aligned}
& v=\frac{g}{f} \frac{\partial \eta}{\partial x} \\
& u=-\frac{g}{f} \frac{\partial \eta}{\partial y}
\end{aligned}
$$

onde $f=2 \Omega \operatorname{sen} \varphi$ é o parâmetro de Coriolis, $\Omega$ é a velocidade angular de rotação da Terra, g é a gravidade e $\frac{\partial \eta}{\partial x}$ e $\frac{\partial \eta}{\partial y}$ são as inclinações do nível do mar (este termo é determinado com a TD).

\section{7 - Análise da TDM e correntes geostróficas médias no Atlântico Sul.}

Erros relativamente pequenos no geóide causam erros na TD (Polito and Sato 2004), assim a precisão dos modelos geoidais é imprescindível para a determinação das correntes geostróficas. Os modelos geoidais atuais possuem precisão compatível com a precisão apresentada pelos dados altimétricos (2 a $3 \mathrm{~cm}$ ), entretanto apresentam ruídos que são outra fonte de erro na estimativa das correntes. Assim, foram feitas as seguintes análises, considerando as TDMs oriundas dos modelos geoidais descritos anteriormente:

- Verificação de ruídos em função do harmônico esférico;

- Aplicação dos filtros SSA e gaussiano e análise dos respectivos resultados.

Após a determinação das TDMs filtradas, foram determinadas as correntes absolutas médias e respectivas correlações espaciais com o modelo numérico HYCOM.

\section{8 - Comparação e análise das TDs e correntes geostróficas absolutas na região da} CBM.

A comparação entre resultados de metodologias diferentes teve como objetivo verificar as potencialidades do método direto (apenas altimetria e geóide) no estudo das variabilidades da TD e correntes absolutas. 
O modelo numérico HYCOM é conhecido na comunidade científica e seus produtos são confiáveis, o que motivou sua escolha na comparação com os resultados provenientes de altimetria e modelos geoidais.

Também foram utilizados dados combinados (MERGED) disponibilizados pela AVISO, onde foram utilizados dados de altimetria e dados in situ na determinação da $\mathrm{TD}$ e correntes. Foram feitas as seguintes comparações na região da $\mathrm{CBM}\left(70^{\circ} \mathrm{W}\right.$ a $30^{\circ} \mathrm{W}$ e $50^{\circ} \mathrm{S}$ a $20^{\circ} \mathrm{S}$ ), no verão e inverno de 2004 a 2005 (período que coincide com a série temporal do modelo $\mathrm{HYCOM}$ ):

1. Comparação entre a Topografia Dinâmica determinada a partir dos dados de altimetria (MGDR) e modelos geoidais (TD), Topografia Dinâmica do modelo numérico HYCOM (TDH) e Topografia dinâmica dos dados AVISO MERGED (TDC) e cálculo das correlações entre as mesmas, considerando o período de 2003 a 2005.

2. Análise das TDs nos pontos assinalados na Figura 3.1;

3. Comparação e determinação das correlações entre as Correntes Geostróficas do HYCOM (CGH) e as Correntes Geostróficas dos dados altimétricos e gravimétricos (CGA) e Correntes Geostróficas oriundas dos dados combinados MERGED (CGC).

4. Analise temporal das correntes geostróficas (componente barotrópica) em pontos localizados na região da $\mathrm{CB}, \mathrm{CM}$ e CAS, conforme Figura 3.2.

\section{8 - Análise das correntes geostróficas.}

A CB e CM são as correntes mais intensas na região de estudo, desta forma foram escolhidos 2 pontos (no período de 1992 e 2005) para analisar como as componentes barotrópicas destas correntes variam, considerando o uso de altimetria e modelos geoidais através do método direto. A localização dos pontos na região da $\mathrm{CB}$ e CM é ilustrada na Figura 3.2. 


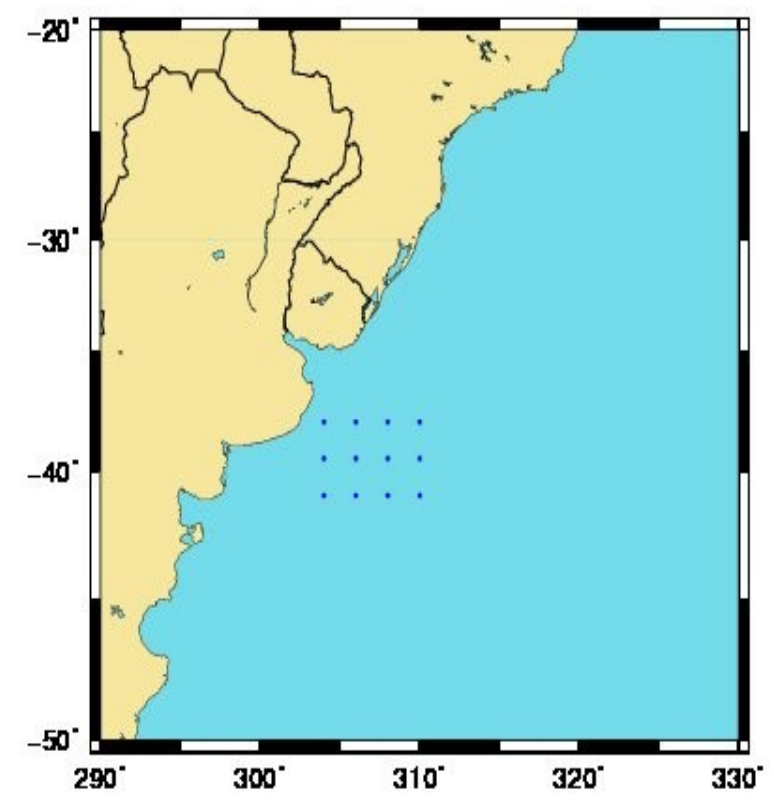

Figura 3.2: Localização dos pontos em que foi analisada a topografia dinâmica

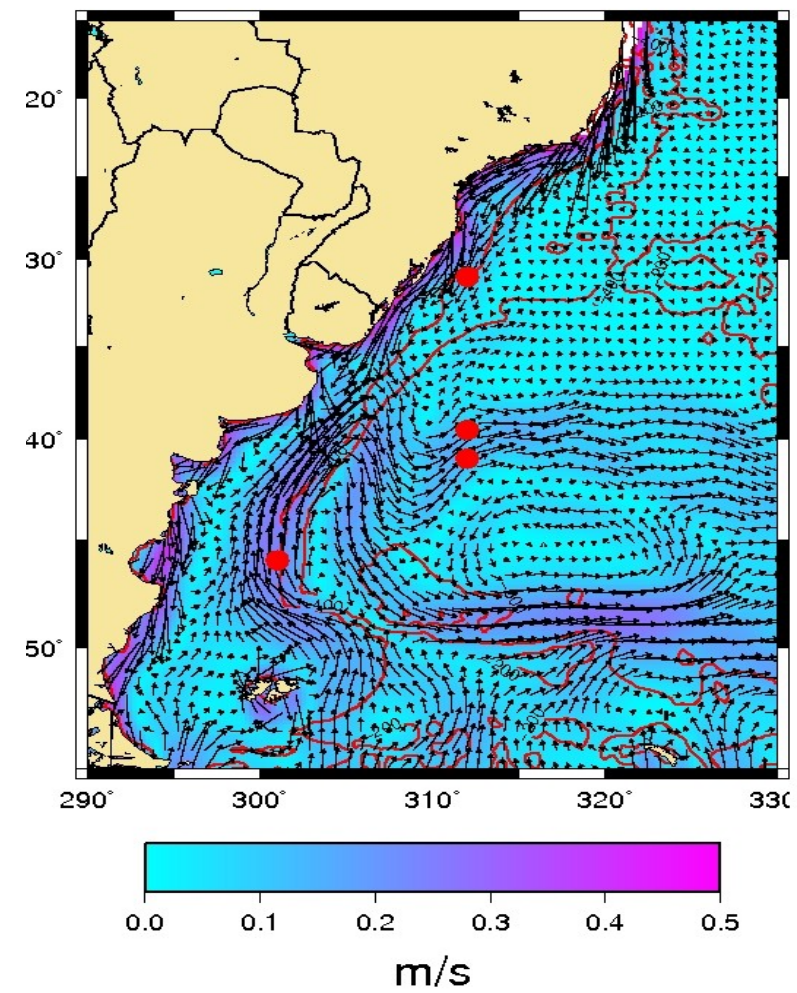

Figura 3.3: Localização dos pontos em que foram analisadas e comparadas as correntes . 


\section{4 -RESULTADOS.}

\section{1 - Os modelos geoidais e respectivas aplicações na determinação da TDM.}

Neste trabalho foram determinados 3 modelos de Topografia Dinâmica Média: TDM-EGM96, TDM-EIGEN5C e TDM-EGM2008; estes modelos de topografia dinâmica foram comparados, com objetivo de analisar a evolução da aplicação dos modelos geoidais em Oceanografia. Conforme foi discutido no Capítulo 2, o modelo EGM2008 apresenta melhor densidade de dados gravimétricos e conseqüentemente melhor resolução; também pode ser observado que os harmônicos esféricos deste modelo apresentam uma melhora significativa até grau e ordem 360 (Figuras 2.3 e 2.4) O grau e ordem de um modelo geoidal influi diretamente na determinação da topografia dinâmica, por estarem diretamente relacionados com sua resolução. Com objetivo de avaliar esta relação foram utilizados 3 modelos de TDM, a partir do modelo EGM2008: TDM-EGM08-2160, TDM-EGM08-360 e TDM-EGM08-120 que correspondem à topografia dinâmica com o modelo geoidal truncado em grau e ordem 2159, 360 e 120, respectivamente. Como pode ser observado nas Figuras 4.1 a 4.3, o grau e ordem do modelo modificam as feições da TDM. No Capítulo 2 foi discutido que modelos com grau e ordem elevados apresentam ruídos com a mesma amplitude dos coeficientes, entretanto no caso do modelo EGM2008 o modelo truncado em grau máximo apresenta melhores resultados para TDM (Figura 4.1). Quando o modelo foi determinado em grau e ordem 360, alguns ruídos foram observados na TDM, ainda sem alterações das feições de grande e meso-escala (Figura 4.2); entretanto, em grau e ordem 120, os ruídos praticamente impossibilitam o cálculo das correntes geostróficas (Figura 4.3). 


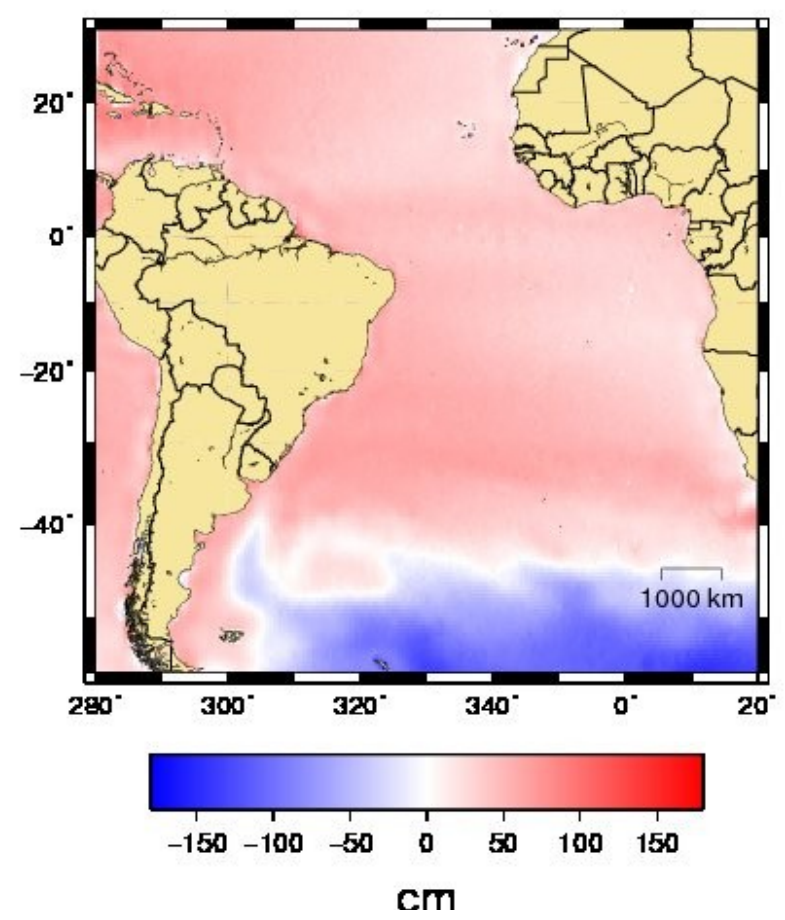

Figura 4.1: Topografia Dinâmica determinada com o modelo geoidal EGM2008 truncado em grau e ordem 2159

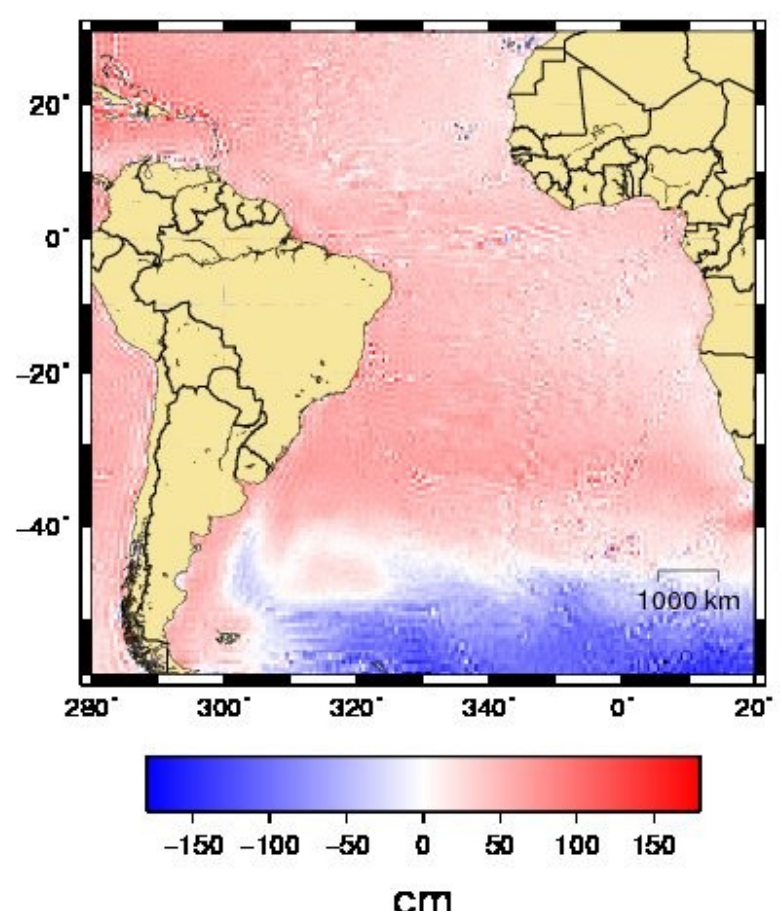

Figura 4.2: Topografia Dinâmica determinada com o modelo geoidal EGM2008 truncado em grau e ordem 360 


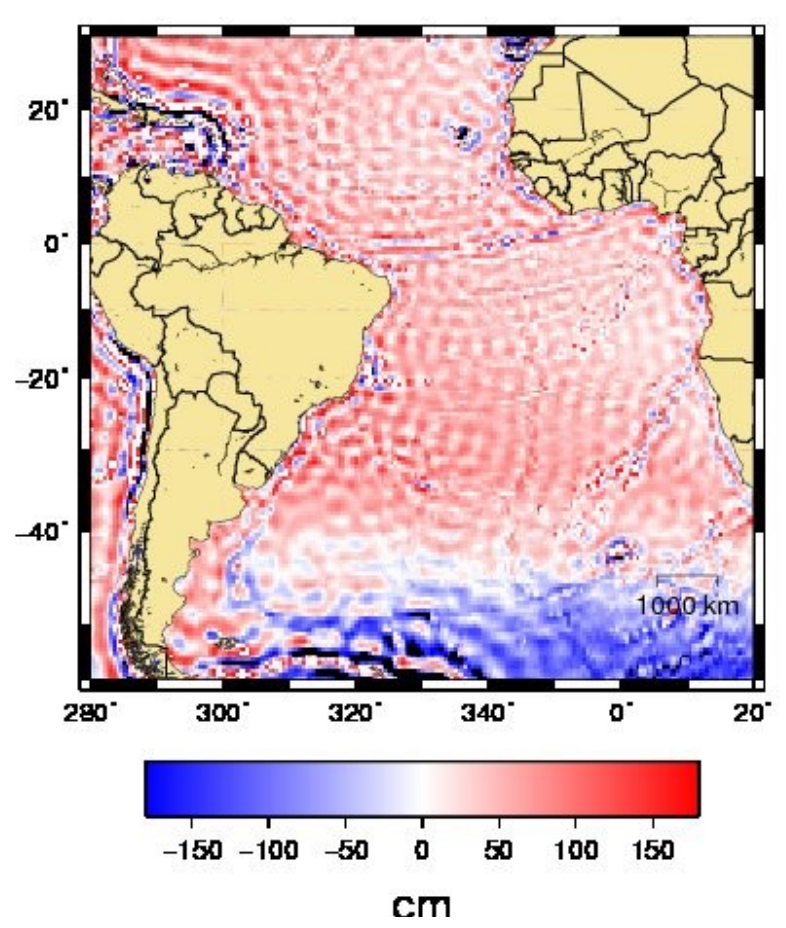

Figura 4.3: Topografia Dinâmica determinada com o modelo geoidal EGM2008 truncado em grau e ordem 120

\section{2 - Aplicação do filtro SSA e comparação com o filtro gaussiano.}

A Figura. 4.4 mostra, como exemplo, o resultado do filtro SSA aplicado à TDM_EGM2008 ao longo da longitude de $20^{\circ} \mathrm{W}$; o valor de $\mathrm{M}$ foi padronizado para todos os $\operatorname{casos}(\mathrm{M}=3)$.

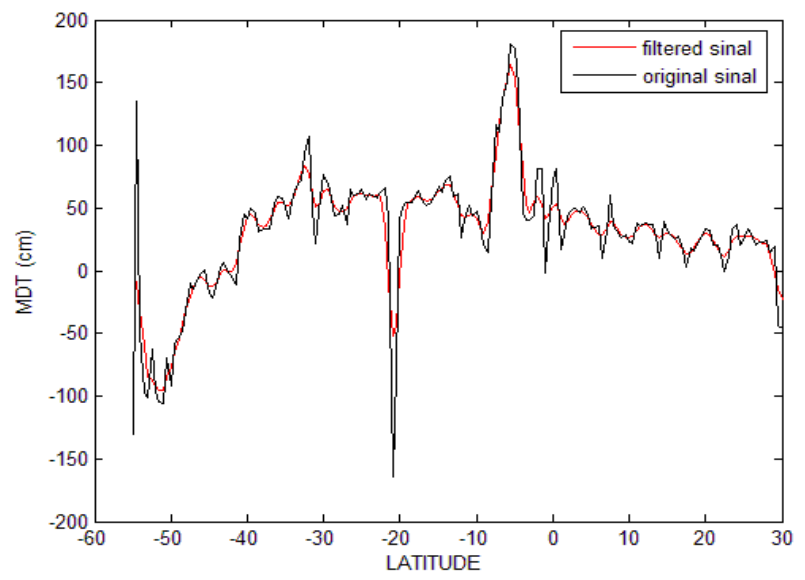

Figura 4.4: Perfil longitudinal da TDM filtrada e não filtrada na longitude $20^{\circ} \mathrm{W}$. 
Como pode ser observado nas Figuras que seguem, a aplicação do filtro é eficiente na remoção de ruídos. Outras vantagens do filtro se encontram na facilidade de aplicação nos contornos laterais e seu uso com pequeno conjunto de dados, podendo ser controlado através da matriz $\mathrm{M}$.

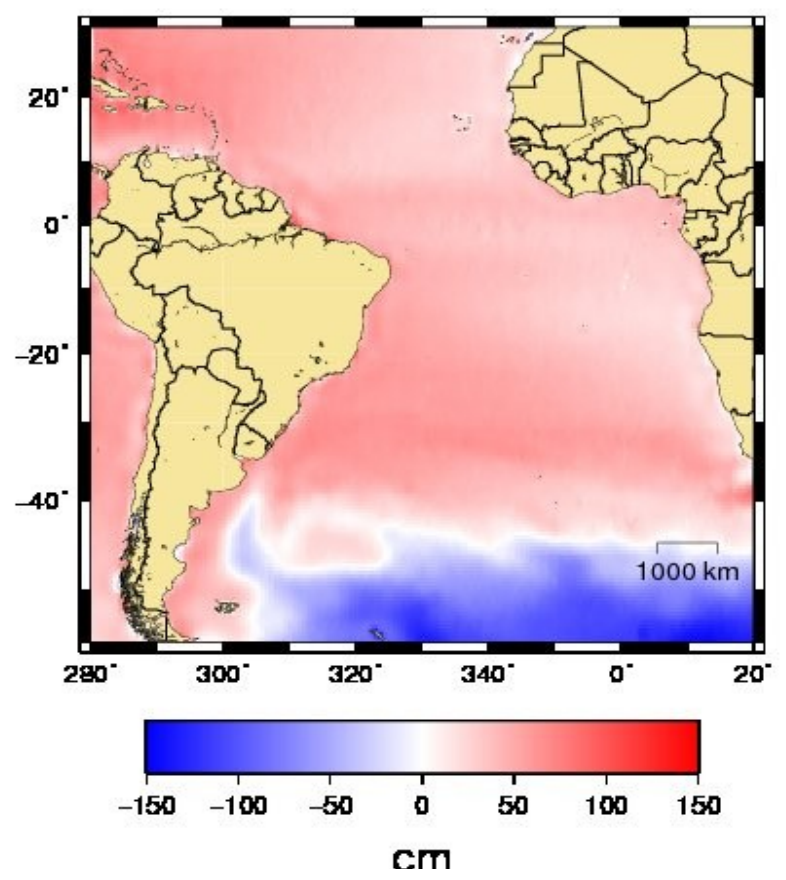

Figura 4.5: TDM_EGM08 não filtrada

Na Figura 4.1 observa-se uma TDM com poucos ruídos, isto se deve ao grau e ordem do modelo geoidal EGM2008 bem como da resolução do modelo de nível médio do mar DSC08. As Figuras 4.6, 4.7, 4.8, 4.9 e 4.10 ilustram as TDMs, não filtradas e filtradas com o filtro SSA, oriundas dos modelos geoidais EGM2008, EIGEN-5C e EGM96, respectivamente.

As Figuras 4.6, 4.7, 4.8, 4.9 e 4.10 ilustram as TDMs, não filtradas e filtradas com o filtro SSA, oriundas dos modelos geoidais EGM2008, EIGEN-5C e EGM96, respectivamente. Finalmente, a Figura 4.11 apresenta a TDM_EIGEN-5C filtrada com filtro gaussiano. 


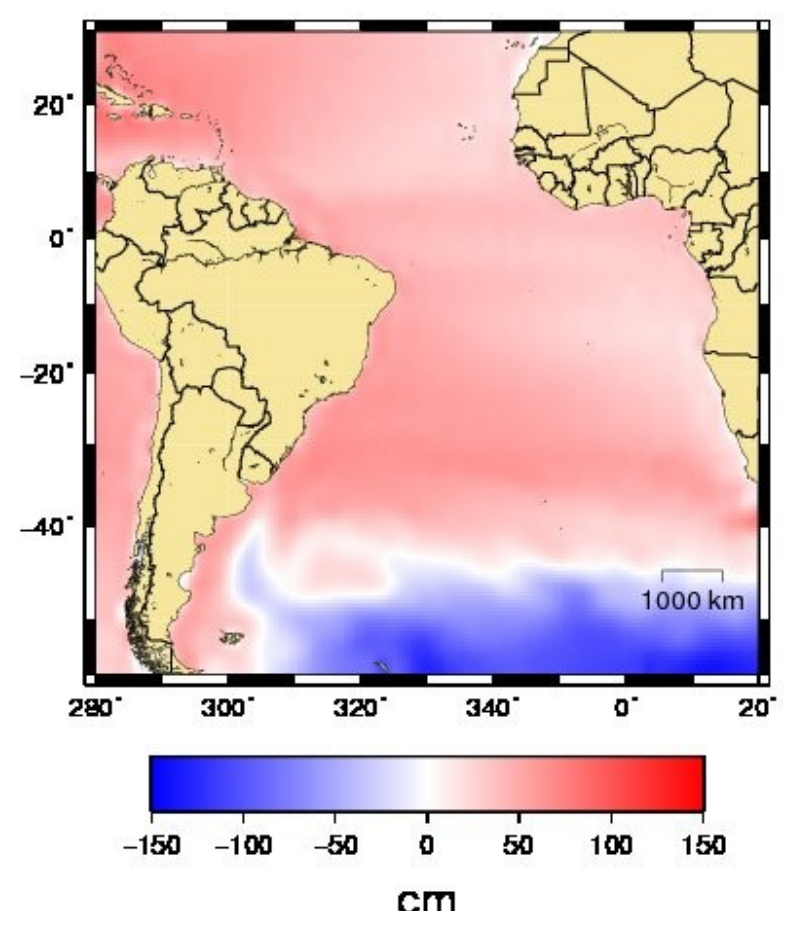

Figura 4.6: TDM_EGM08 filtrada com o filtro SSA

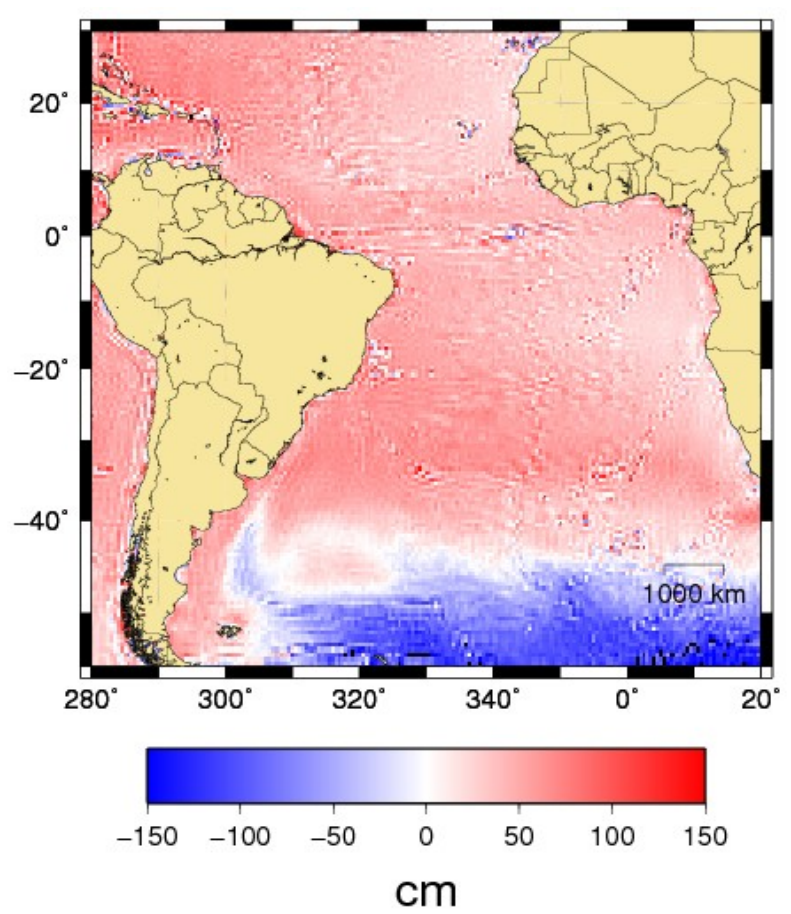

Figura 4.7: TDM_EIGEN não filtrada. 


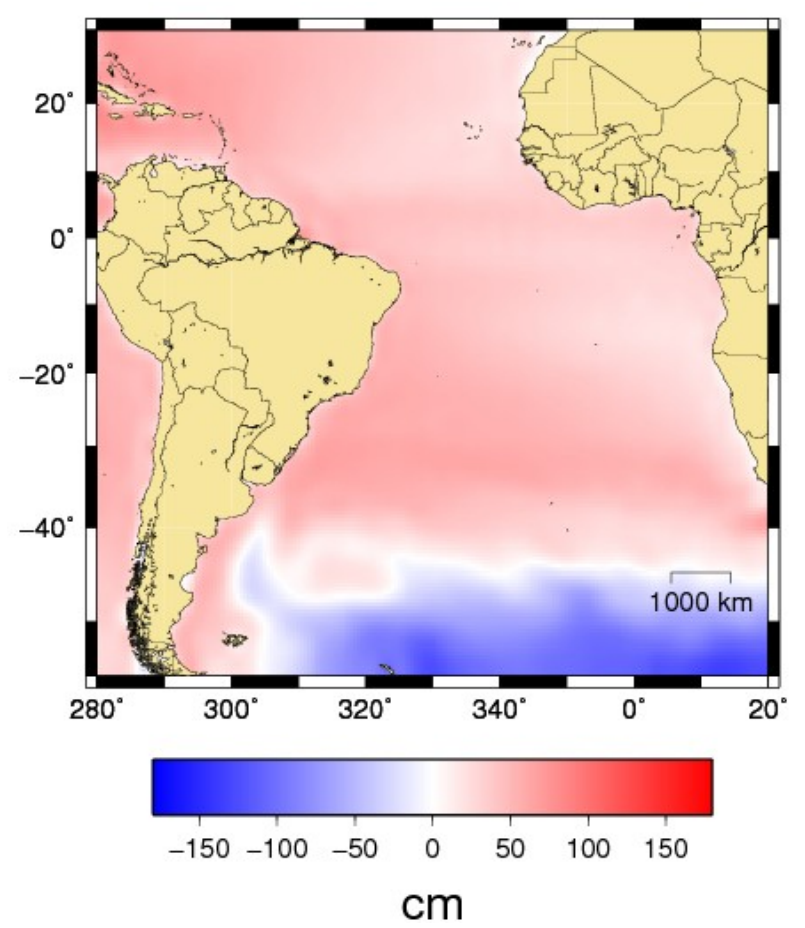

Figura 4.8: TDM_EIGEN filtrada com o filtro SSA.

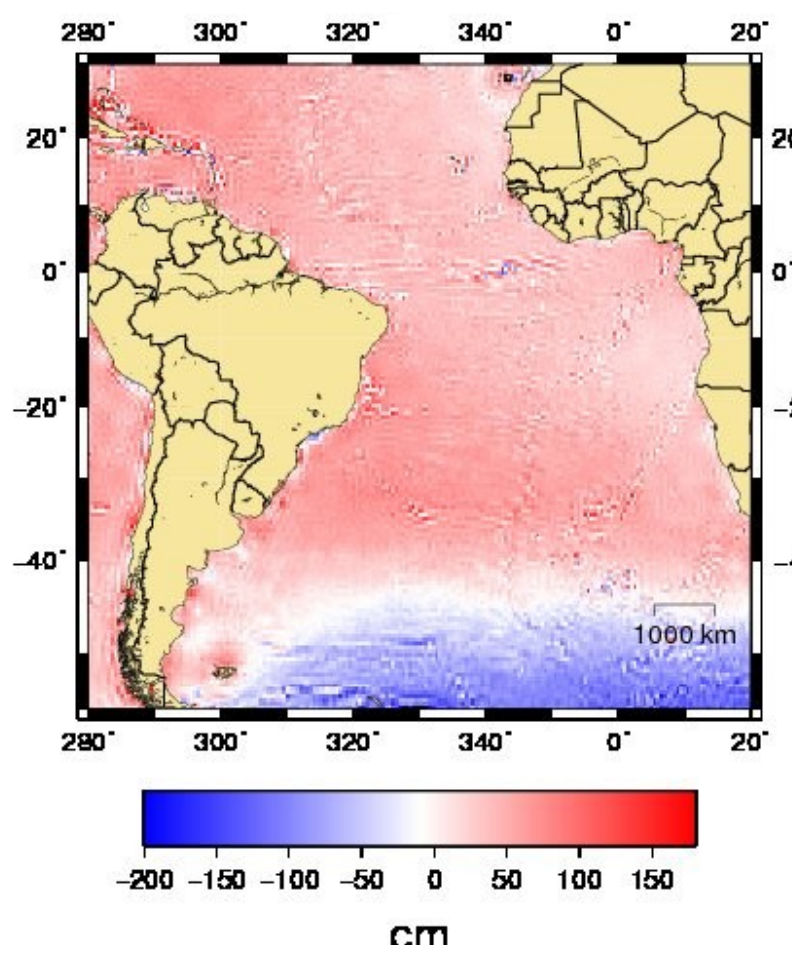

Figura 4.9: TDM_EGM96 não filtrada 

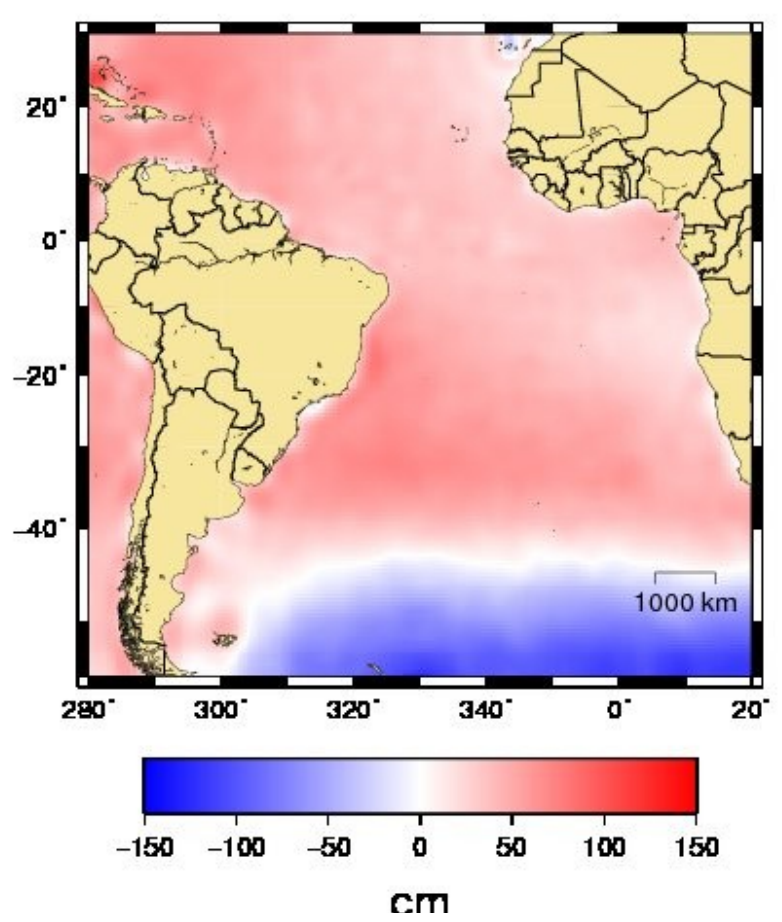

Figura 4.10: TDM_EGM96 filtrada com o filtro SSA.

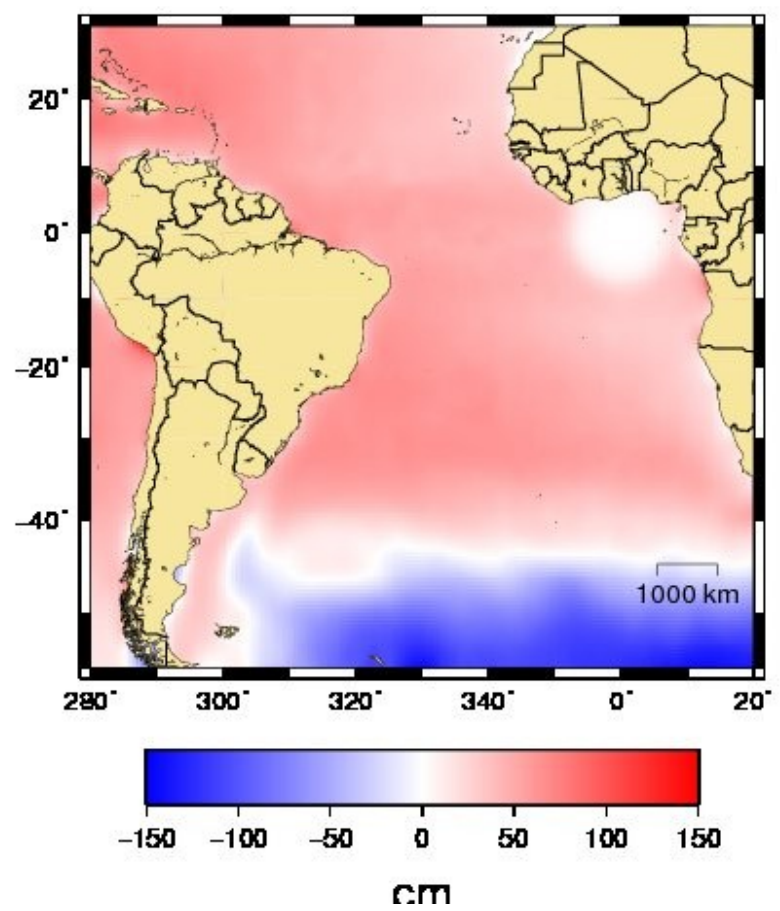

Figura 4.11: MDT_EIGEN filtrada com o filtro gaussiano

Comparando a Figura 4.11 com a Figura 4.8 (filtros aplicados à TDM-EIGEN) 
percebe-se que o filtro gaussiano aparentemente é eficiente na remoção dos ruídos, entretanto apresenta problemas nos contornos laterais, como ocorre na costa da África. Também foi observado que a TDM na região da CBM não apresentou os mesmos resultados quando comparada com a TDM filtrada com o filtro SSA.

\section{3 - Correntes geostróficas médias resultantes.}

As feições de circulação determinadas com o modelo de TDM determinado a partir de modelo geoidal EGM2008 (TDM-EGM08), vide Figura 4.12, são similares aos padrões de circulação apresentados por Stramma and England (1999) nos primeiros 140 $\mathrm{m}$ da coluna d'água (Figura 1.1). As feições do giro subtropical, como CB, CM, CBM e CAS foram facilmente identificadas, A Corrente Sul Equatorial (CSE) também foi identificada, mas deve-se levar em conta que, na região próxima ao Equador a geostrofia não é bem determinada. Utilizando o modelo EIGEN-5C (TDM-EIGEN5C), o mesmo padrão foi observado, porém com ruídos; as diferenças se devem ao fato de que o modelo EIGEN-5C foi calculado com grau e ordem 360 e o EGM2008 com grau e ordem 2159 (Figura 4.13). Os padrões de correntes determinados com o modelo EGM96 (MDT-EGM96) apresentaram resultados distintos, onde sequer foi observada a retroflexão da $\mathrm{CM}$ nas proximidades da latitude $40^{\circ} \mathrm{S}$, o que pode ser justificado pela baixa precisão e resolução do respectivo modelo geoidal (Figura 4.14).

A comparação estatística das correntes para o Atlântico Sul é mostrada na Tabela 4.1, com as correntes do modelo TDM-EGM08 possuindo, em relação ao modelo numérico HYCOM, para as correntes médias no período de 2003 a 2008, maior correlação e menor erro, sendo este calculado como a raiz do erro quadrático médio (REQM); por outro lado, as correntes do modelo TDM-EGM96 apresentam a menor correlação e o maior erro.

Tabela 4.1 - Comparação estatística (médias de todos os pontos de grade) entre as correntes ( $\mathrm{U}$ e $\mathrm{V}$ ) do modelo numérico HYCOM e dos modelos geoidais.

\begin{tabular}{|c|c|c|c|c|c|c|}
\hline \multirow{2}{*}{} & \multicolumn{2}{|c|}{ EGM2008 } & \multicolumn{2}{c|}{ EIGEN-5C } & \multicolumn{2}{c|}{ EGM96 } \\
\cline { 2 - 7 } & UM & VM & UM & VM & UM & VM \\
\hline Correlação & 0.70 & 0.69 & 0.62 & 0.64 & 0.10 & 0.11 \\
\hline REQM & $0.1 \mathrm{~m} / \mathrm{s}$ & $0.06 \mathrm{~m} / \mathrm{s}$ & $0.09 \mathrm{~m} / \mathrm{s}$ & $0.12 \mathrm{~m} / \mathrm{s}$ & $0.12 \mathrm{~m} / \mathrm{s}$ & $0.16 \mathrm{~m} / \mathrm{s}$ \\
\hline
\end{tabular}


As Figuras 4.12, 4.13, 4.14, 4.15 ilustram o padrão de circulação geostrófica no Atlântico Sul a partir da TDM_EGM08, TDM_EIGEN-5C, TDM_EGM96 e HYCOM, respectivamente.

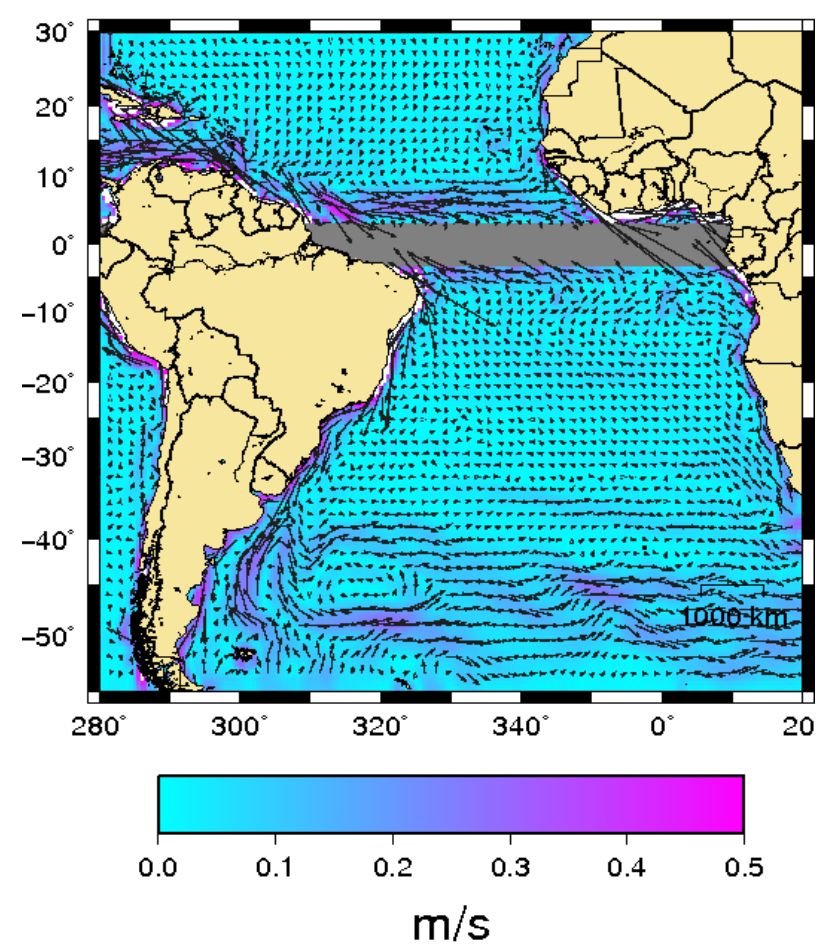

Figura 4.12: Corrente geostrófica determinada a partir da TDM_EGM08

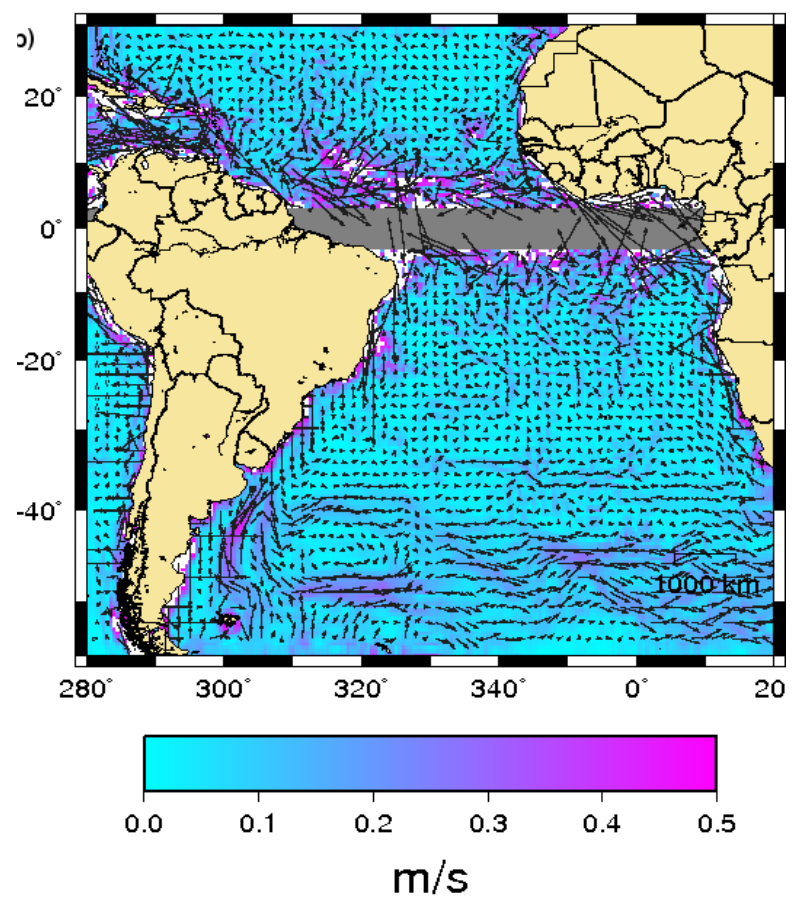

Figura 4.13: Corrente geostrófica determinada a partir da TDM_EIGEN-5C 


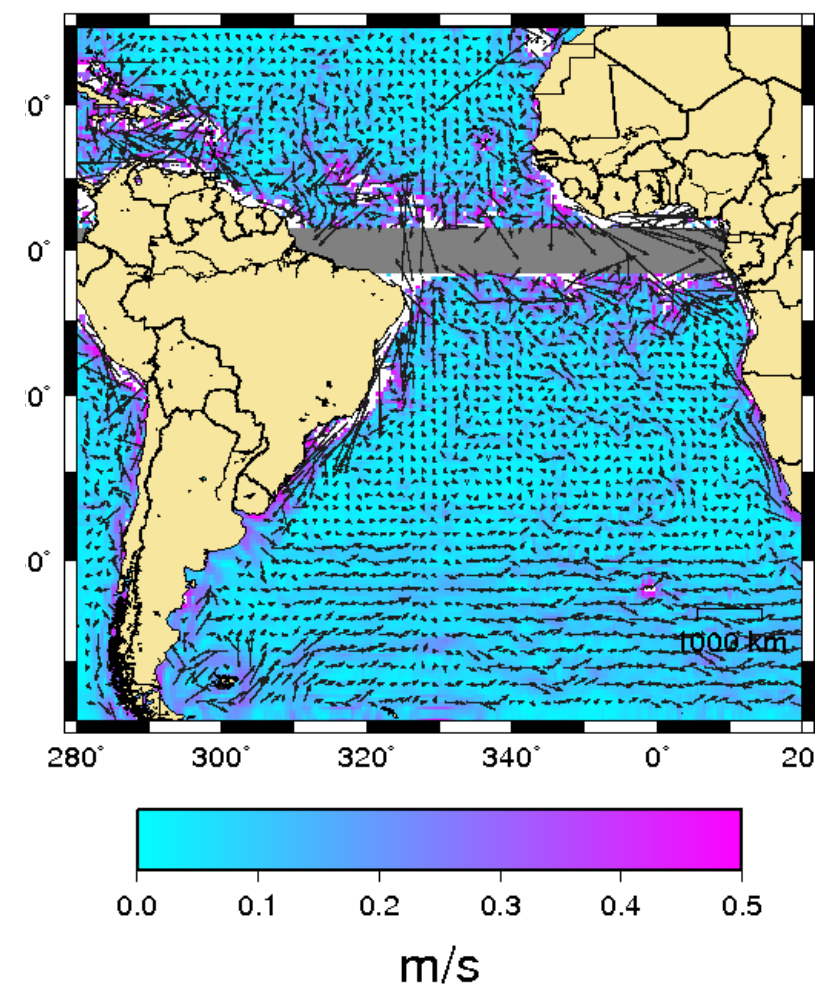

Figura 4.14: Corrente geostrófica determinada a partir da TDM_EGM96

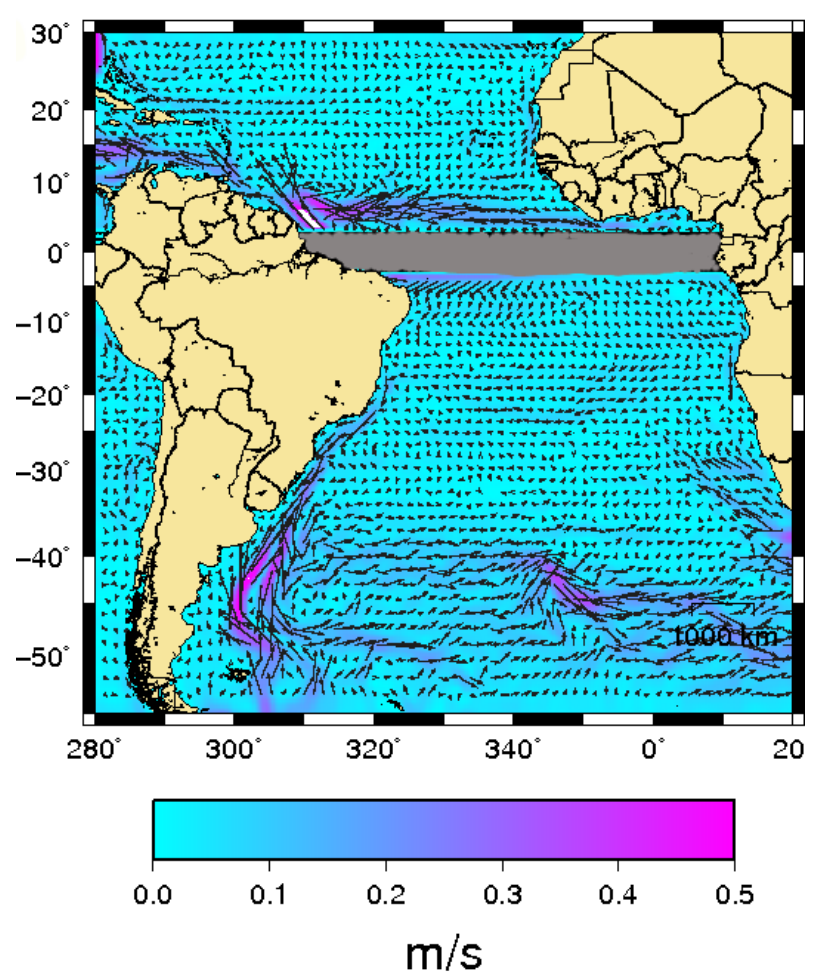

Figura 4.15: Corrente geostrófica média do modelo numérico HYCOM 
Deve-se ressaltar que quando se trata de correntes geostróficas determinadas com TD tem-se apenas a componente barotrópica das correntes. E esse procedimento foi também usado para as correntes geostróficas calculadas a partir dos resultados do HYCOM.

A CB, entre $20^{\circ} \mathrm{S}$ e $30^{\circ} \mathrm{S}$, na isóbata de $200 \mathrm{~m}$, apresentou velocidades resultantes médias de aproximadamente $0.20 \mathrm{~m} / \mathrm{s}$ (desvio padrão de $0.09 \mathrm{~m} / \mathrm{s}$ ), quando determinada com a TDM-EGM2008 (Figura 4.16), $0.22 \mathrm{~m} / \mathrm{s}$ (desvio padrão de 0.12 $\mathrm{m} / \mathrm{s}$ ) utilizando a TDM-EIGEN-5C, embora os ruídos interfiram na estimativa (Figura 4.17) e $0.30 \mathrm{~m} / \mathrm{s}$ (desvio padrão de $0.17 \mathrm{~m} / \mathrm{s}$ ) considerando a TDM-EGM96 (Figura 4.18); o modelo numérico HYCOM forneceu velocidade de $0.25 \mathrm{~m} / \mathrm{s}$ (desvio padrão de $0.13 \mathrm{~m} / \mathrm{s}$ ) na mesma região (Figura 4.19).

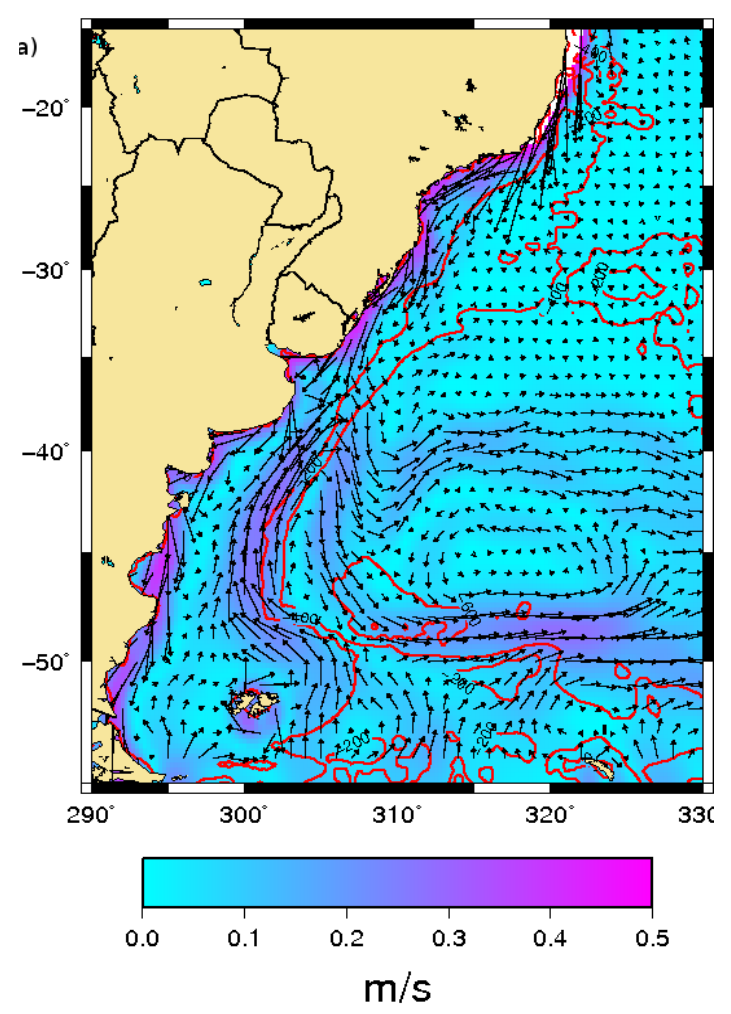

Figura 4.16: Correntes geostróficas médias na região da CBM, a partir da TDM_EGM08 


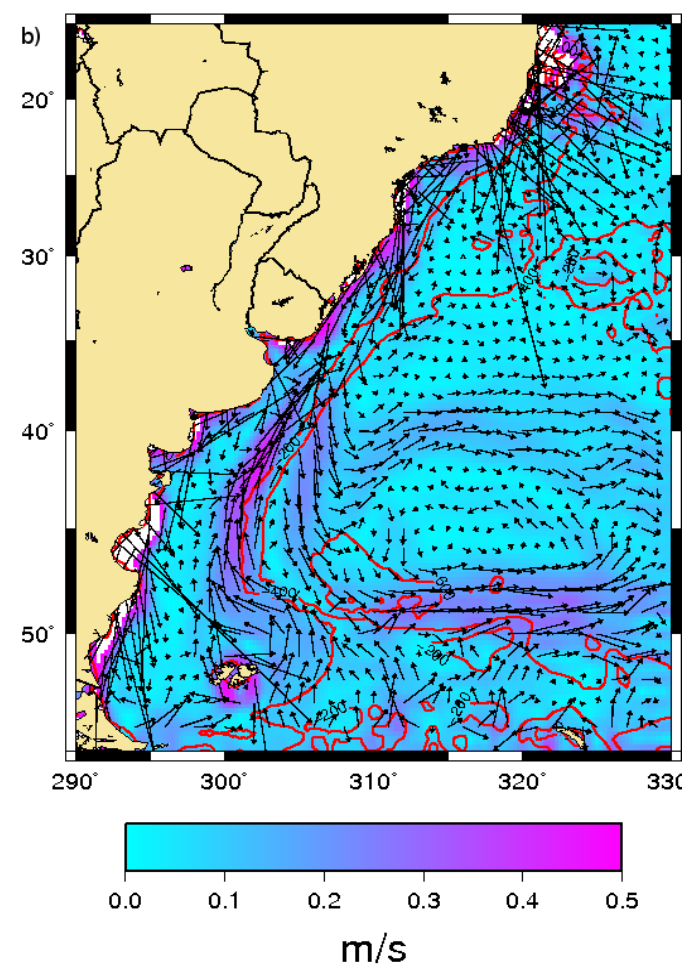

Figura 4.17: Correntes geostróficas médias na região da CBM, a partir da TDM_EIGEN-5C

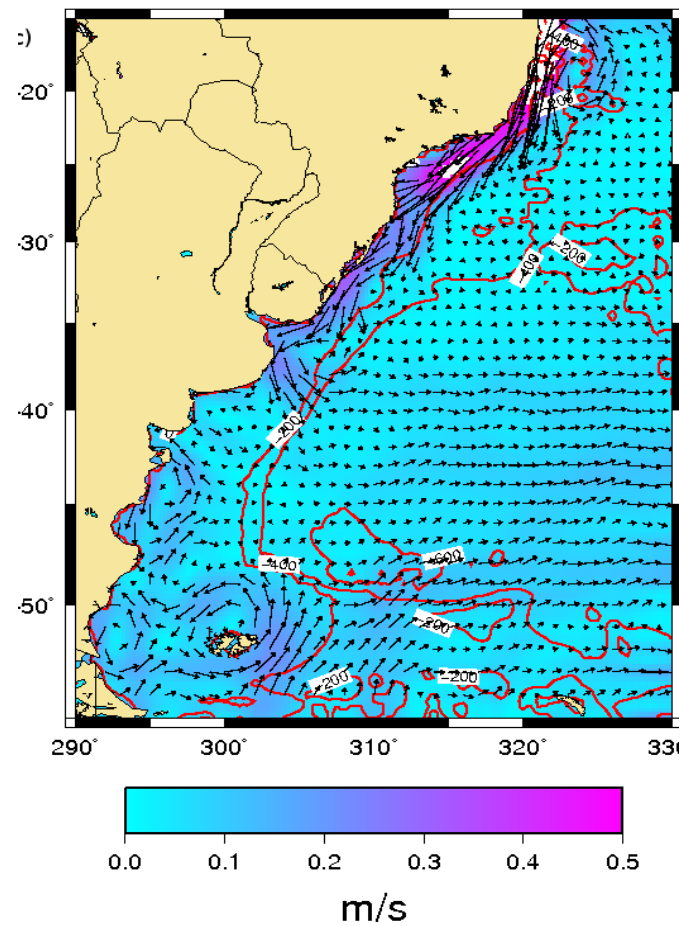

Figura 4.18: Correntes geostróficas médias na região da CBM, a partir da TDM EGM96 


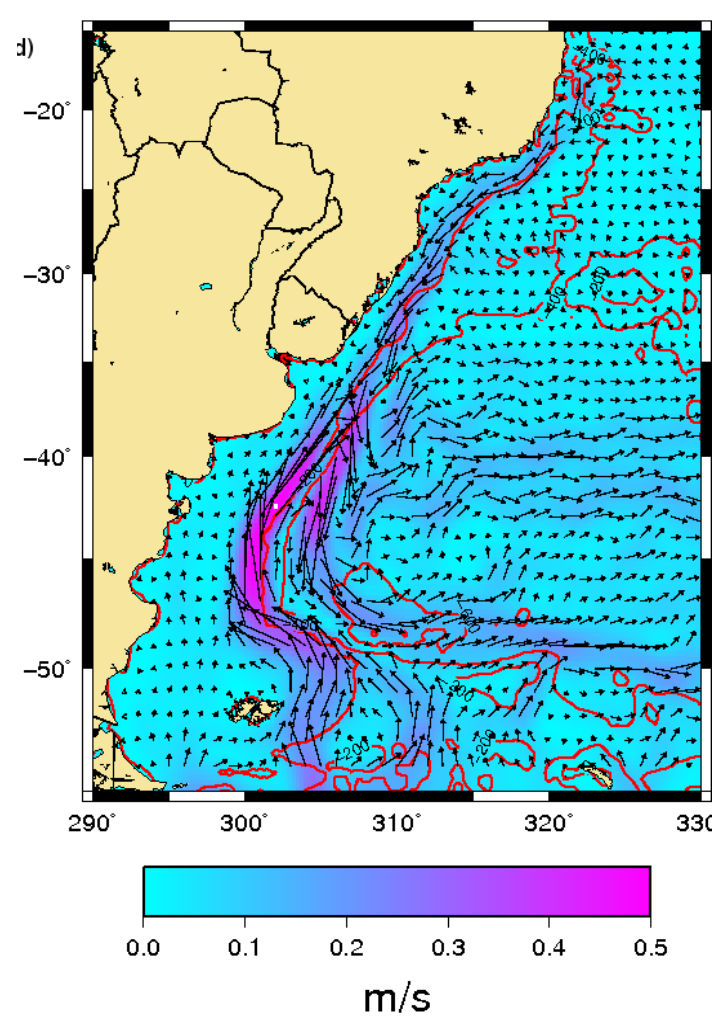

Figura 4.19: Correntes geostróficas médias na região da CBM,fornecidas pelo HYCOM

Os resultados das correntes geostróficas médias refletiram a evolução dos modelos geoidais, onde o modelo EGM2008 apresenta melhor resolução e precisão, enquanto que se tem uma significativa melhora do modelo EIGEN-5C em relação ao modelo EGM96. É importante salientar que os modelos do GRACE foram usados na determinação da TDM disponibilizada pela AVISO.

Com base nos resultados anteriores, será utilizado o modelo geoidal EGM2008 e o filtro SSA na determinação da TD e conseqüentemente das correntes absolutas, para a região da $\mathrm{CBM}$.

4.4 - Variação temporal da TD na região da CBM e comparação dos resultados de diferentes modelos.

Foram determinadas as TDs na região da CBM no período de 01/09/1992 a 12/09/2005, a partir do modelo geoidal EGM2008 e dados altimétricos, sendo filtradas 
com o filtro SSA $(M=3)$. Os mapas a seguir correspondem aos anos de 2004 e 2005, mesmo período de cobertura dos resultados disponibilizados por processamento do HYCOM.

A TD varia com as estações do ano (verão e inverno). No verão de 2004, como pode ser observado na Figura 4.20, os valores da Topografia Dinâmica Altimetria Geóide (TDA), ao norte da latitude de $40^{\circ} \mathrm{S}$, variam aproximadamente entre $50 \mathrm{~cm}$ e $100 \mathrm{~cm}$, enquanto que ao sul desta latitude os valores variam de 0 a $30 \mathrm{~cm}$, evidenciando assim uma separação geográfica de valores da TDA na latitude de $40^{\circ} \mathrm{S}$. Comparando com a Topografia Dinâmica HYCOM (TDH), verifica-se que as mesmas características foram mantidas, entretanto as feições da TDH são melhor detalhadas (Figura 4.21), fato também observado na Topografia Dinâmica dos dados Combinados MERGED (TDC) (Figura 4.22).

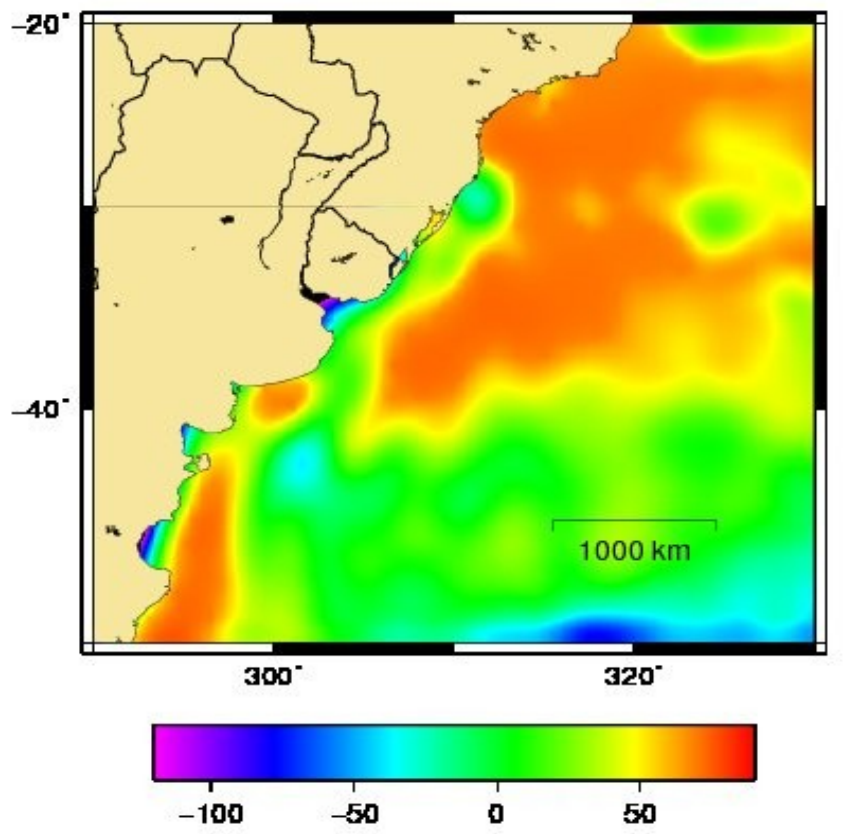

Figura 4.20: TDA (altimetria - geóide) do verão de 2004 (em cm) 


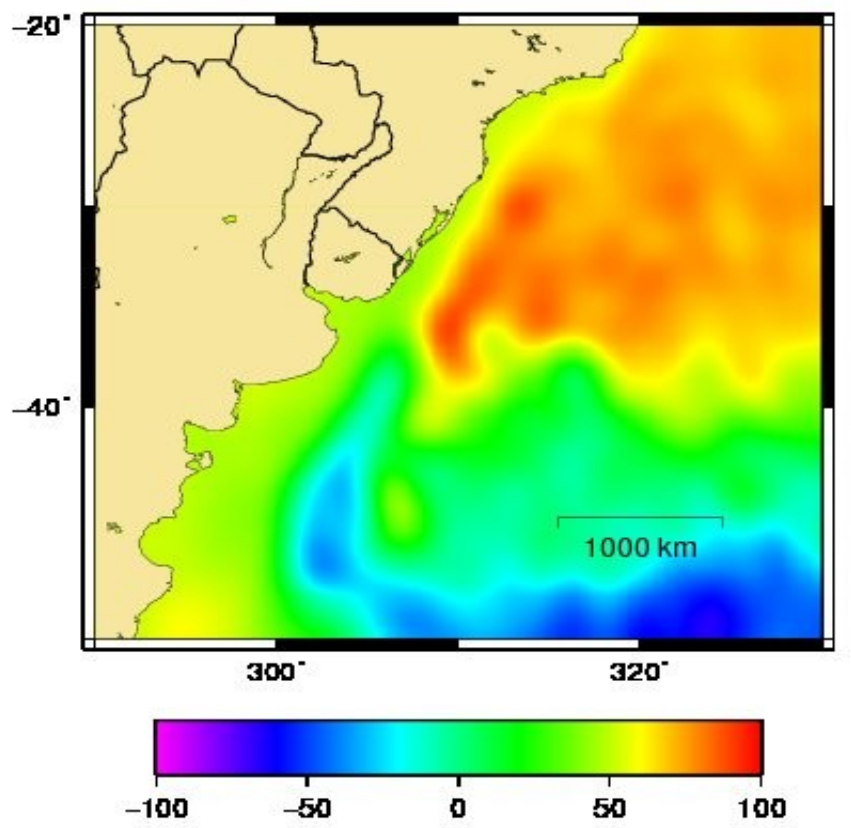

Figura 4.21: Topografia dinâmica do verão de 2004 obtida do modelo HYCOM (em $\mathrm{cm})(\mathrm{TDH})$

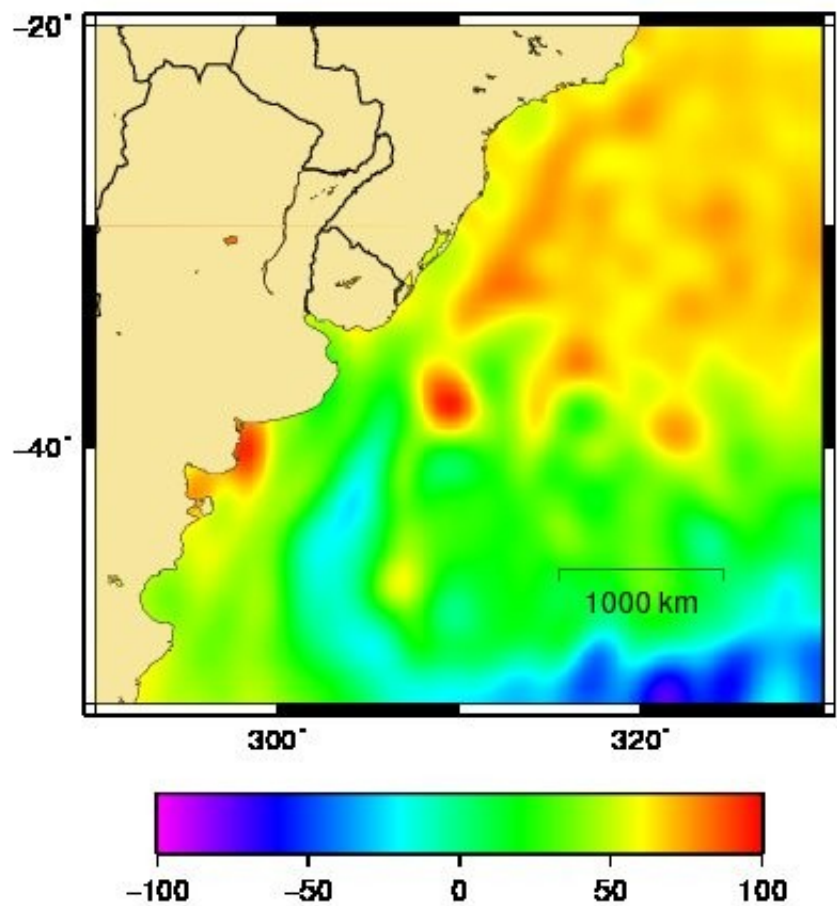

Figura 4.22: Topografia dinâmica do verão de 2004 obtida do modelo de dados combinados MERGED (em cm) (TDC) 
No inverno do mesmo ano ocorre uma redução nos valores da TDA na região da CM (Figura 4.23) e a separação não é evidente quando comparada ao verão; estas mesmas características ocorrem com a TDH (Figura 4.24); já na TDC (Figura 4.25) também observou-se uma redução nos valores, entretanto a separação observada no verão do mesmo ano ficou mais evidenciada.

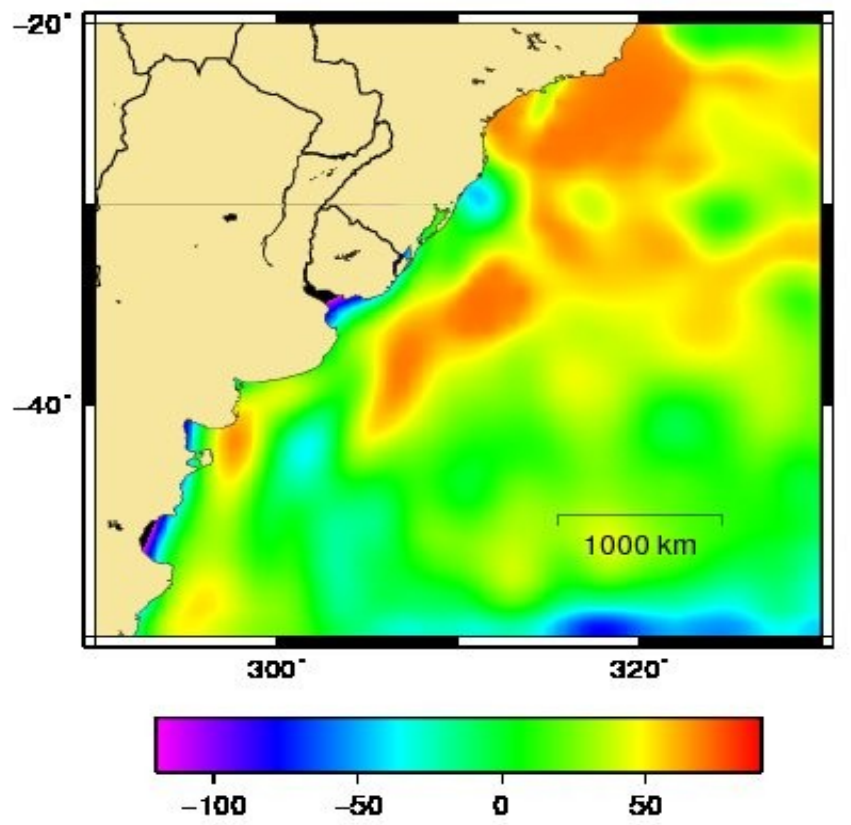

Figura 4.23: TDA do inverno de 2004 (cm) 


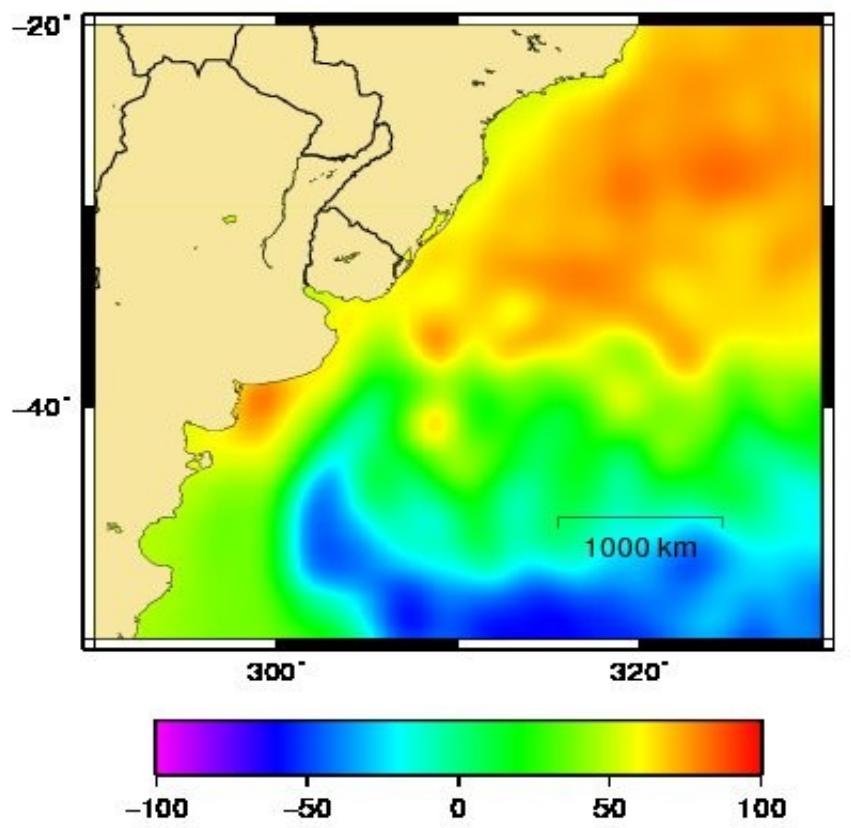

Figura 4.24: TDH no inverno de $2004(\mathrm{~cm})$

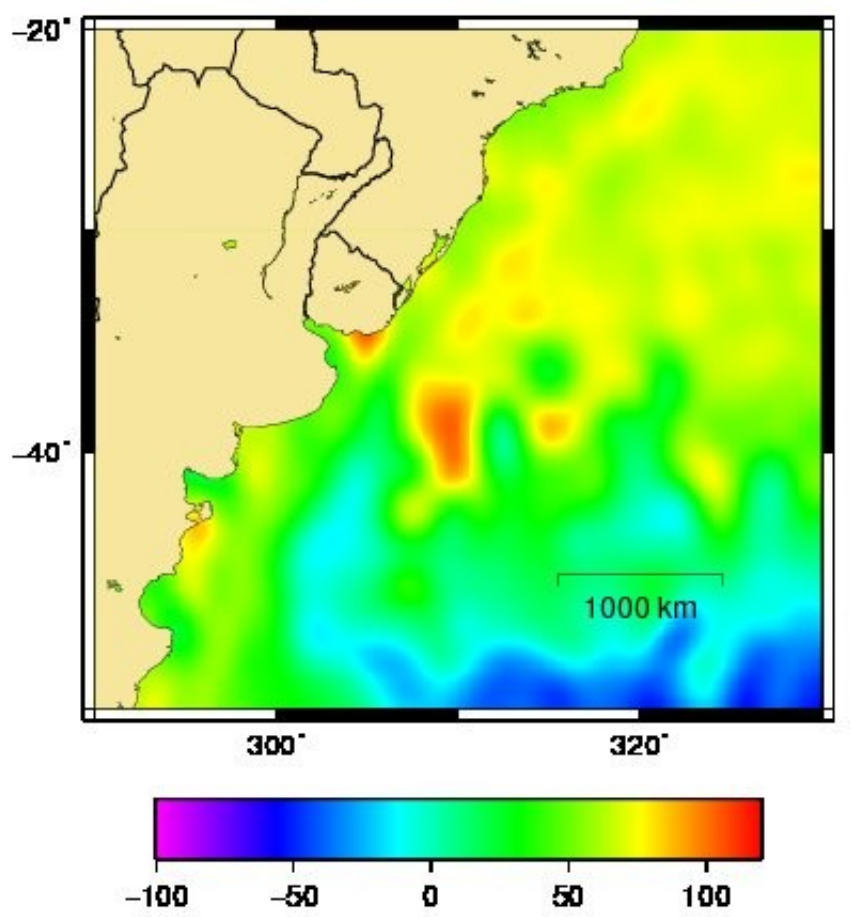

Figura 4.25: TDC no inverno de $2004(\mathrm{~cm})$

No verão de 2005 os mesmos padrões do verão de 2004 foram observados 
entre a TDH (Figura 4.27) e TDC (Figura 4.28), entretanto deve ser observado que na região da CM a TDA (Figura 4.28) apresenta feições diferentes dos outros modelos.

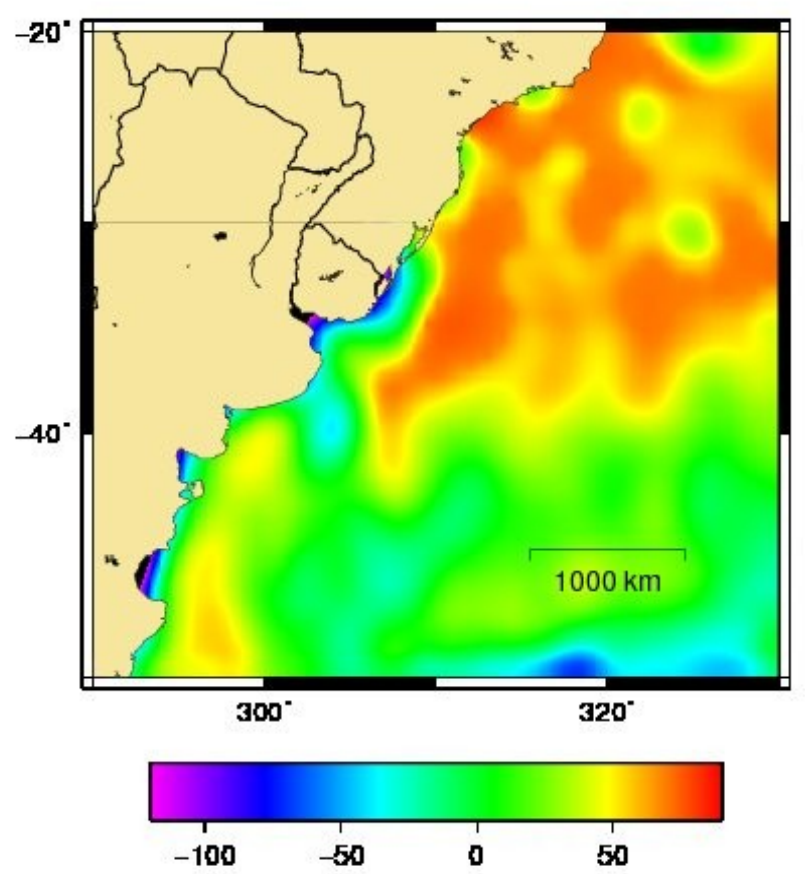

Figura 4. 26: TDA do verão de 2005 (cm)

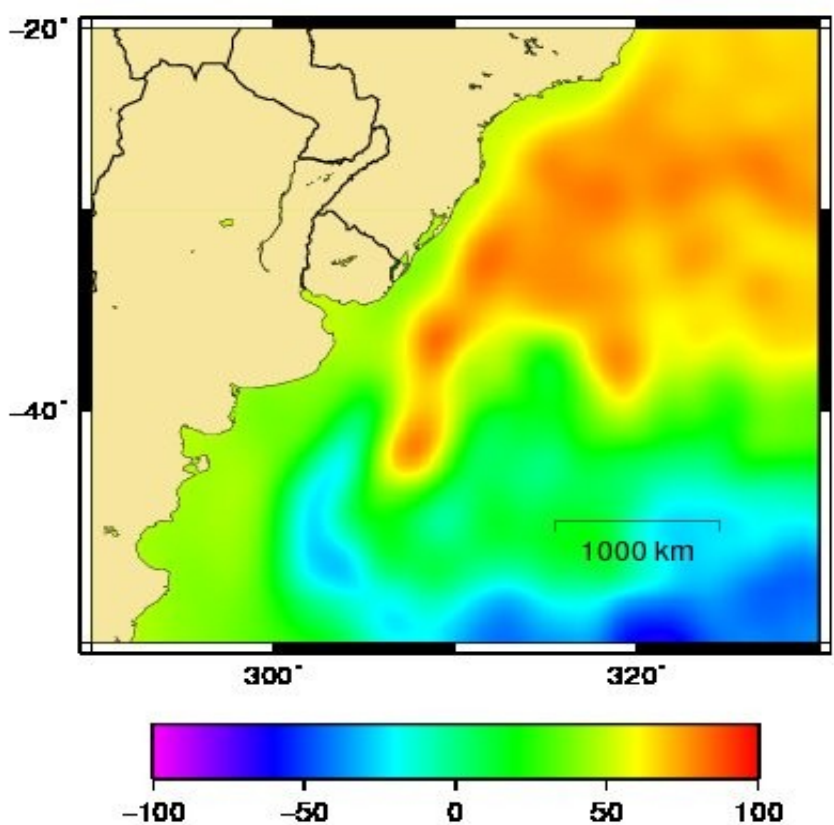

Figura4. 27: TDH, no verão de 2005 (cm) 


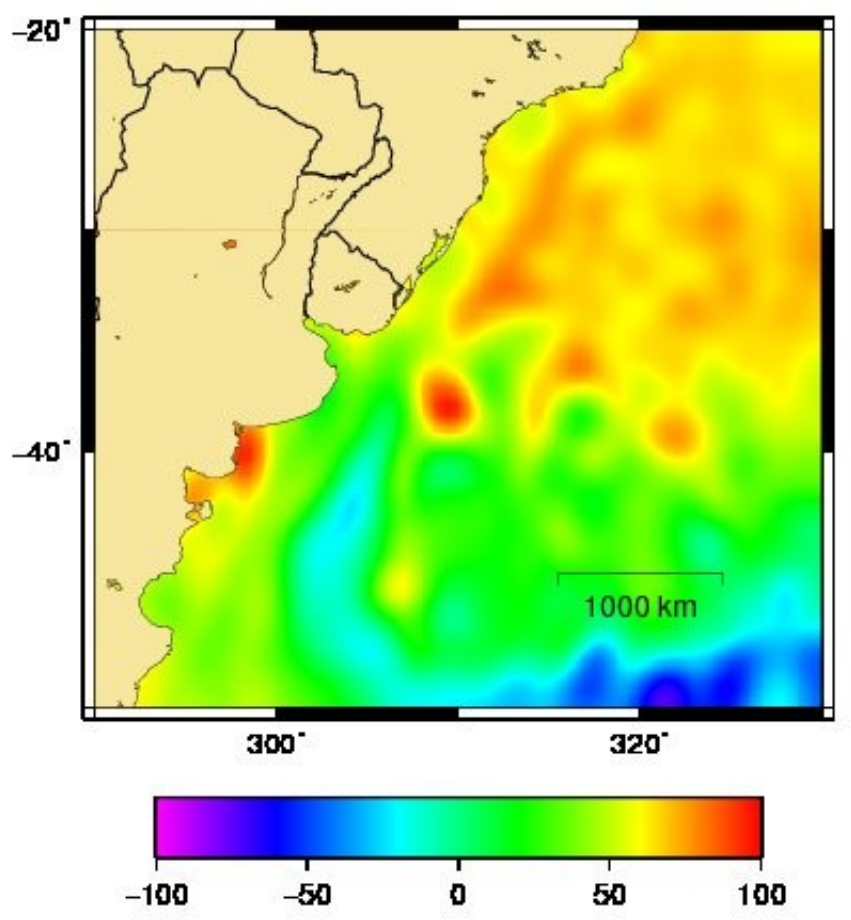

Figura4. 28: TDC (cm) no verão de 2005.

Comparando com o inverno de 2004, no inverno de 2005, observam-se as mesmas características, ou seja, redução nos valores das TDs (Figuras 4.29, 4.30 e 4.31). Assim como acontece nos casos anteriores, a TD determinada pelo método direto apresenta feições diferentes na região da CM. 


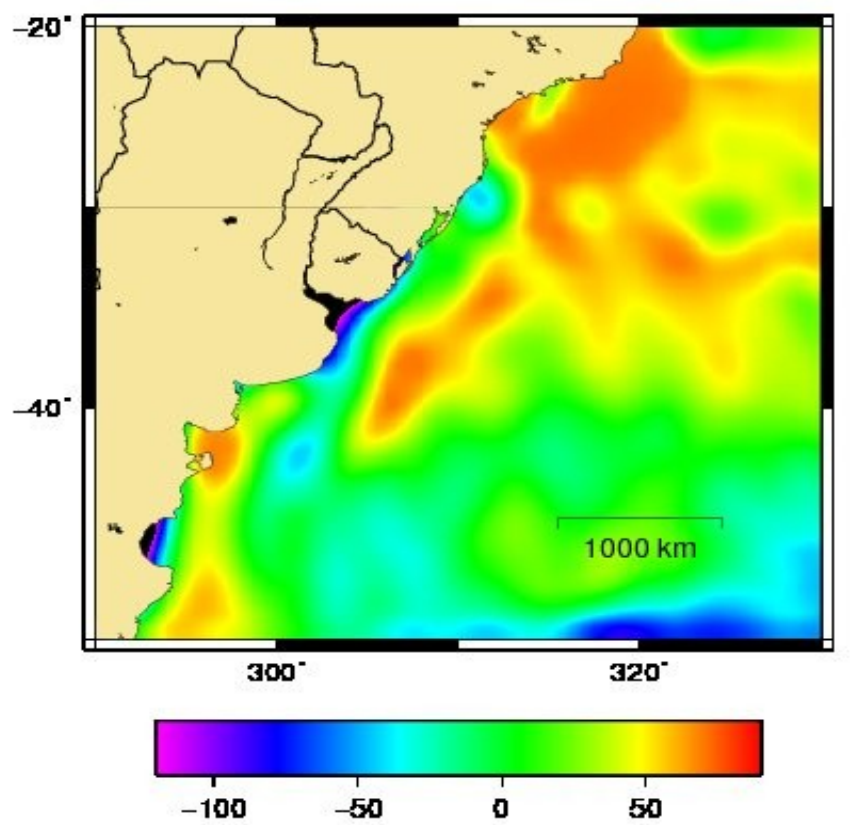

Figura4. 29: TDA no inverno de 2005 (cm).

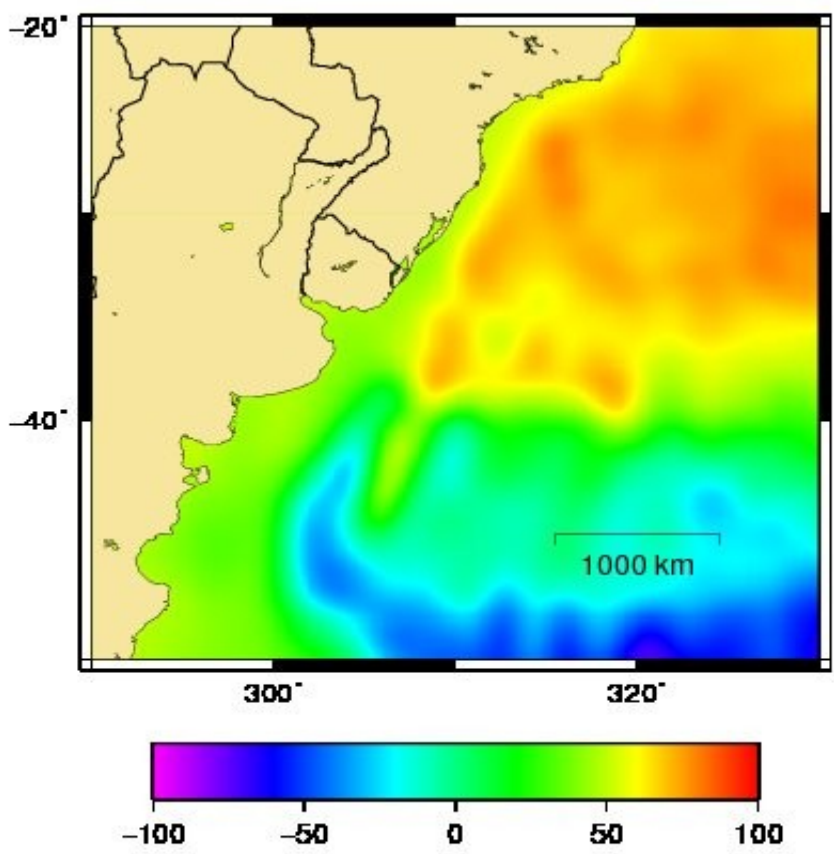

Figura4. 30: TDH no inverno de 2005 (cm) 


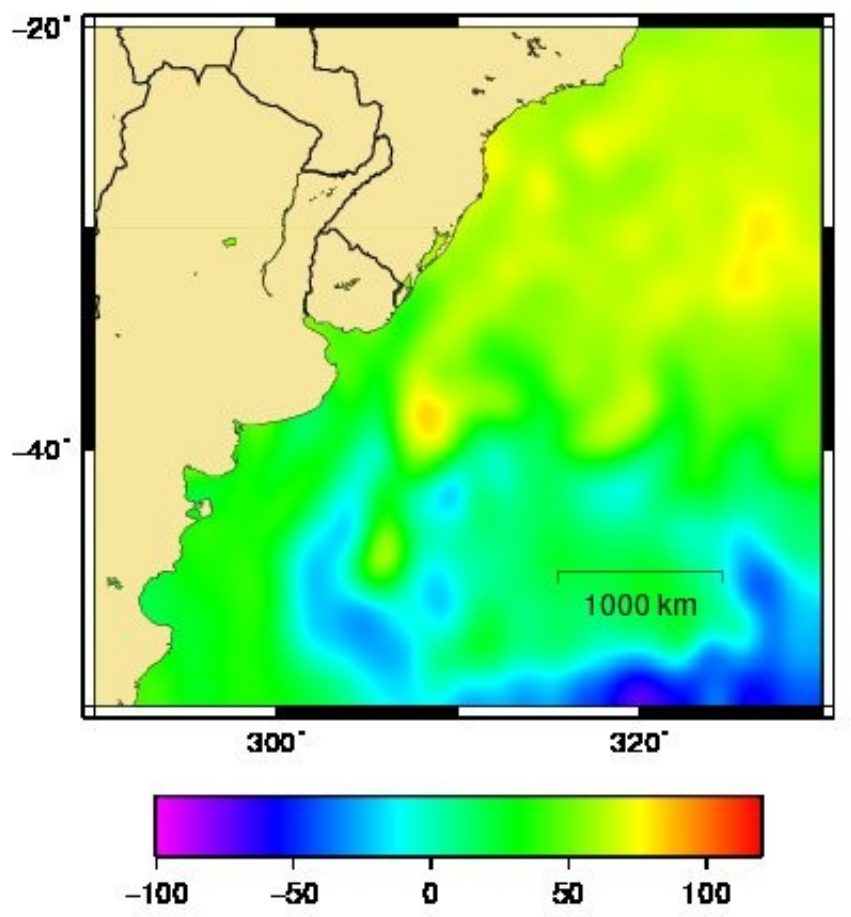

Figura4. 31: TDC no inverno de $2005(\mathrm{~cm})$

Considerando todo o período de 01/09/1992 a 12/09/2005, as feições aqui apresentadas foram mantidas, com poucas variações nas TDs. Apesar das principais feições serem observadas na TDA, fica evidente o maior detalhamento da TDH e TDC, e isto se deve à resolução do $\operatorname{HYCOM}\left(1 / 12^{\circ}\right)$, enquanto que os dados de altimetria apresentam resolução espacial de aproximadamente $1^{\circ} \times 1^{\circ}$, sendo interpolados em grade de $0.5^{\circ} \times 0.5^{\circ}$. Já os dados combinados possuem resolução intermediária, e portanto a respectiva TD é similar à do modelo numérico hidrodinâmico.

A anomalia do nível do mar apresenta feições diferentes, sem a presença dos gradientes observados na TD. A Figura 4.32 mostra exemplo de anomalia do nível médio do mar para o ciclo 16 do TOPEX/Poseidon. 


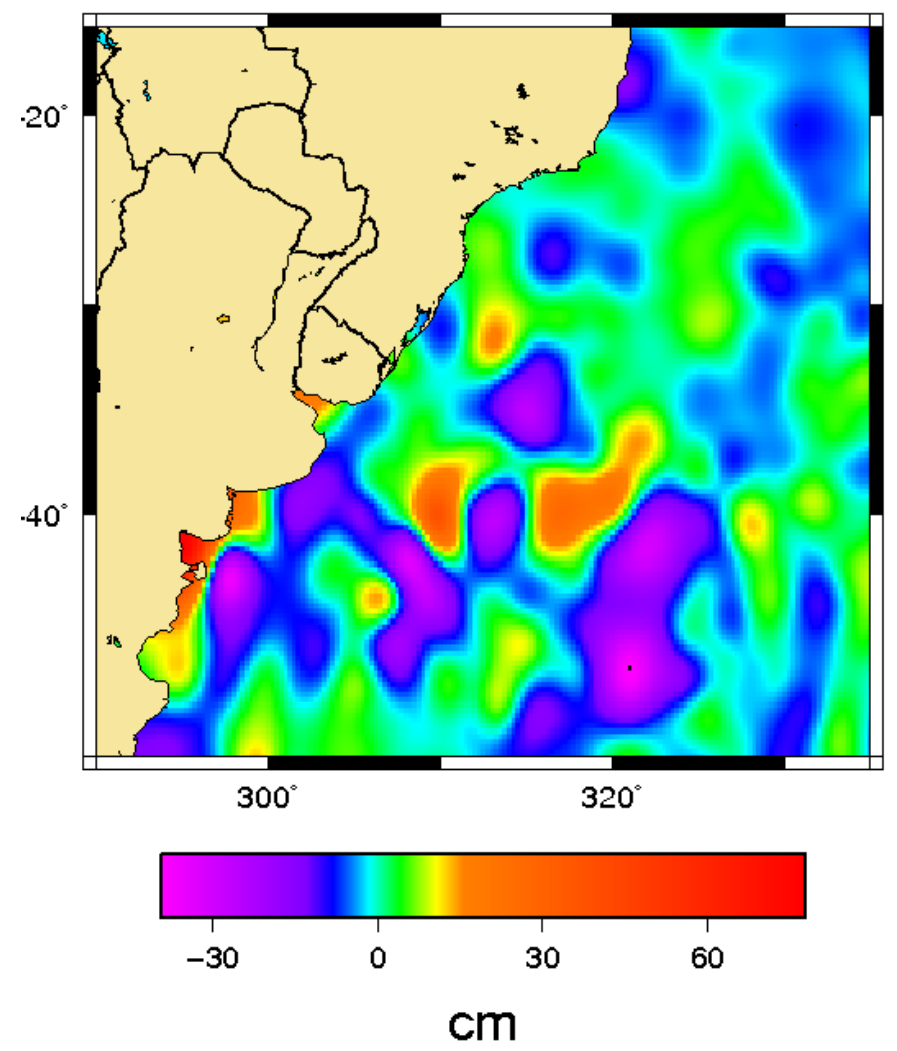

Figura 4. 32: Anomalia do nível do mar em janeiro de 1993

Comparando a TD com a Temperatura da Superfície o Mar (TSM) obtida a partir de dados do modelo numérico Estimating the Circulation and Climate of the Ocean (ECCO) (Stammer et al. 2002), disponibilizados na internet através do site http://www.ecco-group.org/las/v6/dataset/constrain?var=146,

verifica-se uma similaridade da separação nas proximidades da latitude de $40^{\circ} \mathrm{S}$, onde a norte desta latitude as águas possuem temperatura mais elevadas em relação ao Sul (Figuras 4.33 e 4.34). 


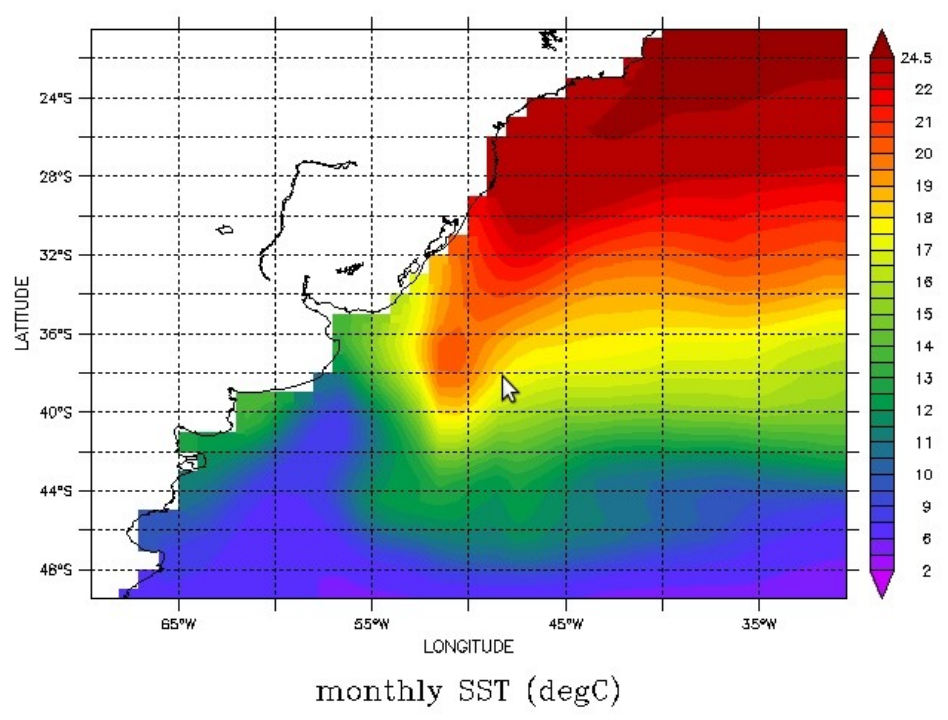

Figura 4.33: Temperatura da superfície do mar calculada pelo modelo ECCO em janeiro de 2004.

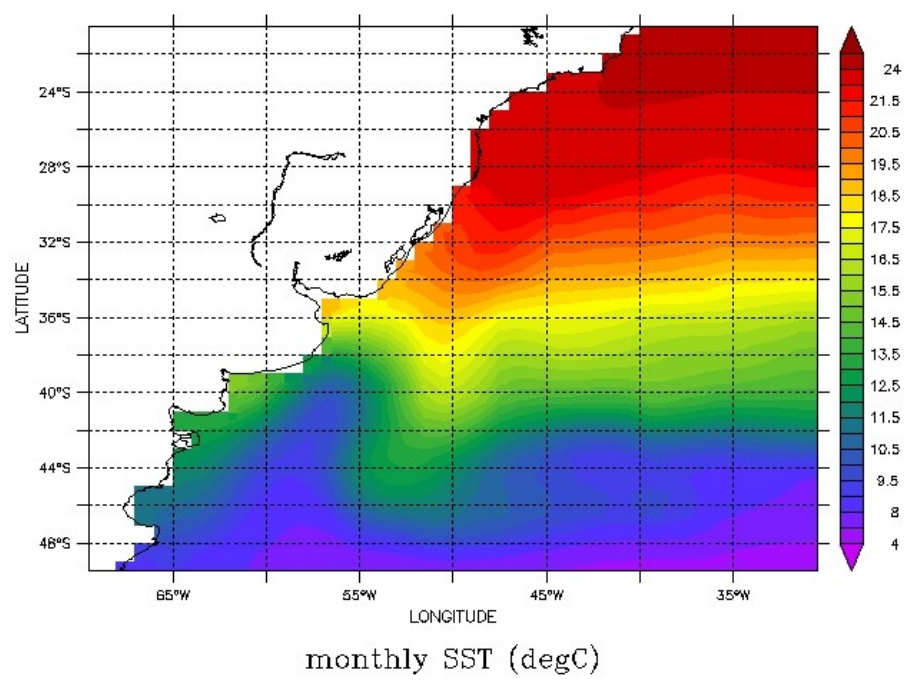

Figura 4.34: Temperatura da superfície do mar calculada pelo modelo ECCO em julho de 2004.

Nos mapas de TD ficou claro que na região compreendia entre $37^{\circ} \mathrm{S}$ e $40^{\circ} \mathrm{S}$, aproximadamente, é caracterizada pela presença de de um forte gradiente da topografia dinâmica. Desta forma foram escolhidos pontos localizados na latitude de $37^{\circ} \mathrm{S}, 39^{\circ} \mathrm{S}$ e $41^{\circ} \mathrm{S}$ e longitudes $54^{\circ} \mathrm{W}, 52^{\circ} \mathrm{W}$ e $50^{\circ} \mathrm{W}$ para análise da TDA, TDH e TDC. As figuras a 
seguir mostram os valores e o espectro da TD nestes pontos.
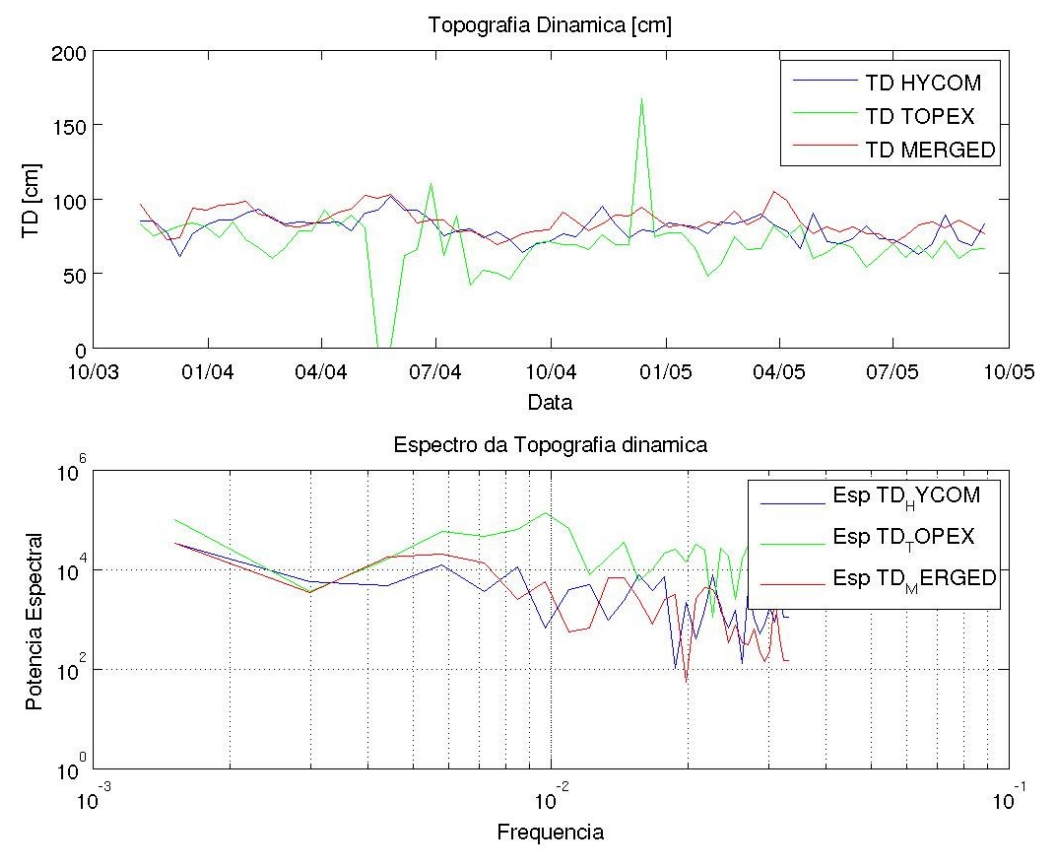

Figura 4.35: Comparação entre TDA, TDH e TDC em $54^{\circ} \mathrm{W}$ e $37^{\circ} \mathrm{S}$ (superior) e seus espectros (inferior)
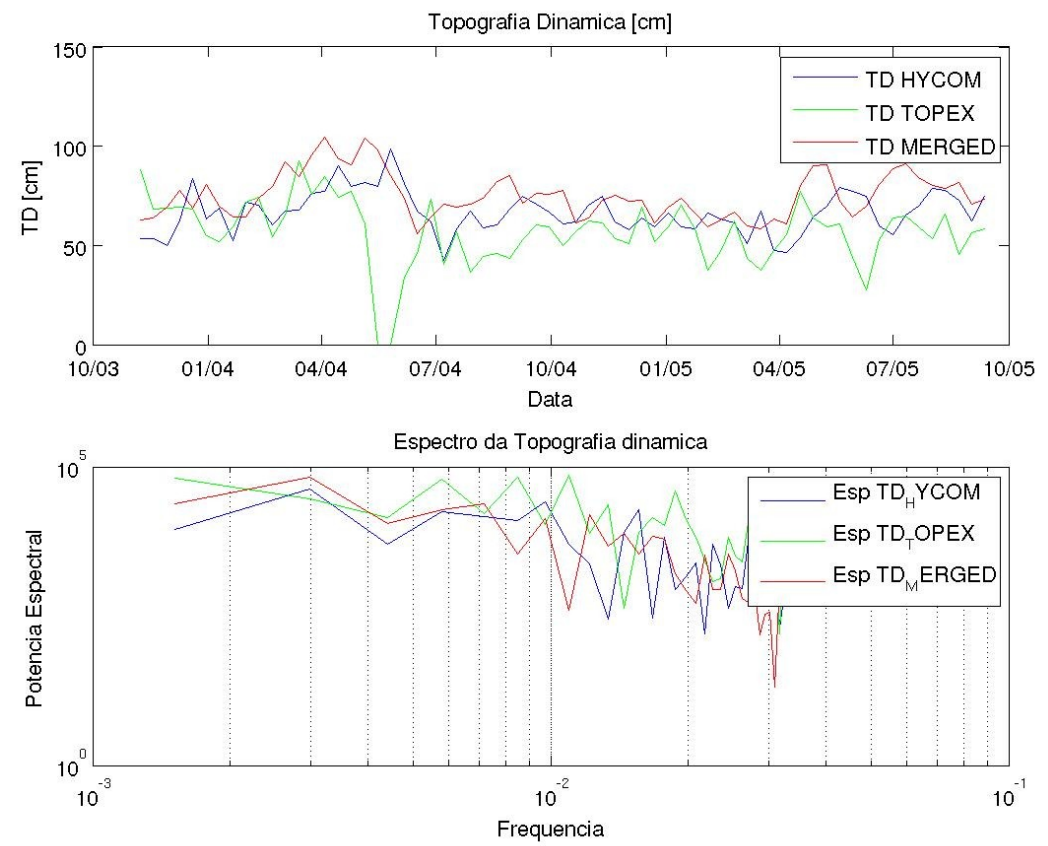

Figura 4.36: Comparação entre TDA, TDH e TDC em $52^{\circ} \mathrm{W}$ e $37^{\circ} \mathrm{S}$ (superior) e seus espectros (inferior) 

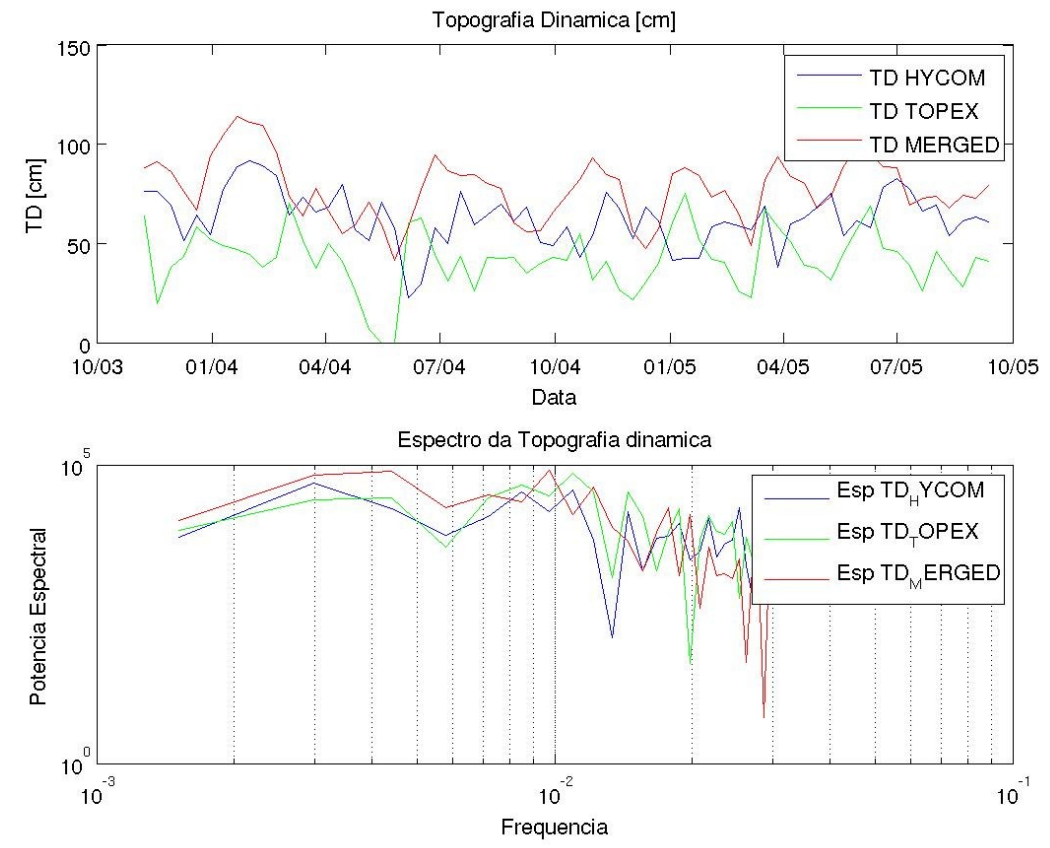

Figura 4. 37: Comparação entre TDA, TDH e TDC em $50^{\circ} \mathrm{W}$ e $37^{\circ} \mathrm{S}$ (superior) e seus espectros (inferior)
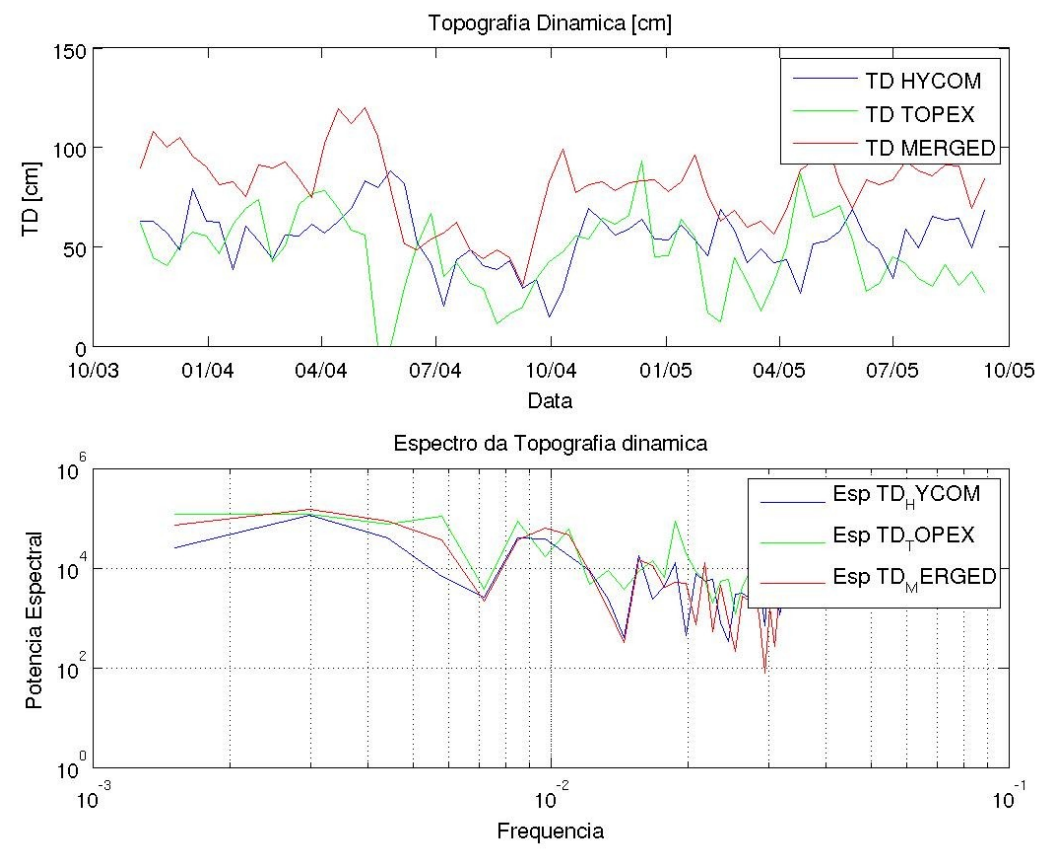

Figura 4. 38: Comparação entre TDA, TDH e TDC em $54^{\circ} \mathrm{W}$ e $39^{\circ} \mathrm{S}$ (superior) e seus espectros (inferior) 

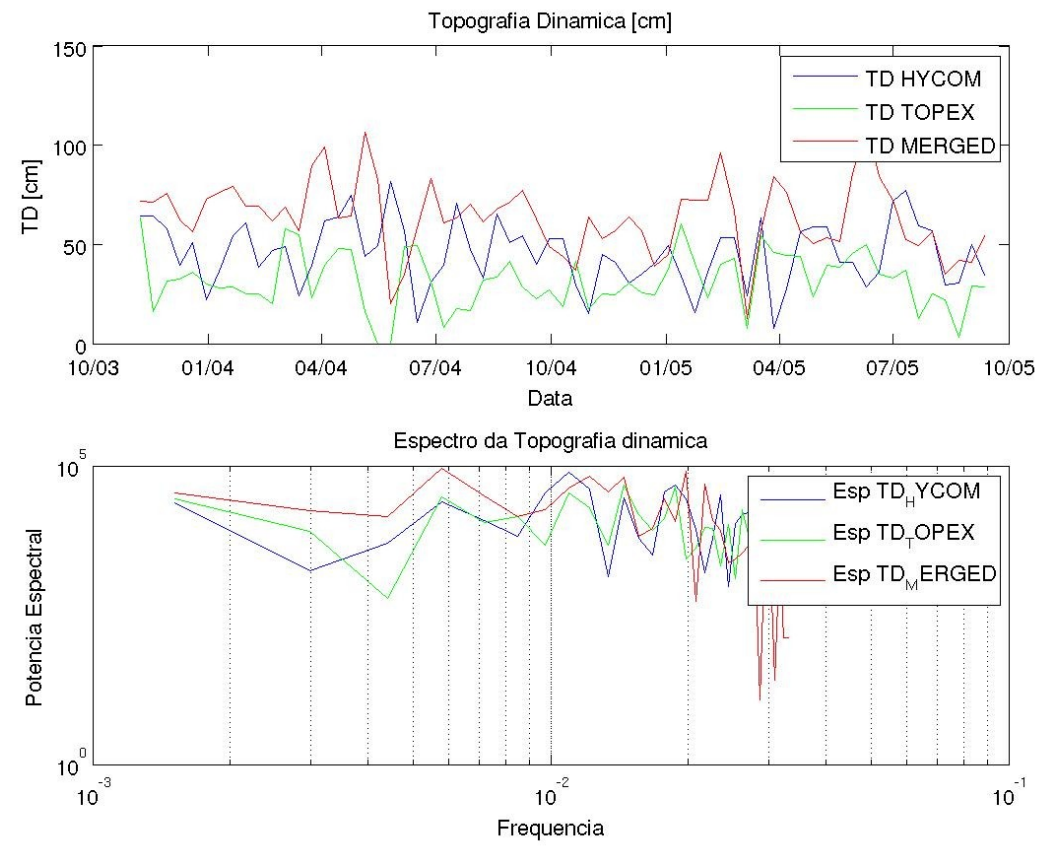

Figura 4.39: Comparação entre TDA, TDH e TDC em $52^{\circ} \mathrm{W}$ e $39^{\circ} \mathrm{S}$ (superior) e seus espectros (inferior)
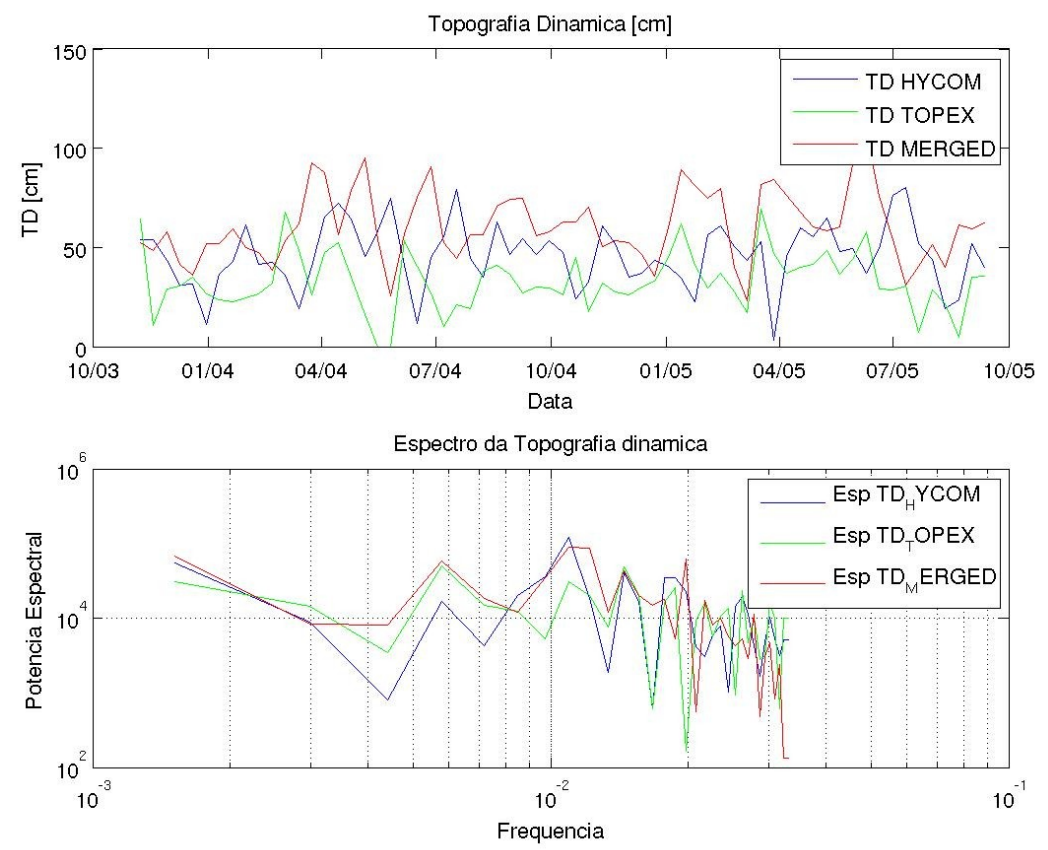

Figura 4.40: Comparação entre TDA, TDH e TDC em $50^{\circ} \mathrm{W}$ e $39^{\circ} \mathrm{S}$ (superior) e seus espectros (inferior) 

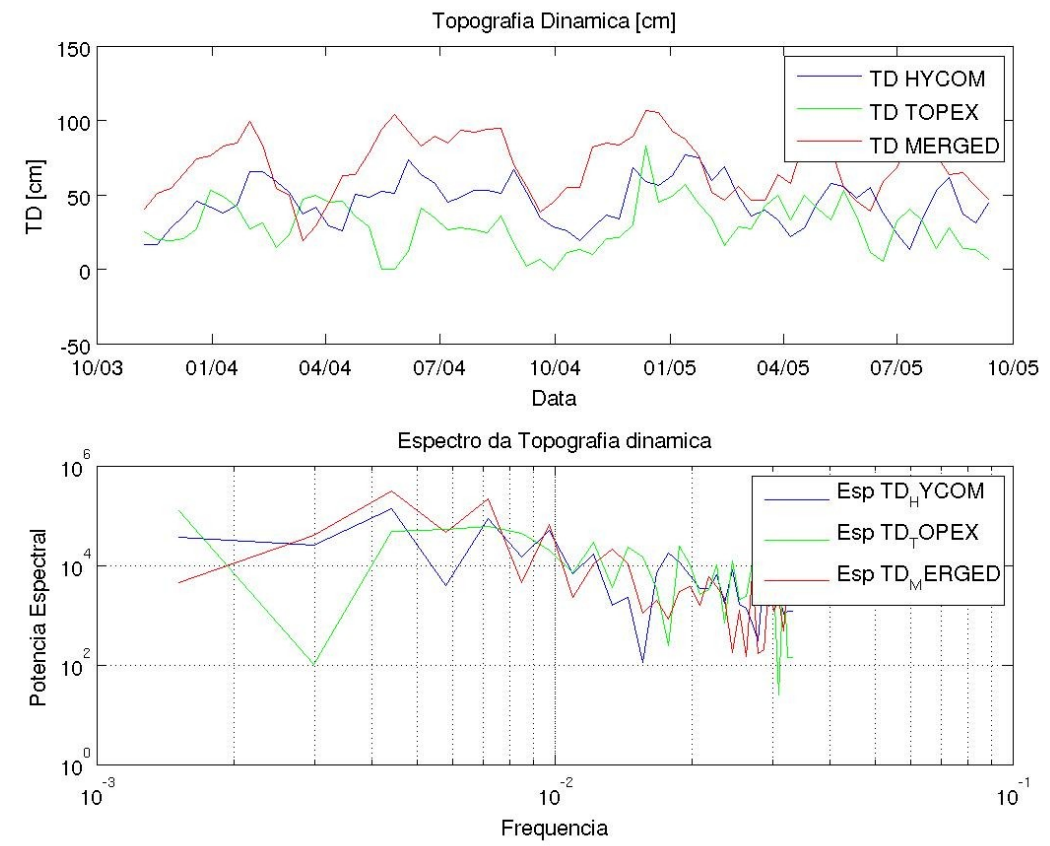

Figura 4. 41: Comparação entre TDA, TDH e TDC em $54^{\circ} \mathrm{W}$ e $41^{\circ} \mathrm{S}$ (superior) e seus espectros (inferior)
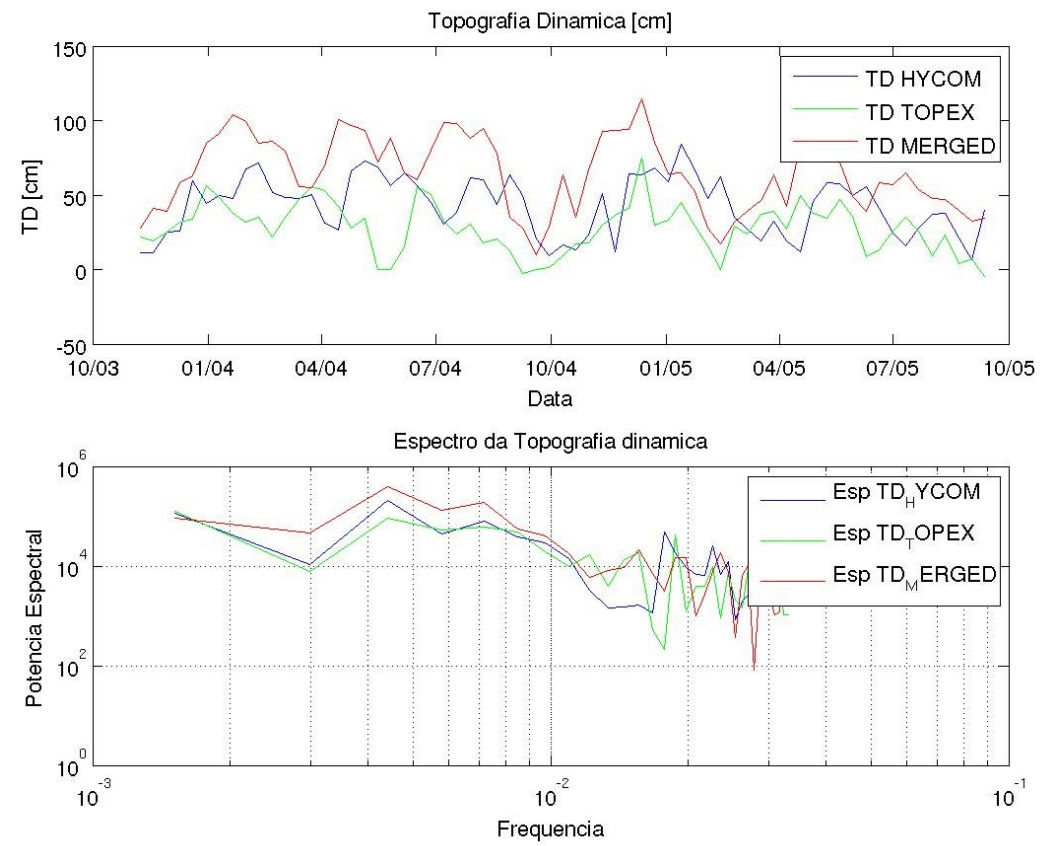

Figura 4.42: Comparação entre TDA, TDH e TDC em $52^{\circ} \mathrm{W}$ e $41^{\circ} \mathrm{S}$ (superior) e seus espectros (inferior) 

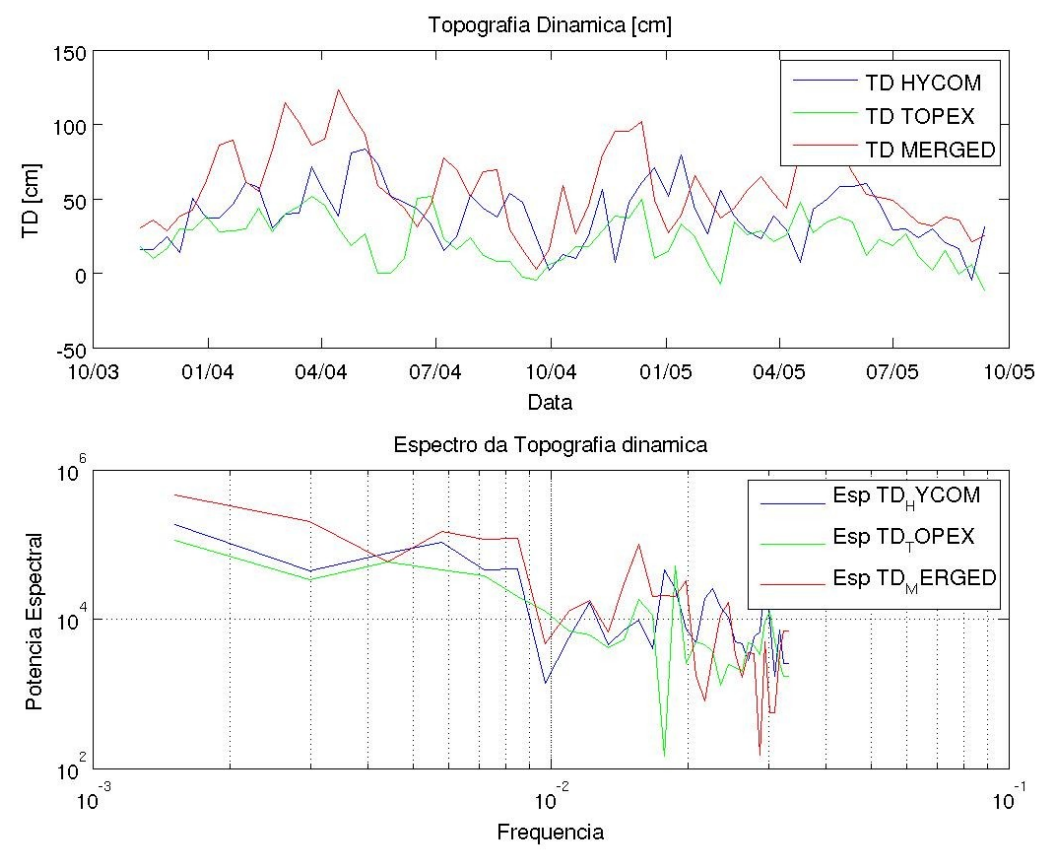

Figura 4.43: Comparação entre TDA, TDH e TDC em $50^{\circ} \mathrm{W}$ e $41^{\circ} \mathrm{S}$ (superior) e seus espectros (inferior)

Os valores da TD nos pontos estudados são próximos, e no geral os espectros são similares, como é o caso dos pontos $52^{\circ} \mathrm{W}-37^{\circ} \mathrm{S}$ (Figura 4.36), $50^{\circ} \mathrm{W}-37^{\circ} \mathrm{S}$ (Figura 4.37), $54^{\circ} \mathrm{W}-39^{\circ} \mathrm{S}$ (Figura 4.38), $50^{\circ} \mathrm{W}-39^{\circ} \mathrm{S}$ (Figura 4.40) e $52^{\circ} \mathrm{W}-41^{\circ} \mathrm{S}$ (Figura 4.42), com maior potência espectral no período compreendido entre 100 e 200 dias. A Tabela abaixo mostra os valores médios (e respectivos desvios padrão) considerando as latitudes de $37^{\circ} \mathrm{S}, 39^{\circ} \mathrm{S}$ e $41^{\circ} \mathrm{S}$, na longitude de $50^{\circ} \mathrm{W}$.

Tabela 4.2 - Valores médios da TD (e respectivos desvios padrão STD) para latitudes de $37^{\circ} \mathrm{S}, 39^{\circ} \mathrm{S}, 41^{\circ} \mathrm{S}$ na latitude de $50^{\circ} \mathrm{W}$.

\begin{tabular}{|c|c|c|c|c|c|c|}
\hline Latitude & \multicolumn{2}{|c|}{$37^{\circ} \mathrm{S}$} & \multicolumn{2}{c|}{$39^{\circ} \mathrm{S}$} & \multicolumn{2}{c|}{$41^{\circ} \mathrm{S}$} \\
\hline & $\mathrm{TD}(\mathrm{cm})$ & $\mathrm{STD}(\mathrm{cm})$ & $\mathrm{TD}(\mathrm{cm})$ & $\mathrm{STD}(\mathrm{cm})$ & $\mathrm{TD}(\mathrm{cm})$ & $\mathrm{STD}(\mathrm{cm})$ \\
\hline TDA $(\mathrm{cm})$ & 65.4 & 16 & 49.3 & 19 & 44.2 & 15 \\
\hline TDH $(\mathrm{cm})$ & 73.5 & 18 & 55.6 & 22 & 46.1 & 17 \\
\hline TDC $(\mathrm{cm})$ & 78.6 & 25 & 64.7 & 23 & 54.3 & 26 \\
\hline
\end{tabular}


Conforme mostra a Tabela 4.2 , em $4^{\circ}$ de latitude $\left(37^{\circ}-41^{\circ}\right)$, os valores de TD diminuem consideravelmente, chegando as reduções a $21.1 \mathrm{~cm}, 27.4 \mathrm{~cm}$ e $24.3 \mathrm{~cm}$ na TDA, TDH e TDC, respectivamente, confirmando os dados mostrados nos mapas anteriores.

\section{5 - Correlação temporal entre as TDs na região da CBM.}

A correlação temporal foi determinada para o período de $01 / 12 / 03$ a 12/09/05; todas as TDs foram filtradas utilizando o filtro SSA com $\mathrm{M}=3$. Como pode ser observado na Figura 4.44, a correlação entre a TD obtida com o modelo geoidal EGM2008 e altimetria (TDA) e a TD fornecida pelo modelo HYCOM (TDH) é fraca $(\sim 0.2)$ a moderada $(\sim 0.6)$ em alguns pontos com significância variando de 0.1 a 0.25 (estes valores indicam alto índice de incerteza); a baixa correlação é explicada pela diferença de resolução entre os dois modelos e o maior nível de detalhamento das feições de pequena escala proporcionado pelo modelo numérico HYCOM e por se tratar de processos ruidosos.
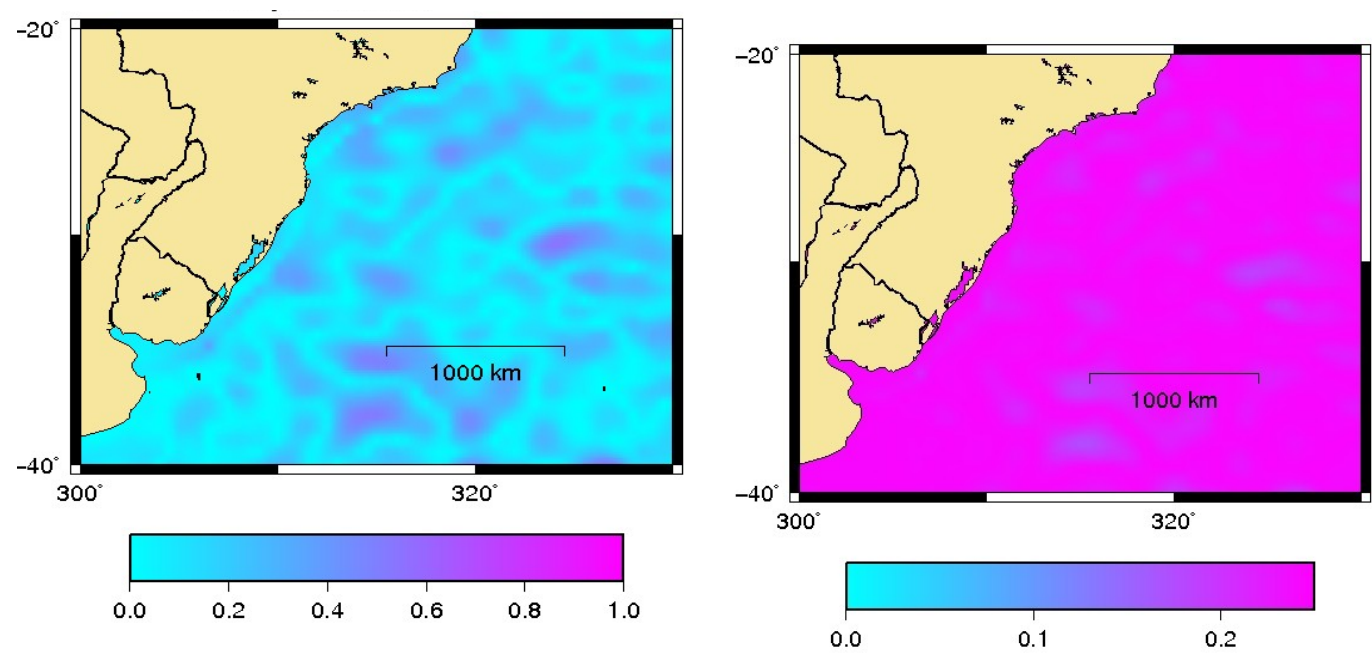

Figura4. 44: Correlação temporal e significância entre a TDH e TDA na região da CBM.

A Correlação entre a TD fornecida pela AVISO (TDC) e a TD do modelo HYCOM (TDH) (Figura 4.45) é maior do que a correlação TDH - TDA, chegando a ultrapassar 0.7 em alguns pontos; conforme foi relatado anteriormente, a resolução 
espacial explica a diferença entre as duas correlações, o modelo HYCOM fornece dados com resolução de $1 / 12^{\circ}$ e os dados combinados da AVISO são fornecidos com resolução de $1 / 3^{\circ}$, ou seja, a diferença de resolução entre estas TDs é menor que a diferença das resoluções entre as TDs do HYCOM e da altimetria pelo método direto, TDH e TDA.
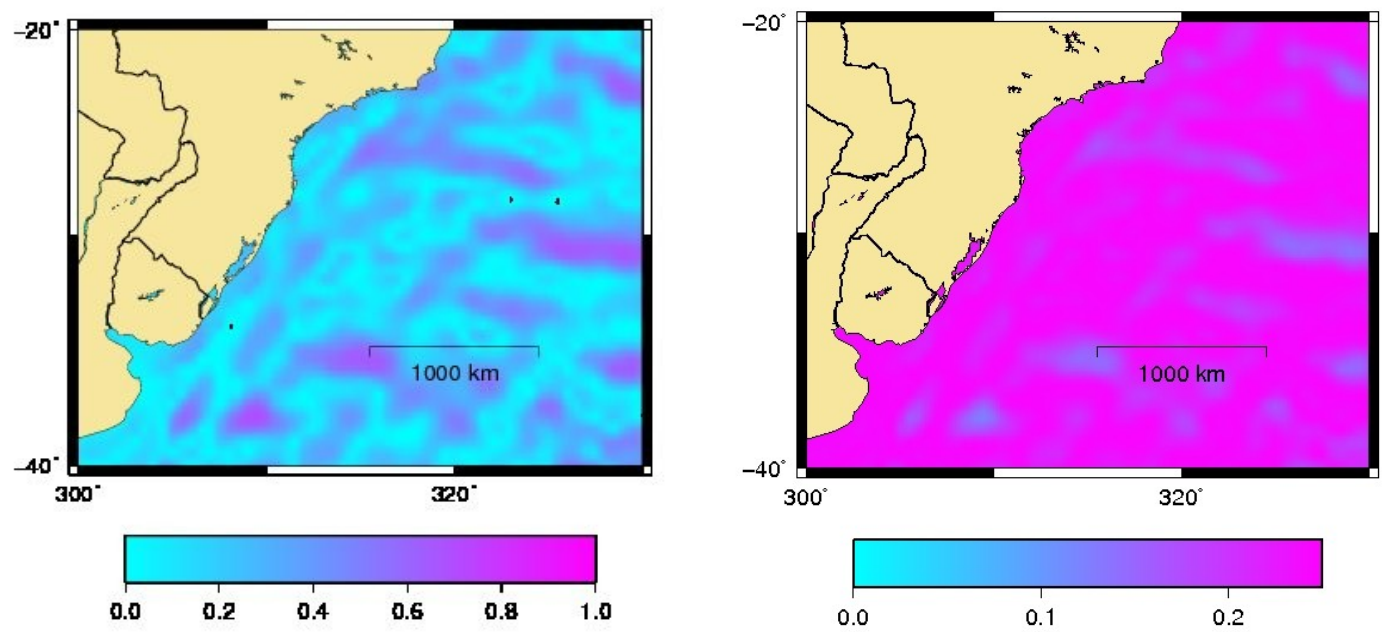

Figura 4.45: Correlação temporal e significância entre a TDH e TDC na região da CBM.

\section{6 - Corrente geostróficas na região da CBM e sua comparação com os produtos do modelo numérico HYCOM.}

A circulação de larga escala é caracterizada pela presença de um sistema de giros, resultante da ação da tensão de cisalhamento do vento sobre a superfície. As correntes localizadas nas bordas oeste dos oceanos, também conhecidas como Correntes de Contorno Oeste, são mais intensas, quando comparadas às correntes de contorno leste, como é o caso da $\mathrm{CB}$; esta corrente de limite oeste encontra a $\mathrm{CM}$, que é formada por águas frias a partir da Corrente Circumpolar Antártica e flui para o norte ao longo da costa da Argentina, separando-se da costa, em latitude que varia entre $37^{\circ} \mathrm{S}$ e $41^{\circ} \mathrm{S}$, na região da CBM. Como foi observado nos mapas de temperatura da superfície do mar (Figuras 4.33 e 4.34), existe uma frente térmica com altos gradientes térmicos na região de separação da CB na costa, esta região representando assim uma fronteira de águas mais quentes e salinas do giro subtropical e águas mais frias e menos salinas do giro sub polar. Nestas regiões podem ocorrer instabilidades e, conseqüentemente, geração de 
meandros e vórtices. Considerando a utilização de dados altimétricos, é possível estudar estes vórtices com a utilização da anomalia de altitude (Lentini et al. 2006). No entanto, a análise desses fenômenos requer a utilização de vários satélites e interpolações específicas, no espaço e no tempo, de modo a detectar essas feições e separá-las de outras similares, como as ondas de Rossby, por exemplo.

As correntes geostróficas aqui mostradas foram calculadas com a TD utilizando o modelo geoidal EGM08, como definido anteriormente.

A Figura 4.46 mostra a circulação geostrófica calculada com a anomalia do nível médio do mar, onde se nota que estes dados não permitem identificar as correntes de contorno e outras correntes, como a CM e CAS.

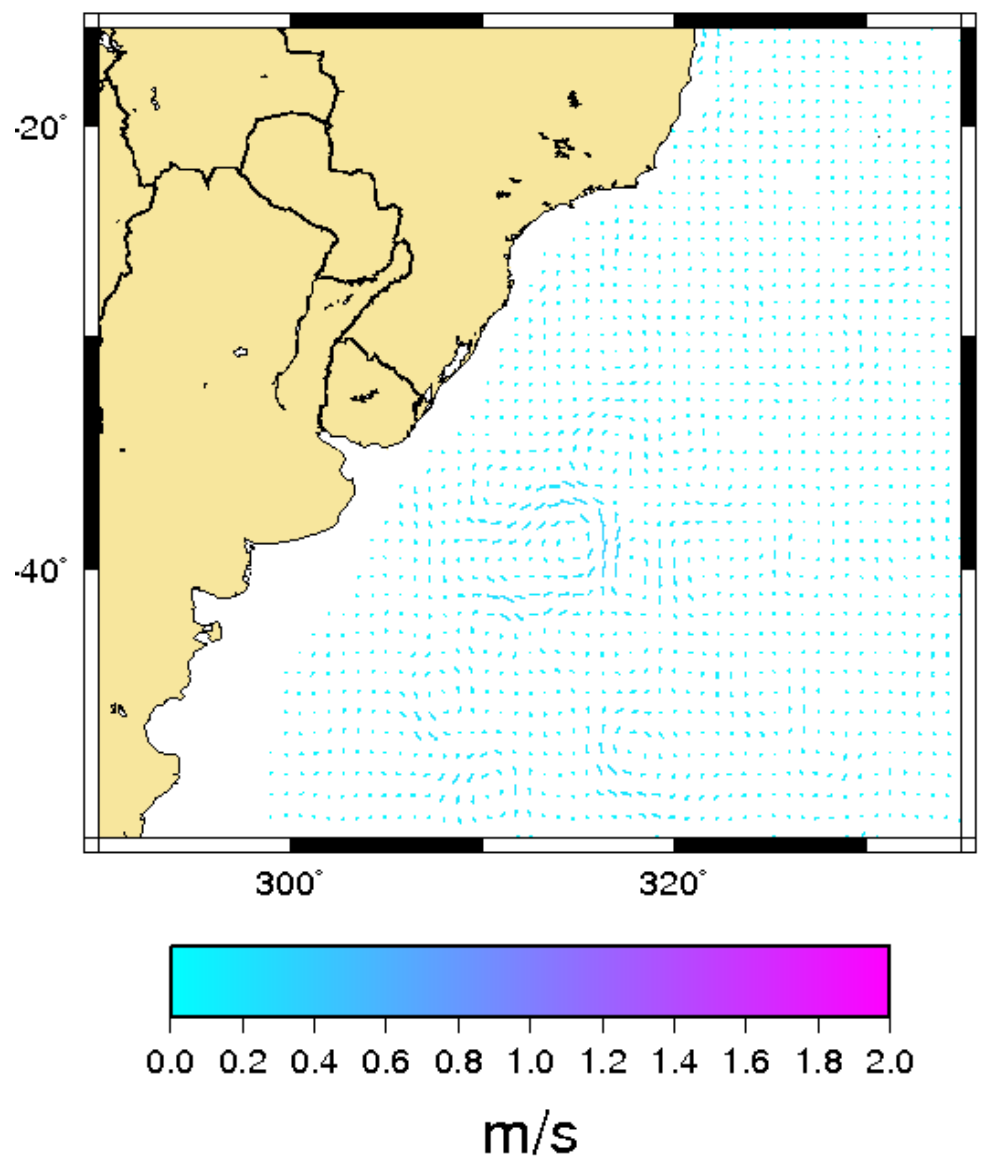

Figura4. 46: Circulação determinada com a anomalia do nível médio do mar em janeiro de 2004.

As correntes geostróficas determinadas com os dados de altimetria e modelos 
geoidais (CGA) abrangem o período de 1992 a 2005, porém aqui serão mostradas as de verão e inverno de 2004 e 2005, período em que foi possível comparar os resultados com as Correntes Geostróficas do HYCOM (CGH).

A Figura 4.47 mostra a Corrente Geostrófica determinada com a TDA (CGA) no verão de 2004 e as Figuras 4.48 e 4.49 mostram a Corrente Geostrófica do modelo HYCOM (CGH) e a Corrente Geostrófica disponibilizada pela AVISO (CGC), respectivamente. Em todos os casos foi utilizado o filtro SSA, com M=3.

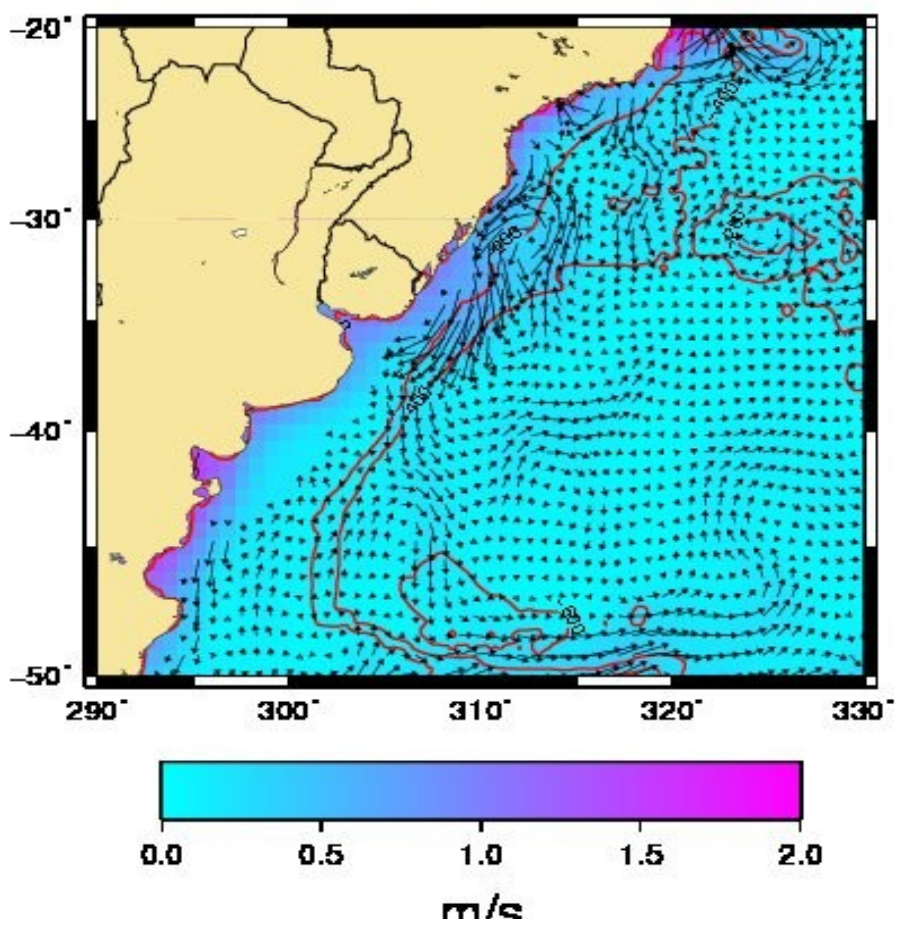

Figura 4. 47: Correntes geostróficas determinadas com dados altimétricos e o modelo geoidal EGM08 (CGA) no verão de 2004 


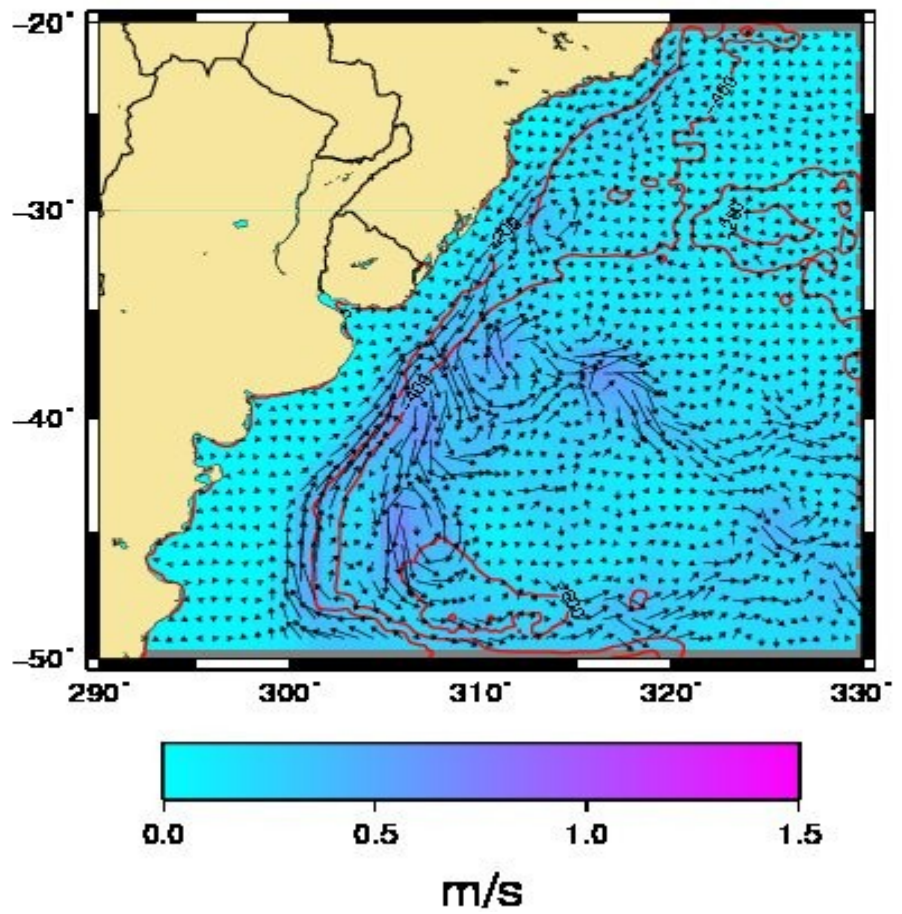

Figura 4.48: Correntes geostróficas determinadas com dados do modelo numérico HYCOM (CGH) no verão de 2004

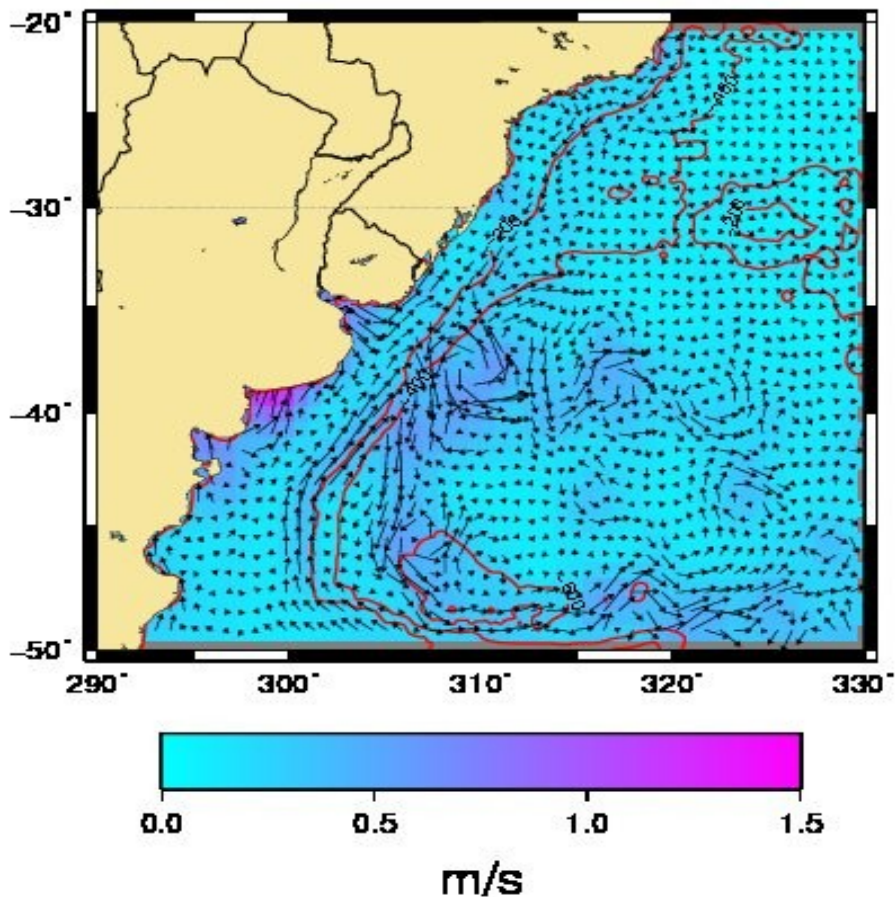

Figura4. 49: Correntes geostróficas determinada com dados combinados (CGC) no verão de 2004 
No texto, as correntes determinadas com os modelos acima apresentados são descritas com os nomes conhecidos na literatura (CB, CB e CAS), entretanto, em todos os casos trata-se das componentes geostróficas barotrópicas das mesmas.

Considerando a CGA no verão de 2004 (Figura 4.47), tomando como referência as isóbata de $-200 \mathrm{~m}$, na região da Convergência Subtropical $\left(33^{\circ} \mathrm{S}\right.$ a $\left.40^{\circ} \mathrm{S}\right)$ a $\mathrm{CB}$ foi identificada com muitos ruídos e, nas proximidades de $42^{\circ} \mathrm{S}$, ela se afasta da costa, fluindo para leste, como parte da circulação intermediária associada ao giro subtropical. A CM foi bem caracterizada, entretanto com melhor detalhamento nos mapas CGH e CGC (Figuras 4.47 e 4.48). O uso da altimetria em regiões mais próximas da costa é impreciso, prejudicando assim a determinação das correntes em algumas regiões; por outro lado, a Corrente Circumpolar Antártica (CCA) foi identificada (a $50^{\circ}$ S) em todos os modelos.

As Figuras 4.50, 4.51 e 4.52 mostram as correntes geostróficas para o inverno de 2004, calculadas a partir do EGM08/altimetria, HYCOM e dados combinados da AVISO, respectivamente (CGA, CGH e CGC).

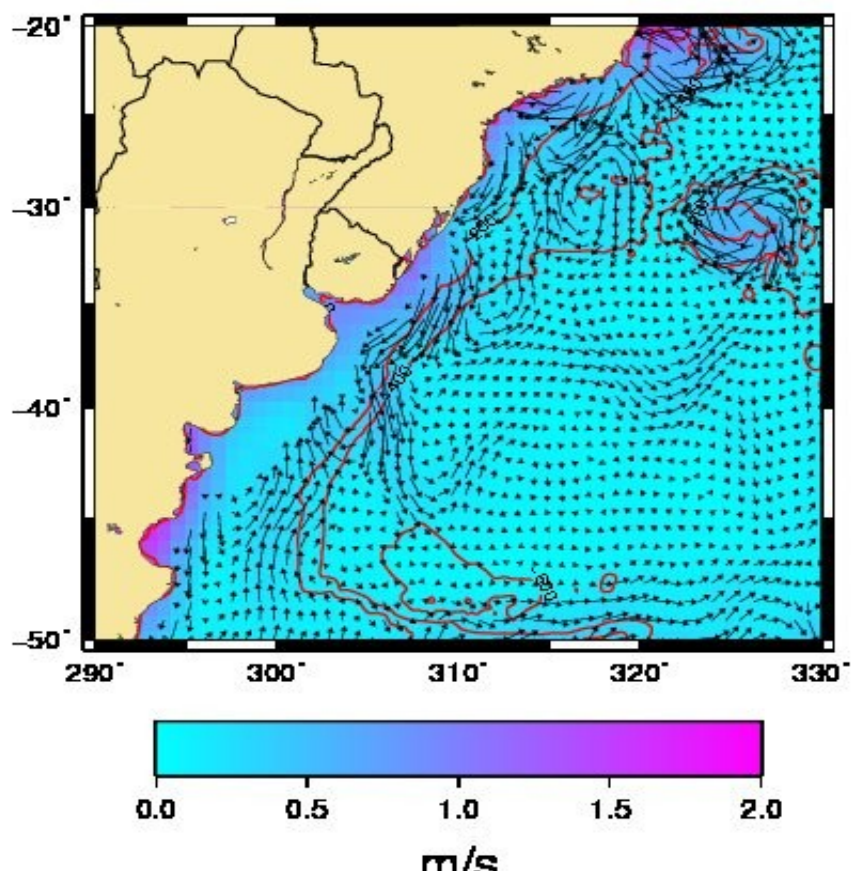

Figura 4.50: Correntes geostróficas determinadas com dados altimétricos e o modelo geoidal EGM2008(CGA) no inverno de 2004. 


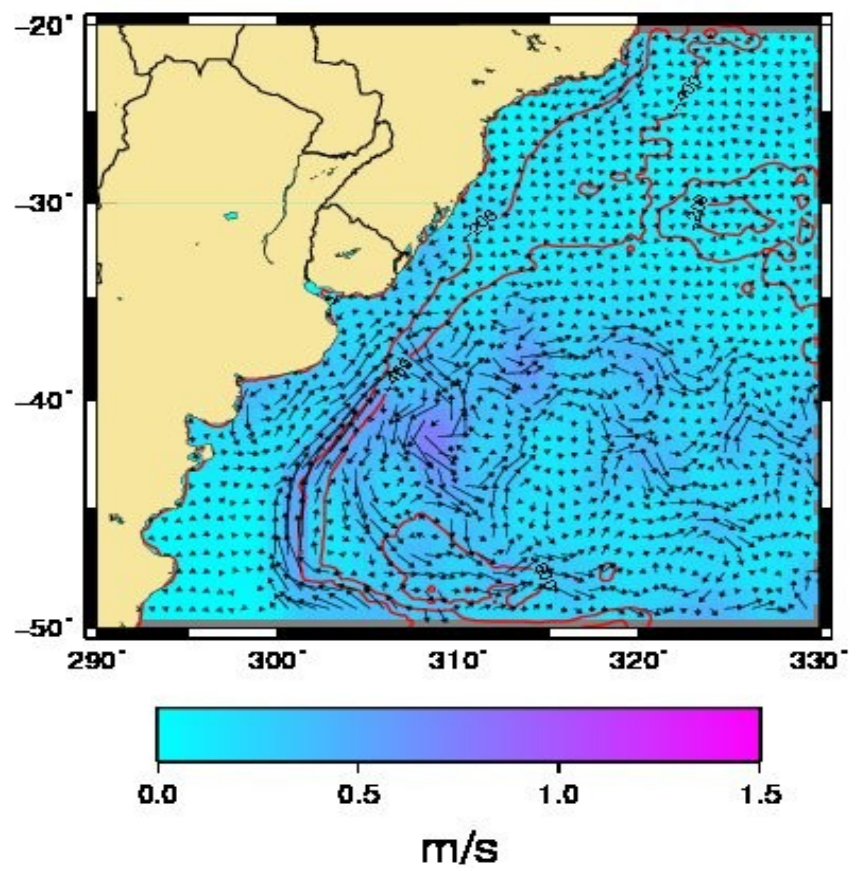

Figura 4.51: Correntes geostróficas determinadas com dados do modelo numérico HYCOM (CGH) no inverno de 2004

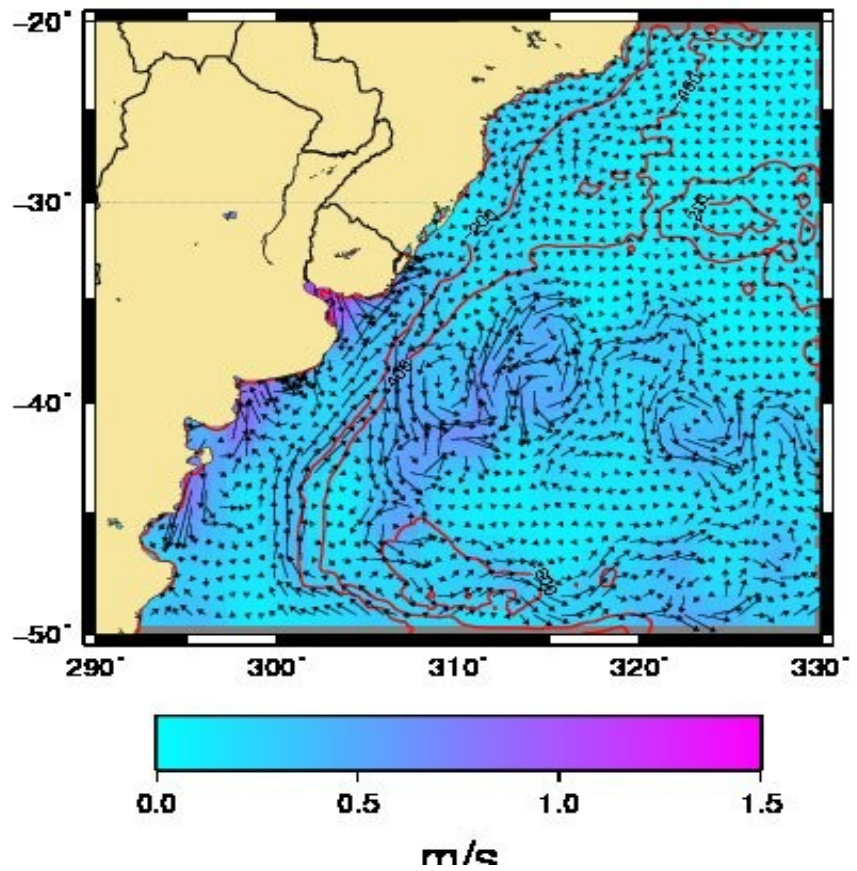

Figura 4.52: Correntes geostróficas determinadas com dados combinados (CGC) no inverno de 2004 
No inverno de 2004, a CB enfraquece e a CM se intensifica no mapa de CGA (Figura 4.50), o que também ocorre com os mapas determinados a partir dos dados do HYCOM e os dados combinados da AVISO, como pode ser observado nos mapas de CGH (Figura 4.51) e CGC (Figura 4.52).

No verão de 2005, no mapa de CGA (Figura 4.53) o padrão de circulação é similar ao do verão de 2004, ou seja, CB mais intensa e CM mais fraca. Nos mapas CGH (Figura 4.54) e CGC (Figura 4.55) os resultados são similares, com a CM bem identificada encontrando com a CB na latitude de $40^{\circ} \mathrm{S}$, aproximadamente. Entretanto, a diferença de intensidade entre a CB e CM é mais visível no mapa de CGA(Figura 4.53).

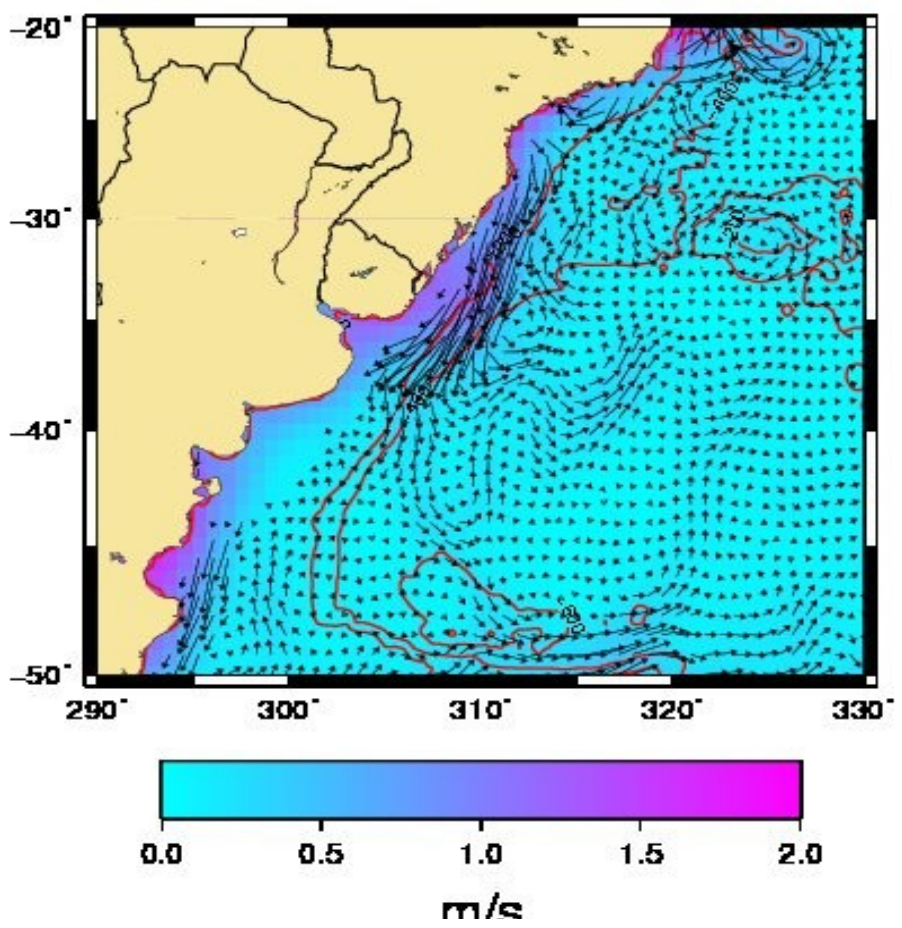

Figura 4.53: Correntes geostróficas determinadas com dados altimétricos e o modelo geoidal EGM08 (CGA) no verão de 2005 


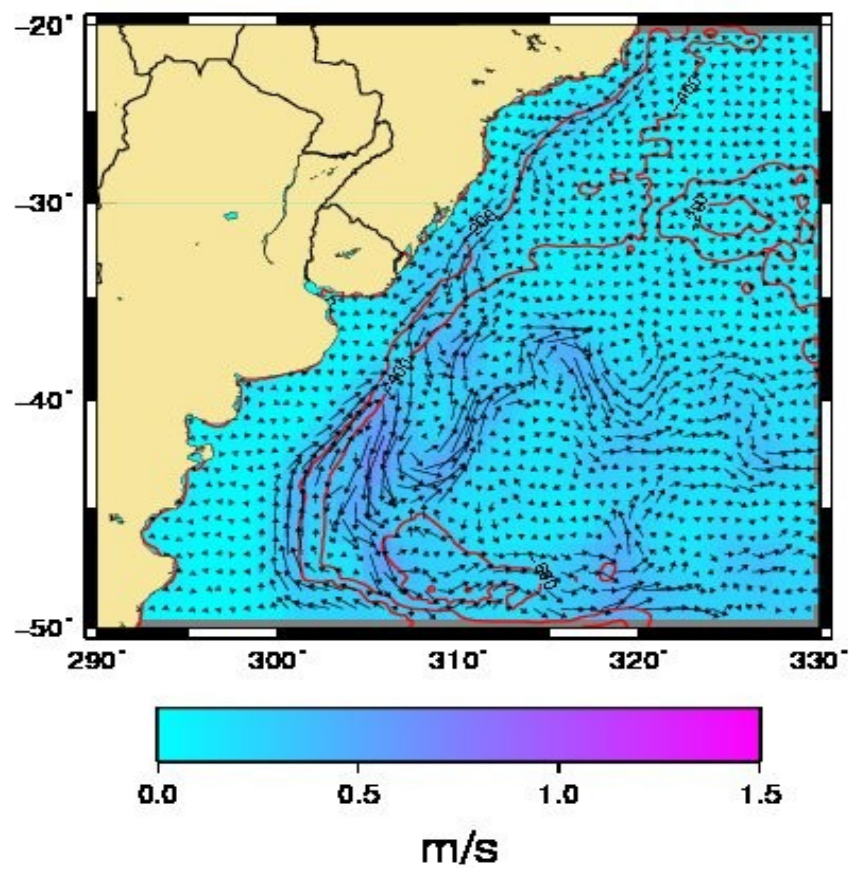

Figura 4.54: Correntes geostróficas determinadas com dados do modelo numérico HYCOM (CGH) no verão de 2005

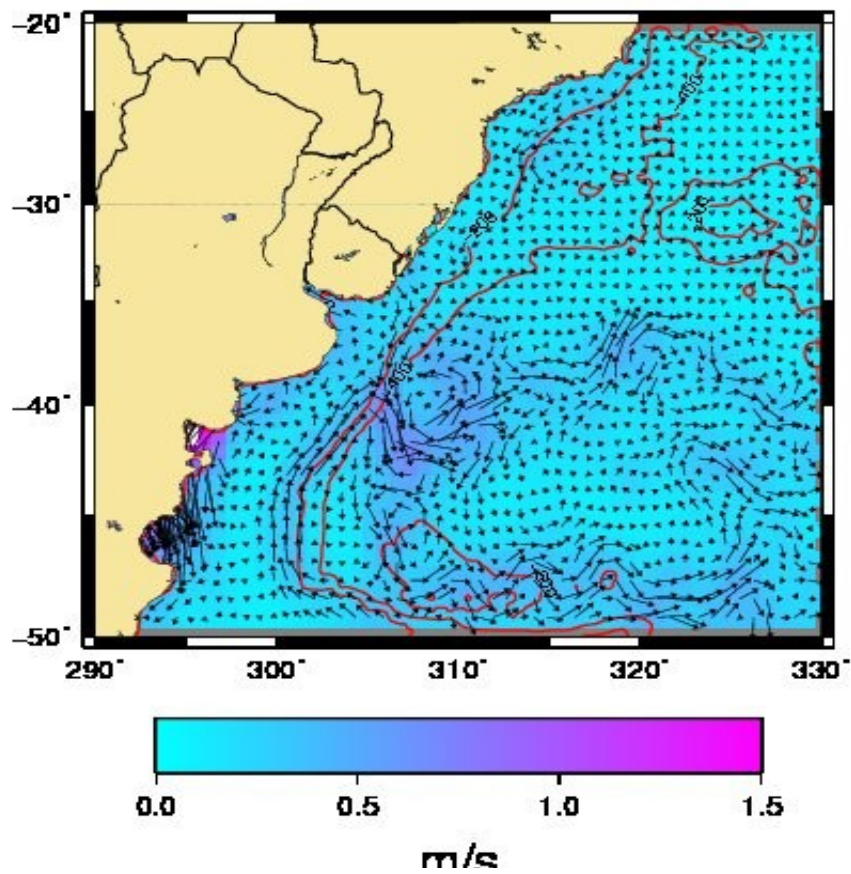

Figura4. 55: Correntes geostróficas determinadas com dados combinados (CGC) no verão de 2005 
No inverno de 2005 o mapa da CGA (Figura 4.56) mostra que a CM fica mais intensa e é melhor identificada que no verão do mesmo ano, entretanto a $\mathrm{CB}$ também é identificada; por outro lado, nos mapas da CGH (Figura 4.57) e CGC (Figura 4.58) apenas a CM é plenamente identificada.

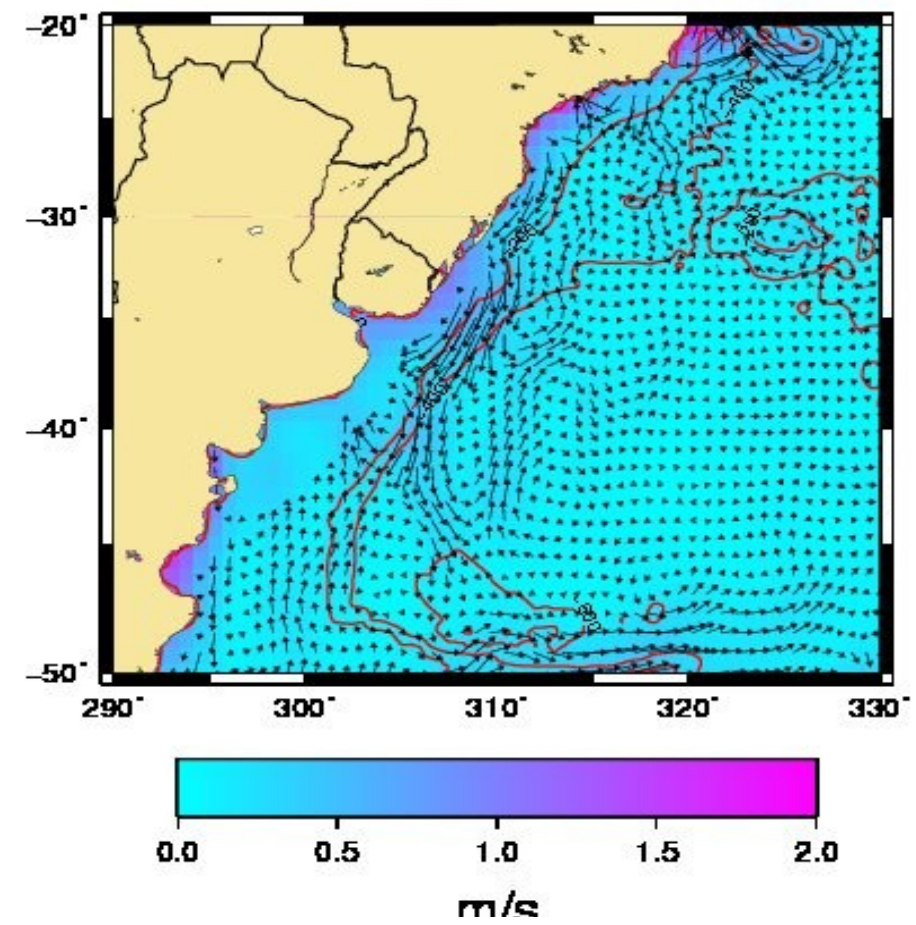

Figura 4.56: Correntes geostróficas determinadas com dados altimétricos e o modelo geoidal EGM08 (CGA) no inverno de 2005. 


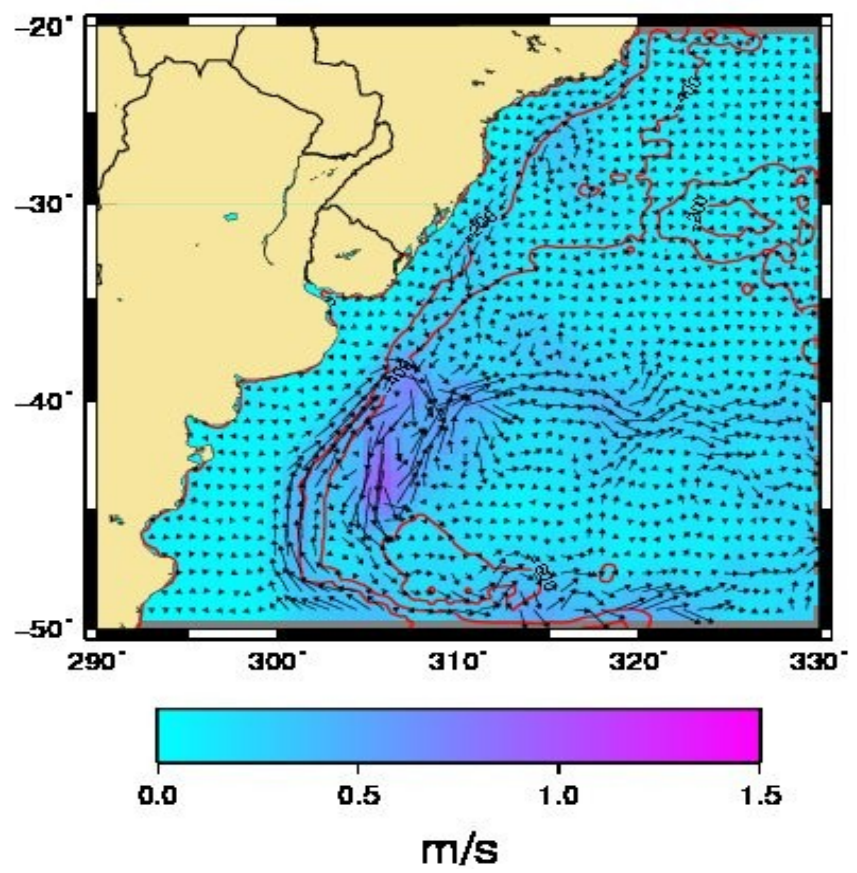

Figura4. 57: Correntes geostróficas determinadas com dados do modelo numérico HYCOM (CGH) no inverno de 2005

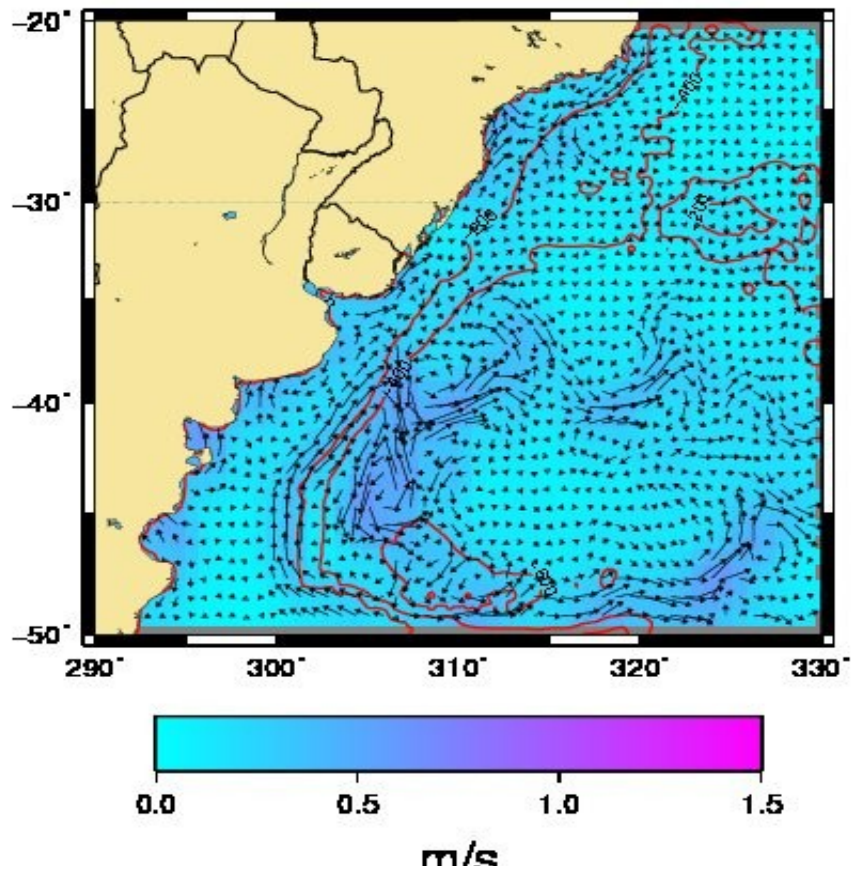

Figura4. 58: Correntes geostróficas determinadas com dados combinados (CGC) no inverno de 2005 
O cenário observado em 2004 e 2005 repete-se para todo o período de 1992 a 2005 com pequenas variações; em geral, a CB fica mais intensa no verão, separando-se da costa na latitude de $40^{\circ} \mathrm{S}$, mas com os resultados obtidos é difícil a identificação precisa da latitude de separação da CB da costa, havendo necessidade de um estudo com resolução espacial superior para esta finalidade.

Mesmo com a identificação principais feições da circulação, o uso de altimetria no estudo de correntes absolutas carece de dados em espaçamento de grade menor, pois um espaçamento de aproximadamente $1^{\circ}$ (além de falhas nos dados) prejudica as análises. Quando a corrente é calculada com a TDM, as correntes ficam bem identificadas, pois os problemas da resolução espacial, e outros erros, são sanados no modelo de nível médio do mar.

Como o cálculo das correntes é realizado através das equação (3.6), a velocidade é determinada apenas com o gradiente de altura, de modo que a mesma representa o movimento geostrófico barotrópico; desta forma, foram comparados os valores médios das correntes $\mathrm{CGH}$ e CGA (componentes barotrópicas) com as correntes fornecidas pelo modelo numérico HYCOM $(\mathrm{CH})$ (componente barotrópica + componente baroclínica), ao longo das latitudes de $38^{\circ} \mathrm{S}, 39^{\circ} \mathrm{S}, 40^{\circ} \mathrm{S}$ e $41^{\circ} \mathrm{S}$, entre as longitudes de $60^{\circ} \mathrm{W}$ e $30^{\circ} \mathrm{W}$ como mostram as Figuras 4.59, 4.60, 4.61 e 4.62 .

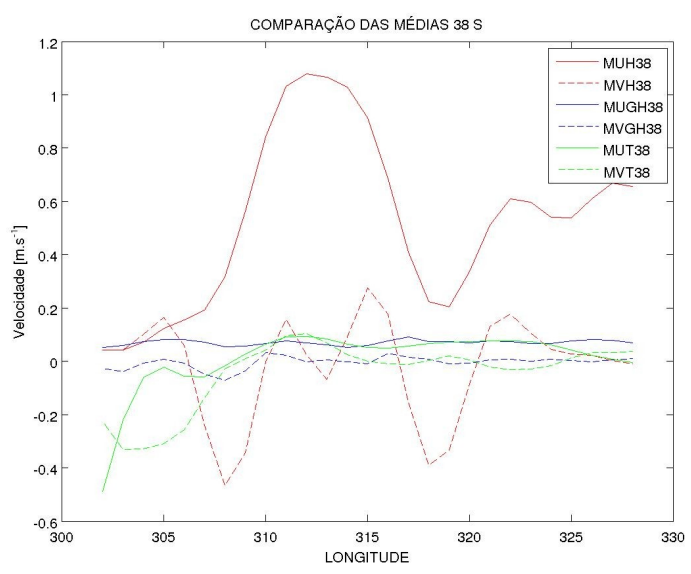

Figura 4.59: Comparação das médias de u e v, sendo MUH38/MVH38 as correntes fornecidas pelo modelo HYCOM (componente barotrópica e baroclínica), MUGH38/MVGH38 as correntes geostróficas determinadas com a TDH e MUT38/MVT38 as correntes geostróficas com a TDA, na latitude de $38^{\circ} \mathrm{S}$ 


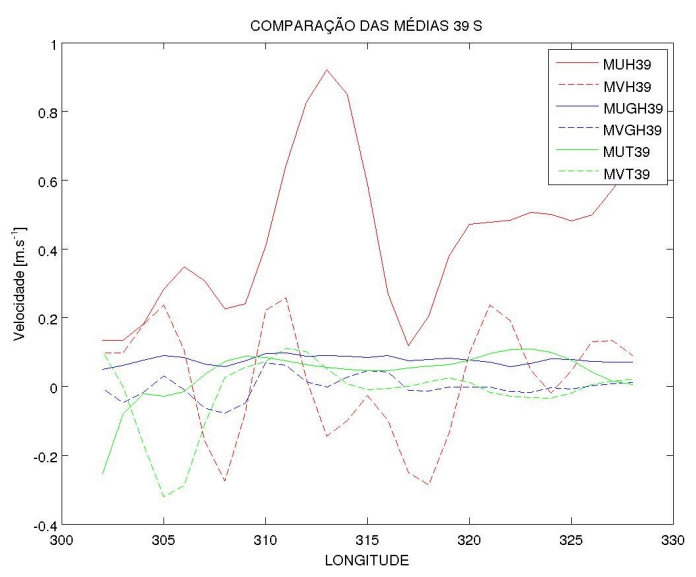

Figura 4.60: Comparação das médias de u e v, sendo MUH39/MVH39 as correntes fornecidas pelo modelo HYCOM (componente barotrópica e baroclínica), MUGH39/MVGH39 as correntes geostróficas determinadas com a TDH e MUT39/MVT39 as correntes geostróficas com a TDA, na latitude de $39^{\circ} \mathrm{S}$.

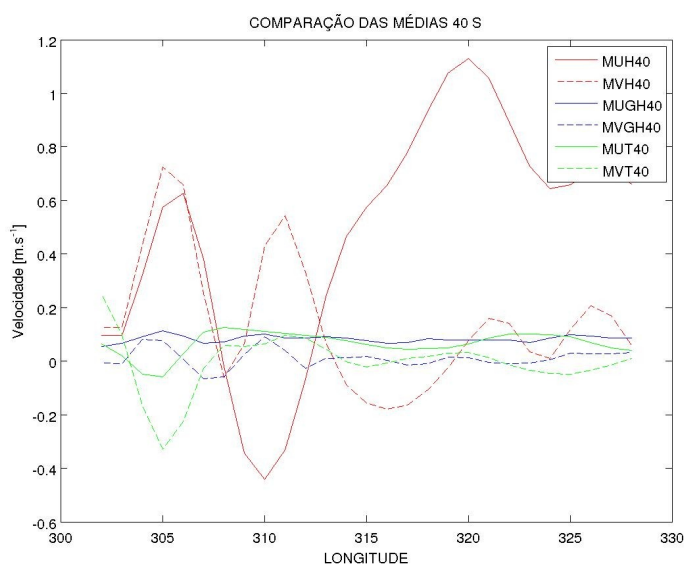

Figura 4.61: Comparação das médias de u e v, sendo MUH40/MVH40 as correntes fornecidas pelo modelo HYCOM (componente barotrópica e baroclínica), MUGH40/MVGH40 as correntes geostróficas determinadas com a TDH e MUT40/MVT40 as correntes geostróficas com a TDA, na latitude de $40^{\circ} \mathrm{S}$. 


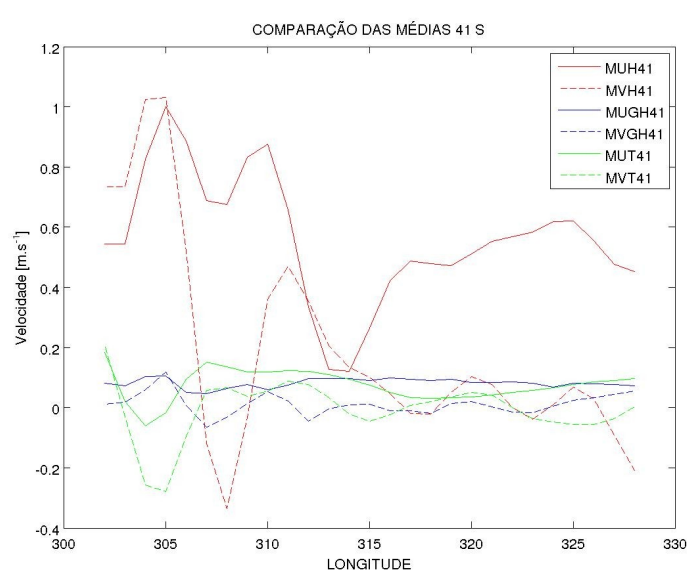

Figura4. 62: Comparação das médias de u e v, sendo MUH41/MVH41 as correntes fornecidas pelo modelo HYCOM (componente barotrópica e baroclínica), MUGH41/MVGH41 as correntes geostróficas determinadas com a TDH e MUT41/MVT41 as correntes geostróficas com a TDA, na latitude de $41^{\circ} \mathrm{S}$.

Os valores médios CGH e CGA (componentes barotrópicas) não ultrapassam $0.2 \mathrm{~m} / \mathrm{s}$, enquanto as correntes $\mathrm{CH}$ (componente barotrópica e baroclínica) variam de 0 a $1 \mathrm{~m} / \mathrm{s}$, indicando uma forte componente baroclínica, nestas longitudes. Na região de encontro da $\mathrm{CB}$ com a $\mathrm{CM}$ (longitudes de $305^{\circ} \mathrm{E}$ a $310^{\circ} \mathrm{E}$ ), a variabilidade em todos os casos é maior, se comparado com os valores em outra longitudes.

\section{7 - Variabilidade temporal das componentes barotrópicas da Corrente do Brasil,} Corrente das Malvinas e Corrente do Atlântico Sul.

Afim de estudar as variabilidades temporais das componentes barotrópicas da $\mathrm{CB}, \mathrm{CM}$ e CAS foram escolhidos pontos nas regiões onde fluem, conforme ilustrado na Figura 3.2. A Figura 4.63 mostra os valores das componentes de corrente meridional e zonal, no período de $11 / 2003$ a $09 / 2005$, para a CB (a $\left.31^{\circ} \mathrm{S} 48^{\circ} \mathrm{W}\right)$. 

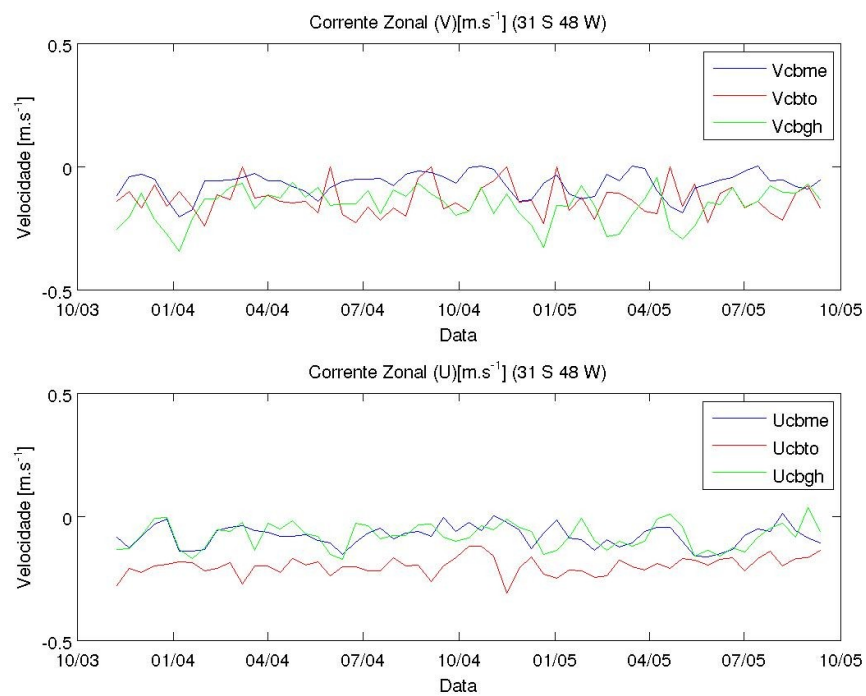

Figura 4.63: Valores de u e v da $\mathrm{CB}$ em $31^{\circ} \mathrm{S}$ e $48^{\circ} \mathrm{W}$, sendo U/Vcbme (azul) valores

das correntes dos dados combinados, U/Vcbto (vermelho) valores das correntes oriundas de altimetria - geóide e U/Vcbgh (verde) valores da correntes geostróficas do

\section{HYCOM.}

As Tabelas 4.3 e 4.4 mostram as estatísticas das componentes zonal e meridional em $31^{\circ} \mathrm{S}$ e $48^{\circ} \mathrm{W}$, respectivamente.

Tabela 4.3 - Valores médios, desvios padrão, máximos e mínimos da componente barotrópica da CB (u) em $31^{\circ} \mathrm{S}$ e $48^{\circ} \mathrm{W}(\mathrm{em} \mathrm{m} / \mathrm{s})$

\begin{tabular}{|c|c|c|c|c|}
\hline ORIGEM DOS DADOS & Média & STD & Máximo & Mínimo \\
\hline TDC & -0.07 & 0.06 & 0.01 & -0.13 \\
\hline TDA & -0.15 & 0.09 & -0.10 & -0.26 \\
\hline TDH & -0.09 & 0.05 & 0.01 & -0.14 \\
\hline
\end{tabular}

Tabela 4.4 - Valores médios, desvios padrão, máximos e mínimos da componente barotrópica da $\mathrm{CB}(\mathrm{v}) \mathrm{em} 31^{\circ} \mathrm{S}$ e $48^{\circ} \mathrm{W}(\mathrm{em} \mathrm{m} / \mathrm{s})$

\begin{tabular}{|c|c|c|c|c|}
\hline ORIGEM DOS DADOS & Média & STD & Máximo & Mínimo \\
\hline TDC & -0.17 & 0.08 & 0.01 & -0.20 \\
\hline TDA & -0.19 & 0.11 & 0.02 & -0.26 \\
\hline TDH & -0.25 & 0.09 & 0.02 & -0.32 \\
\hline
\end{tabular}

A Figura 4.64 mostra os valores das componentes de correntes meridional e zonal no período de $10 / 2003$ a 09/2005 para a $\mathrm{CM}\left(46^{\circ} \mathrm{S}\right.$ e $\left.59^{\circ} \mathrm{W}\right)$. 

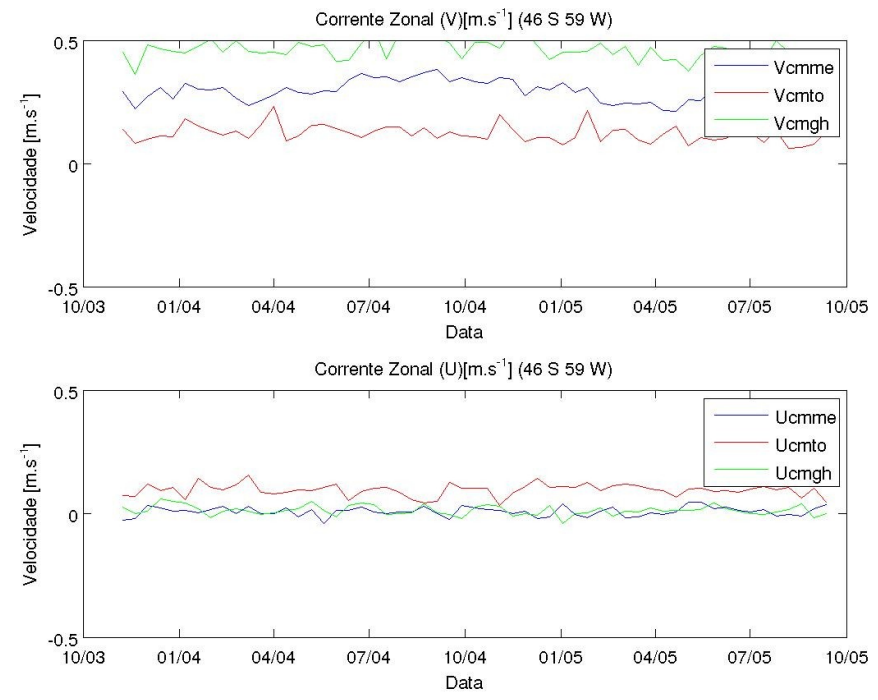

Figura4. 64: Valores de u e v da CM ( $46^{\circ} \mathrm{S}$ e $\left.59^{\circ} \mathrm{W}\right)$, sendo U/Vcmme (azul) valores das correntes dos dados combinados, U/Vemto (vermelho) valores das correntes oriundas de altimetria - geóide e U/Vcmgh (verde) valores da correntes geostróficas do HYCOM.

As tabelas 4.5 e 4.6 mostram as estatísticas das componentes zonal e meridional em $46^{\circ} \mathrm{S}$ e $59^{\circ} \mathrm{W}$, respectivamente.

Tabela 4.5 - Valores médios, desvios padrão, máximos e mínimos da componente barotrópica da $\mathrm{CM}(\mathrm{u})$ em $46^{\circ} \mathrm{S}$ e $59^{\circ} \mathrm{W}(\mathrm{em} \mathrm{m} / \mathrm{s})$

\begin{tabular}{|c|c|c|c|c|}
\hline ORIGEM DOS DADOS & Média & STD & Máximo & Mínimo \\
\hline TDC & -0.02 & 0.02 & 0.04 & -0.08 \\
\hline TDA & 0.09 & 0.04 & 0.13 & -0.01 \\
\hline TDH & -0.02 & 0.01 & 0.03 & -0.07 \\
\hline
\end{tabular}

Tabela 4.6 - Valores médios componente barotrópica da CM (v) em $46^{\circ} \mathrm{S}$ e $59^{\circ} \mathrm{W}(\mathrm{em}$ $\mathrm{m} / \mathrm{s})$

\begin{tabular}{|c|c|c|c|c|}
\hline ORIGEM DOS DADOS & Média & STD & Máximo & Mínimo \\
\hline TDC & 0.29 & 0.08 & 0.35 & 0.21 \\
\hline TDA & 0.14 & 0.11 & 0.25 & 0.10 \\
\hline TDH & 0.41 & 0.08 & 0.51 & 0.29 \\
\hline
\end{tabular}


Nos gráficos e tabelas acima se observa que a $\mathrm{CM}$ é mais intensa que a $\mathrm{CB}$ quando determinada com os dados do HYCOM e combinados, confirmando o que foi mostrados nos mapas anteriores e confirmando a forte componente barotrópica que esta corrente possui, conforme relata Francisco (2007). Os valores da componente de corrente meridional são discrepantes entre os três modelos, chegando a ocorrer diferença de $0.25 \mathrm{~m} / \mathrm{s}$ entre os valores do HYCOM e altimetria-geóide.

As Figuras 4.65 e 4.66 mostram os valores para a CAS em $39.5^{\circ} \mathrm{S} 48^{\circ} \mathrm{W}$ e $40^{\circ} \mathrm{S}$ $48^{\circ} \mathrm{W}$, sendo as estatísticas dos referidos pontos mostradas nas Tabelas 4.7, 4.8, 4.9 e 4.10.
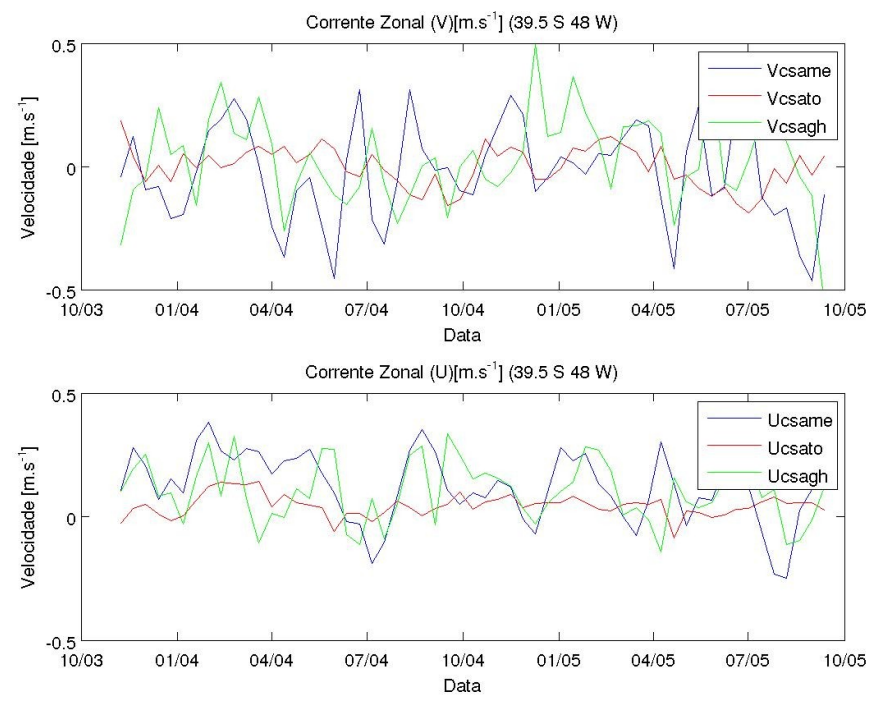

Figura4. 65: Valores de u e v da CAS $\left(39.5^{\circ} \mathrm{S}\right.$ e $\left.48^{\circ} \mathrm{W}\right)$ sendo U/Vcsame (azul) valores das correntes dos dados combinados, U/Vcsato (vermelho) valores das correntes oriundas de altimetria - geóide e U/Vcsagh (verde) valores da correntes geostróficas do HYCOM.

As tabelas 4.7 e 4.8 mostram as estatísticas das componentes zonal e meridional em $39.5^{\circ} \mathrm{S}$ e $48^{\circ} \mathrm{W}$, respectivamente.

Tabela 4.7 - Valores médios, desvios padrão, máximos e mínimos da componente barotrópica da CSA (u) em $39.5^{\circ} \mathrm{S}$ e $48^{\circ} \mathrm{W}(\mathrm{em} \mathrm{m} / \mathrm{s})$.

\begin{tabular}{|c|c|c|c|c|}
\hline ORIGEM DOS DADOS & Média & STD & Máximo & Mínimo \\
\hline TDC & 0.10 & 0.09 & 0.38 & -0.25 \\
\hline TDA & 0.08 & 0.04 & 0.14 & -0.08 \\
\hline TDH & 0.11 & 0.10 & 0.33 & -0.14 \\
\hline
\end{tabular}


Tabela 4.8 - Valores médios, desvios padrão, máximos e mínimos da componente barotrópica da CSA (v) em $39.5^{\circ} \mathrm{S}$ e $48^{\circ} \mathrm{W}(\mathrm{em} \mathrm{m} / \mathrm{s})$.

\begin{tabular}{|c|c|c|c|c|}
\hline ORIGEM DOS DADOS & Média & STD & Máximo & Mínimo \\
\hline TDC & 0.05 & 0.09 & 0.31 & -0.39 \\
\hline TDA & -0.01 & 0.08 & 0.09 & -0.13 \\
\hline TDH & 0.03 & 0.10 & 0.50 & -0.49 \\
\hline
\end{tabular}
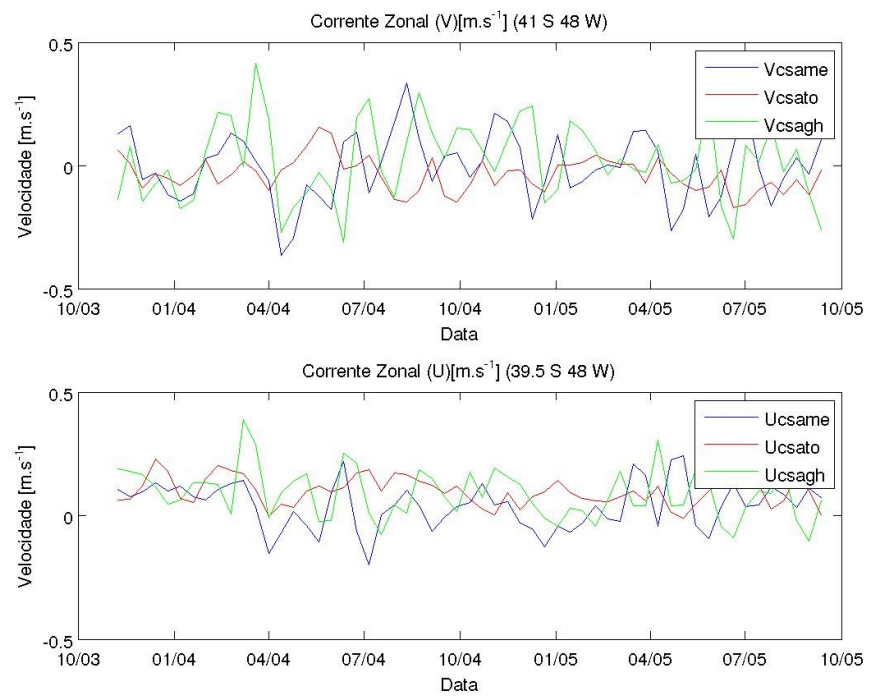

Figura4. 66: Valores de u e v da CAS $\left(41^{\circ} \mathrm{S}\right.$ e $\left.48^{\circ} \mathrm{W}\right)$, sendo U/Vcsame (azul) valores das correntes dos dados combinados, U/Vcsato (vermelho) valores das correntes oriundas de altimetria geóide e U/Vcsagh (verde) valores da correntes geostróficas do

\section{HYCOM.}

As tabelas 4.9 e 4.10 mostram as estatísticas das componentes zonal e meridional em $41^{\circ} \mathrm{S}$ e $48^{\circ} \mathrm{W}$, respectivamente.

Tabela 4.9 - Valores médios, desvios padrão, máximos e mínimos da componente barotrópica da CSA (u) em $41^{\circ} \mathrm{S}$ e $48^{\circ} \mathrm{W}(\mathrm{em} \mathrm{m} / \mathrm{s})$.

\begin{tabular}{|c|c|c|c|c|}
\hline ORIGEM DOS DADOS & Média & STD & Máximo & Mínimo \\
\hline TDC & 0.09 & 0.09 & 0.38 & -0.17 \\
\hline TDA & 0.09 & 0.06 & 0.09 & -0.06 \\
\hline TDH & 0.10 & 0.12 & 0.39 & -0.10 \\
\hline
\end{tabular}


Tabela 4.10 - Valores médios, desvios padrão, máximos e mínimos da componente barotrópica da CSA (v) em $41^{\circ} \mathrm{S}$ e $48^{\circ} \mathrm{W}(\mathrm{em} \mathrm{m} / \mathrm{s})$.

\begin{tabular}{|c|c|c|c|c|}
\hline ORIGEM DOS DADOS & Média & STD & Máximo & Mínimo \\
\hline TDC & -0.02 & 0.14 & 0.32 & -0.46 \\
\hline TDA & 0.02 & 0.23 & 0.15 & -0.17 \\
\hline TDH & 0.05 & 0.12 & 0.50 & -0.50 \\
\hline
\end{tabular}

Nos dois pontos escolhidos na CAS verificou-se uma corrente menos intensa, predominado a componente zonal $(\mathrm{u})$ da corrente, entretanto com alto desvio padrão, principalmente quando determinadas com os dados do HYCOM e dados combinados.

\section{8 - Análise da Corrente do Brasil e Corrente das Malvinas através do método direto, para o período de 1992 a 2005.}

Neste trabalho foram processadas toda a série temporal do TOPEX/Poseidon e a série do Jason 1 até dezembro de 2005, período para o qual as correntes geostróficas foram calculadas com o modelo geoidal EGM2008 e filtradas com o filtro SSA, com $\mathrm{M}=3$. Os gráficos que seguem (Figura 4.67, 4.68, 4.69 e 4.70) ilustram as variações temporais das componentes barotrópicas da $\mathrm{CB}$ e $\mathrm{CM}$, respectivamente, no período de 1992 a 2005, considerando os mesmos pontos selecionados na Figura 3.2 . 

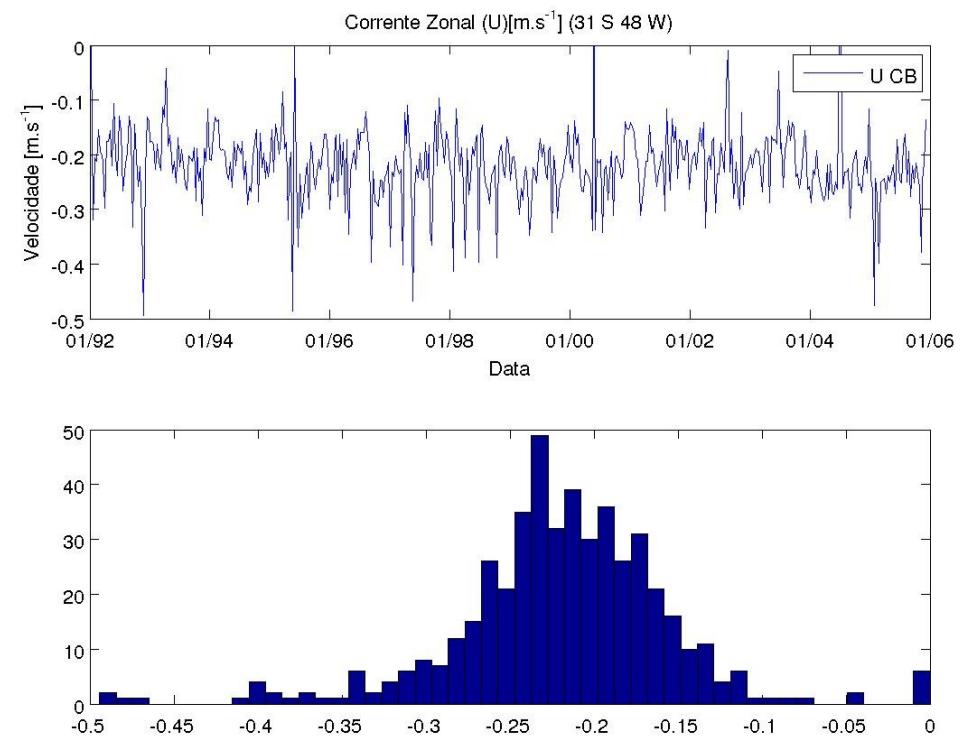

Figura 4.67: Valores da componente de corrente zonal u e seu histograma, para a componente barotrópica da CB, no período de 1992 a 2005.

O gráfico acima mostra que a componente barotrópica zonal da $\mathrm{CB}$ em $31^{\circ} \mathrm{S}$ e $48^{\circ} \mathrm{W}$ (Figura 4.67) varia entre $-0.5 / \mathrm{s}$ e $0 \mathrm{~m} / \mathrm{s}$, com média de $-0.21 \mathrm{~m} / \mathrm{s}$ e desvio padrão de $0.06 \mathrm{~m} / \mathrm{s}$. A Figura 4.68 ilustra a componente meridional (v) da CB.
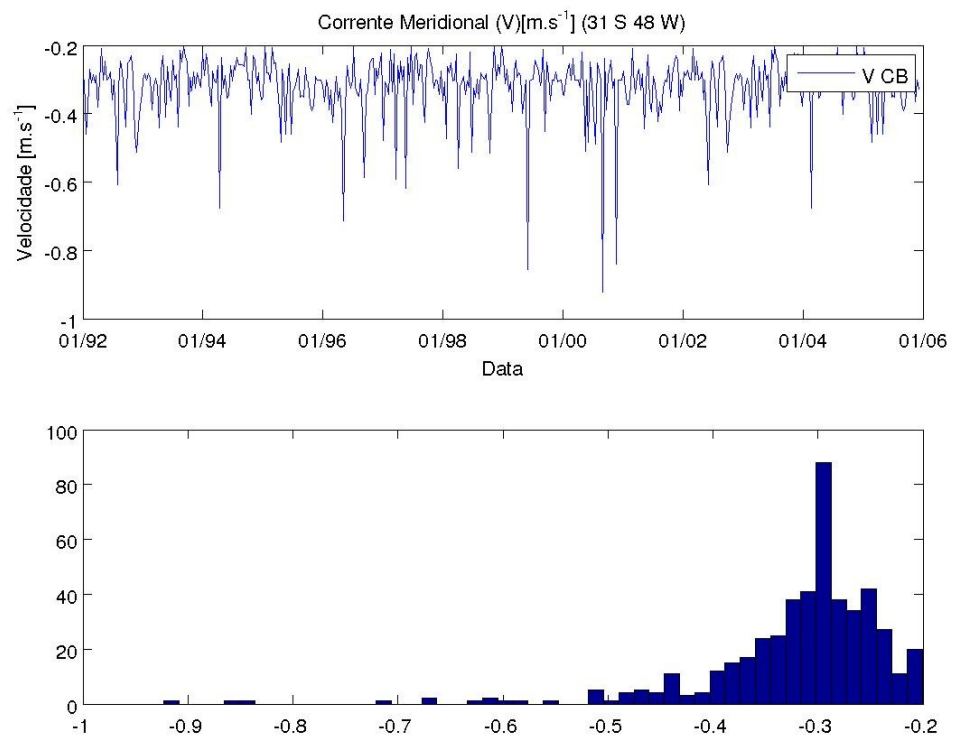

Figura4. 68: Valores da componente de corrente meridional v e seu histograma, para a componente barotrópica da CB, no período de 1992 a 2005. 
Conforme a Figura 4.68, a componente meridional da CB para o período compreendido entre 1992 e 1995 varia entre $-0.20 \mathrm{~m} / \mathrm{s}$ e $-0.92 \mathrm{~m} / \mathrm{s}$, com média de -0.29 $\mathrm{m} / \mathrm{s}$ e desvio padrão de $0.08 \mathrm{~m} / \mathrm{s}$.

Figuras 4.69 e 4.70 mostram os valores para a $\mathrm{CM}$ em $46^{\circ} \mathrm{S} 59^{\circ} \mathrm{W}$, segundo as componentes zonal $(\mathrm{u})$ e meridional $(\mathrm{v})$, respectivamente.
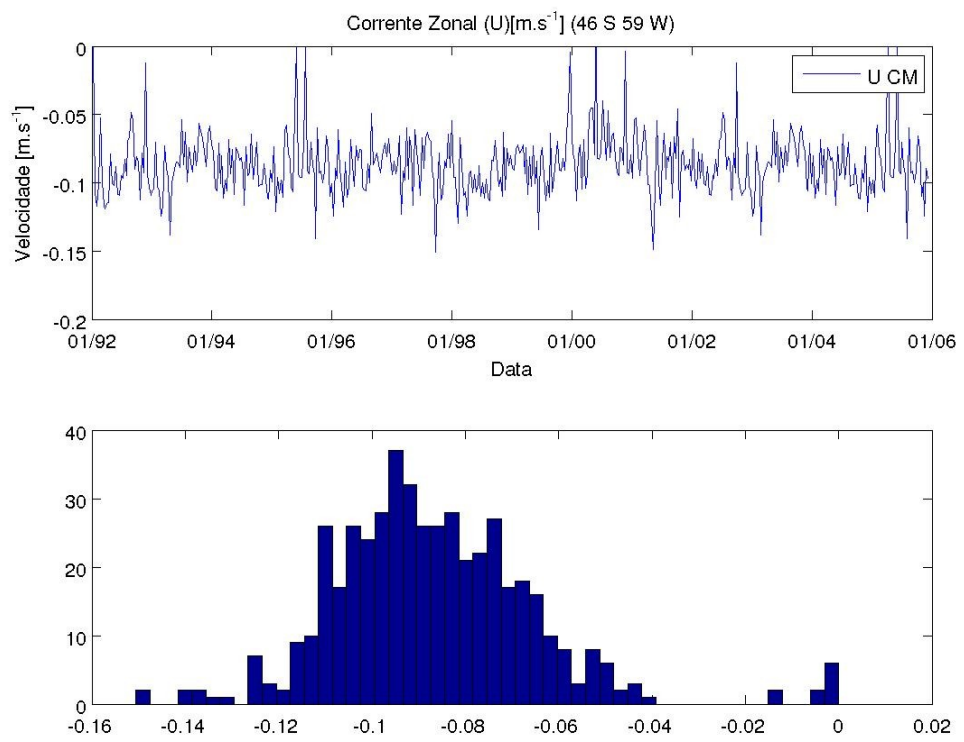

Figura 4.69: Valores da componente de corrente zonal u e seu histograma para a componente barotrópica da CM, no período de 1992 a 2005.

Os valores de u para a CM variam ente 0 e $-0.15 \mathrm{~m} / \mathrm{s}$ com média de $-0.08 \mathrm{~m} / \mathrm{s}$ e desvio padrão de $0.02 \mathrm{~m} / \mathrm{s}$. 

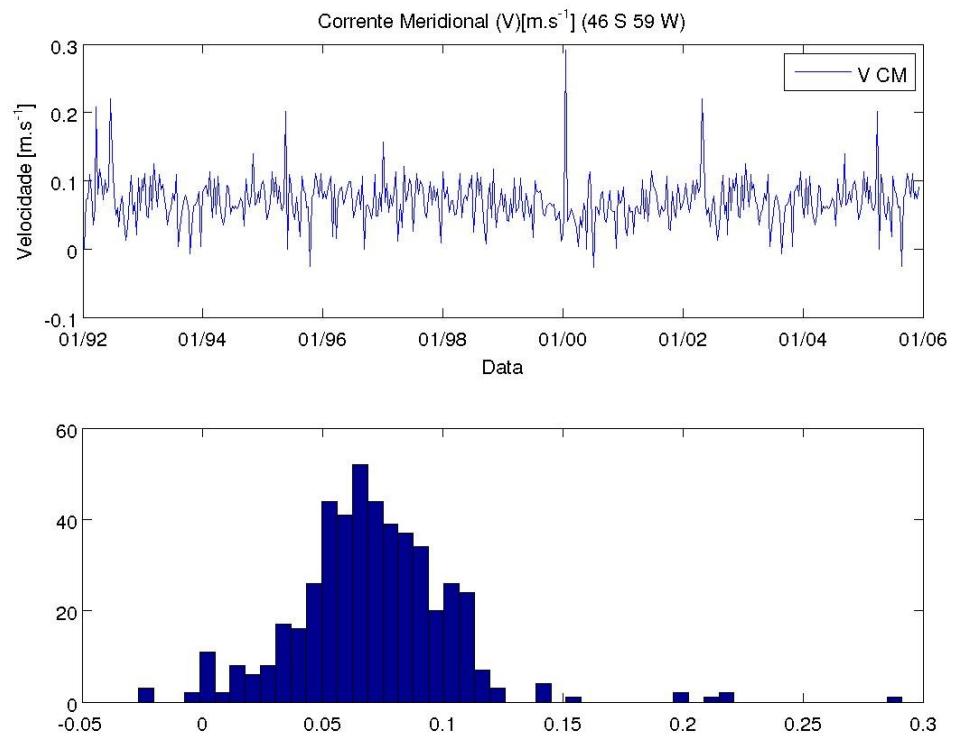

Figura 4.70: Valores da componente de corrente meridional v e seu histograma para a componente barotrópica da CM, no período de 1992 a 2005.

A componente meridional da CM no ponto analisado varia entre -0.03 e 0.23 $\mathrm{m} / \mathrm{s}$ com média de $0.09 \mathrm{~m} / \mathrm{s}$ e desvio padrão de $0.03 \mathrm{~m} / \mathrm{s}$.

Como foi observado nos mapas CGH e CGC, bem como nas Figuras 4.63 e 4.64, a CM é mais intensa que a CB (localizada aproximadamente na isóbata de $200 \mathrm{~m}$ na região de estudo); este fato não foi observado com o método direto (CGA), pois além da baixa resolução espacial, estes dados possuem erros em regiões com profundidades menores que $1000 \mathrm{~m}$, e uma das principais fontes de erros são os modelos utilizados na correção de marés.

\section{9 - Correlações entre as correntes geostróficas obtidas com modelos geoidais as correntes geostróficas do modelo numérico HYCOM}

Foram determinadas as correlações entre as séries temporais da Corrente Geostrófica CGH com CGA e CGC, no período entre 08/11/03 a 12/09/05.

As Figuras 4.71 e 4.72 mostram as correlações e significâncias entre a CGH e a CGA, para para as componentes $\mathrm{u}$ e $\mathrm{v}$ de corrente, respectivamente; se observam valores de correlação moderados $(\sim 0.7)$, tanto para u como para v. Nos mapas de significância encontram-se valores que variam entre 0.15 e 0.25 , indicando uma 
incerteza alta.
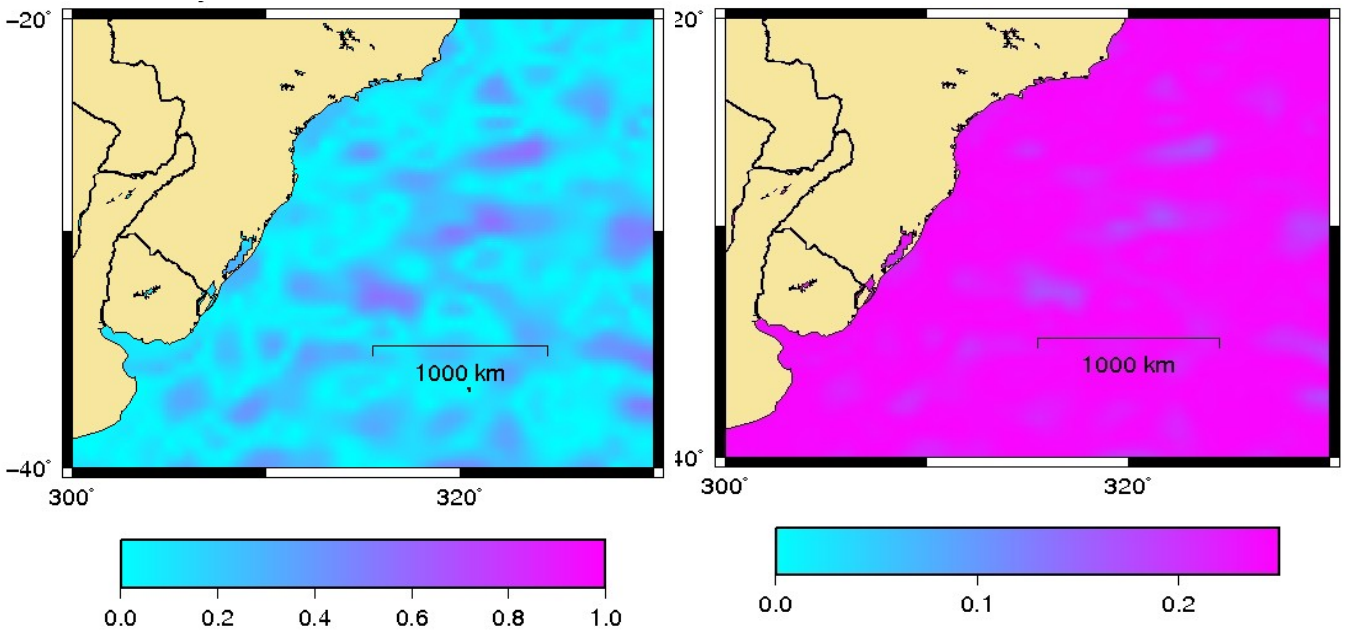

Figura4. 71: Correlação (esquerda) e significância (direita) da corrente zonal u entre CGH e CGA.
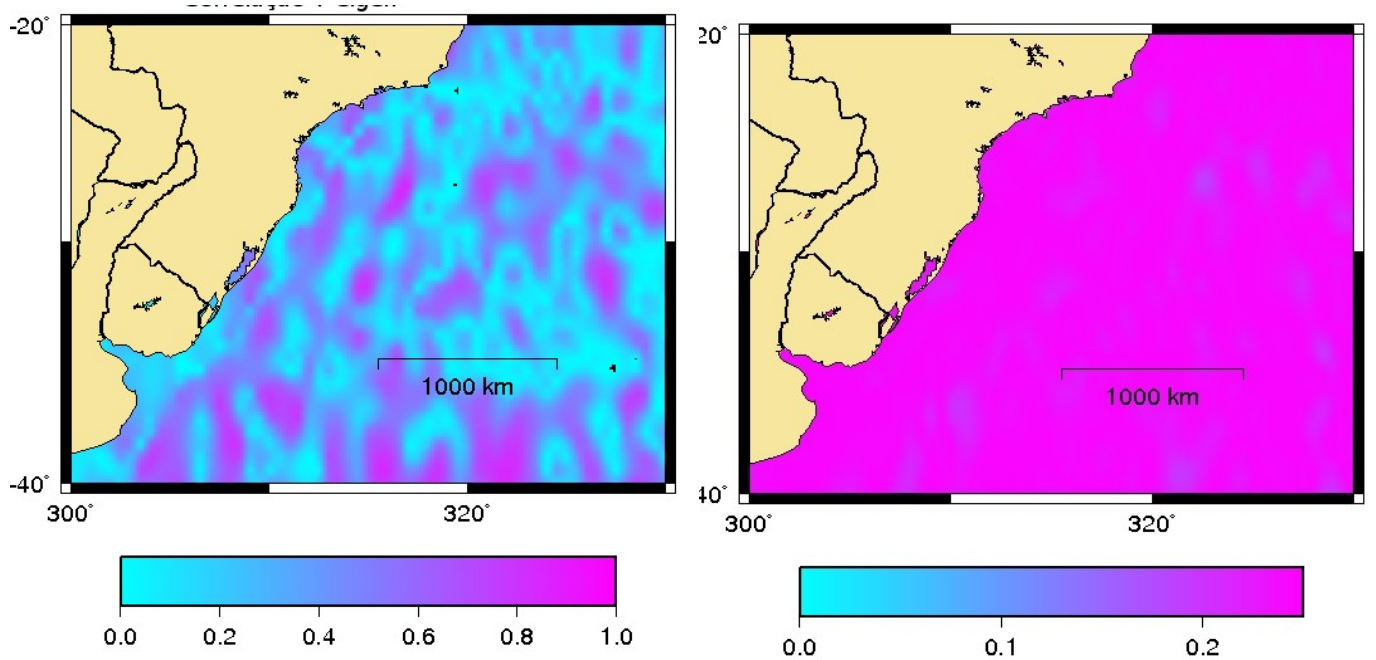

Figura4. 72: Correlação (esquerda) e significância (direita) da corrente meridional v entre CGH e CGA.

Gráficos similares são apresentados para as correlações entre os cálculos com dados do HYCOM e as estimativas com dados combinados, nas Figuras 4.73 e 4.74, as quais chegam a 0.9 em alguns pontos; este fato é explicado pela resolução espacial dos dados, de modo que as feições de circulação são melhor identificadas com os dados do HYCOM e combinados. Considerando os mapas de significância, se nota melhora em relação às obtidas entre os dados dos HYCOM e os dados oriundos do método direto. 

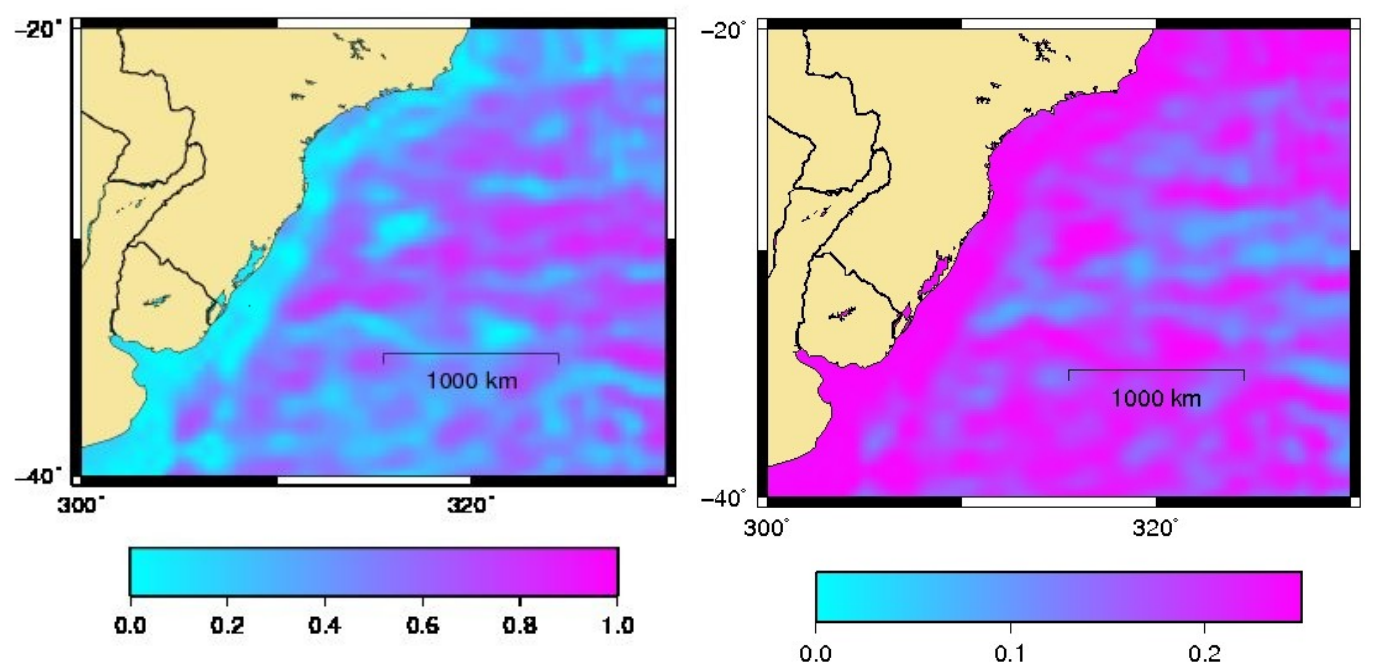

Figura 4.73: Correlação (esquerda) e significância (direita) da corrente zonal u entre a CGH e CGC.
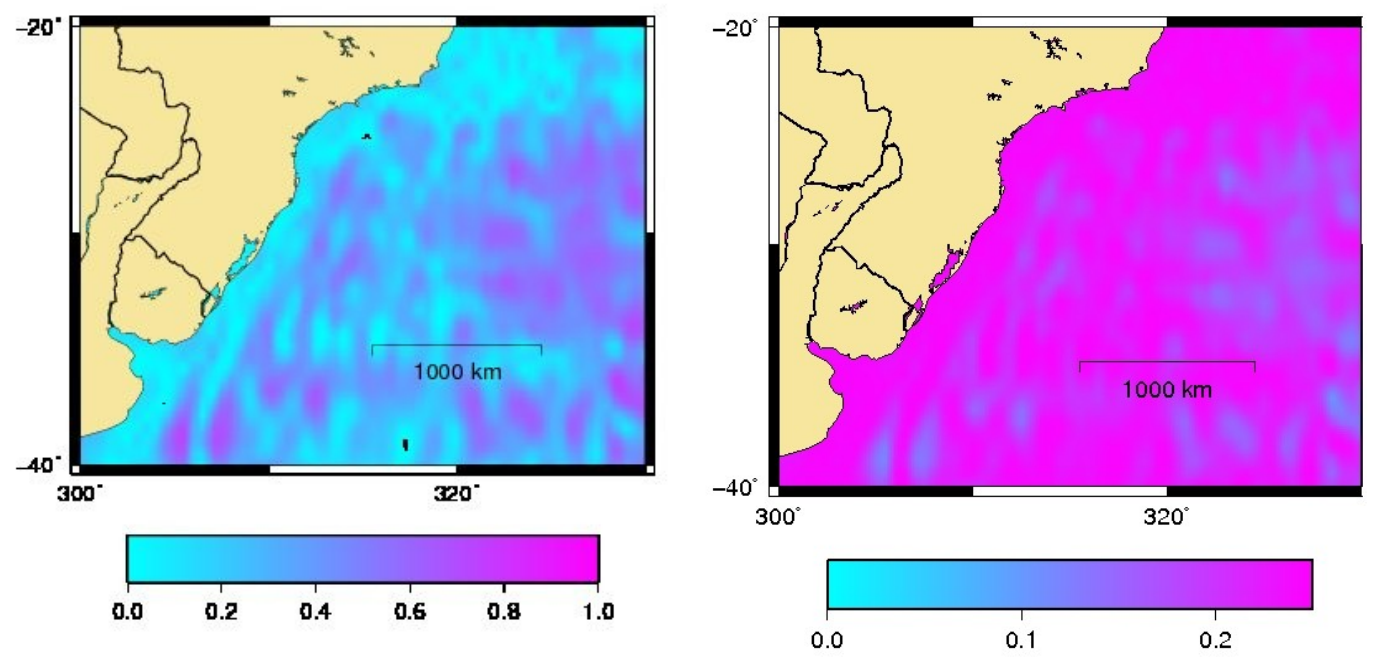

Figura 4.74: Correlação (direita) e significância (esquerda) da corrente meridional v entre a CGH e CGC. 


\section{5 - DISCUSSÕES}

Os recursos oferecidos pela altimetria por satélite e modelos geoidais (com resolução espacial capaz de favorecer os estudos das variabilidades do nível do mar e correntes geostróficas) constituem uma fonte complementar no estudo da dinâmica do oceano, pois se trata de dados medidos diretamente a nível global com metodologia padronizada. De fato, os dados de altimetria / geóide podem complementar várias metodologias de estudo dos oceanos, como a modelagem numérica e observações in-situ.

Apesar da altimetria/geóide fornecer apenas a componente barotrópica das correntes, o uso de dados combinados multi-satélites / modelagem numérica / observações in-situ proporciona meios de estudos de alta resolução espaço - temporal, como vórtices e meandros, que em geral são associados a instabilidades das correntes.

Os modelos geoidais vem sendo aprimorados para uso em Oceanografia, de modo que sua utilização, juntamente com os dados de satélites altimétricos, tem se mostrado uma ferramente útil para o monitoramento de correntes geostróficas absolutas, ou na assimilação de dados de nível do mar em modelos hidrodinâmicos operacionais.

Nos cálculos dos modelos geoidais deve-se atentar para o fato dos referenciais geodésicos (elipsóide de referência, parâmetros de rotação, etc.) serem compatíveis com os referenciais utilizados nos satélites altimétricos. Outro parâmetro importante é a definição do grau e ordem harmônicos nos quais o modelo foi determinado. Como foi observado no Capítulo 4, o fato de truncar o harmônico em grau e ordem 120 impossibilitou a determinação de correntes geostróficas de boa qualidade com o modelo EGM2008.

Os modelos geoidais do sistema GRACE foram pioneiros em aplicações oceanográficas de precisão, entretanto os ruídos apresentados ainda constituem um problema na determinação das correntes geostróficas. A filtragem dos dados possibilitou os primeiros estudos, como em Vianna et al. (2007), que usaram o filtro SSA para filtrar a TD.

Os modelos geoidais truncados em grau e ordem elevados possuem desvio padrão da ordem do coeficiente do grau harmônico, o que se torna uma preocupação em aplicações oceanográficas, como no caso do modelo EGM2008; ainda sim, os resultados com os modelos geoidais recentes mostraram que, mesmo em grau e ordem elevados, os resultados, 
em termos de ruídos, são melhores do que os de outros modelos.

Os dados altimétricos utilizados (MGDR do TOPEX/Poseidon e Jason 1) possuem uma resolução espacial de aproximadamente $1^{\circ} \mathrm{X} 1^{\circ}$, tendo sido interpolados para grade de $0.5^{\circ}$ X $0.5^{\circ}$; entretanto, estes dados possuem pequena resolução, se comparada com a resolução proporcionada pelos modelos geoidais recentes, em especial o EGM2008, que possui resolução de aproximadamente 10' (10 minutos de grau). Este fato foi constatado com o uso do modelo do nível médio do mar DNSC08 e com os dados combinados da AVISO,os quais proporcionaram uma resolução de $1 / 3^{\circ} \times 1 / 3^{\circ}$. As feições de circulação foram então melhor representadas, em relação às obtidas com o uso exclusivo dos dados de superfície do nível do mar do TOPEX/Poseidon e Jason 1. As falhas dos dados altimétricos também constituem um problema a ser questionado.

Apesar das feições serem identificadas, observou-se que feições conhecidas, como a $\mathrm{CB}$, apresentam valores diferentes ao comparar o modelo numérico e dados combinados, ou seja, os dados de altimetria (referenciados a um elipsóide) ainda devem atingir melhor resolução espacial.

Para comparações, foram escolhidos o modelo numérico hidrodinâmico HYCOM e dados combinados (MERGED) disponibilizados pela AVISO. Na análise temporal da topografia dinâmica, foram necessários dados de origens diferentes, pois ainda não foram realizados trabalhos que avaliassem as variações temporais do nível do mar e correntes através do método direto.

A TDM obtida com modelo geoidal EGM2008, truncado em grau e ordem 2160, não apresentou ruídos que comprometessem o cálculo de correntes, enquanto que o modelo EIGEN-5C apresentou as mesmas feições com ruídos, já o modelo EGM96 sequer reproduziu as feições características da circulação.

O papel do filtro é importante na determinação das correntes, conforme mostrado no Capítulo 4; o Filtro SSA (com M=3 para a TDM, em todos os casos) foi adequado, pois reduziu os ruídos sem descaracterizar as feições. O filtro gaussiano também é eficiente na remoção dos ruídos, no entanto o mesmo apresenta problemas nos contornos.

Considerando as correntes geostróficas médias, foi constatado que o modelo EGM2008 truncado em grau e ordem 2160 apresenta os melhores resultados, evoluindo 
consideravelmente em relação ao modelo EGM96; isto foi constatado nos mapas de topografia dinâmica média e respectivos mapas de correntes. O método de filtragem é importante para melhor representação das feições de correntes.

No mapa de correntes oriundas do modelo geoidal EGM2008 e do nível médio do mar DNSC08 (Figura 4.12) foram identificadas as seguintes feições:

- A CB sendo originada a $10^{\circ} \mathrm{S}$ e separando da costa em torno de $40^{\circ} \mathrm{S}$, com velocidades resultantes de $0.3 \mathrm{~m} / \mathrm{s}$ a $0.4 \mathrm{~m} / \mathrm{s}$.

- Na região da CBM, a CB se encontra com a CM, na latitude de $40^{\circ}$ aproximadamente, formando-se a Corrente do Atlântico Sul (CAS), com valores médios de $0.3 \mathrm{~m} / \mathrm{s}$, aproximadamente. Também é identificada a Frente Subantática em $50^{\circ}$ de latitude. Correntes de menor intensidade não foram plenamente identificadas.

Com o modelo EIGEN-05C as mesmas feições foram identificadas, porém com ruídos. O modelo EGM96 sequer identificou as feições da CBM.

Comparando as feições descritas acima com as correntes médias do modelo numérico HYCOM, verifica-se que o modelo EGM2008 apresenta os melhores resultados, mas também é notória a evolução do EIGEN-5C em relação ao EGM96.

$\mathrm{Na}$ avaliação temporal da TD e correntes geostróficas, foram comparados os resultados do método direto e dados combinados (MERGED) com o modelo numérico HYCOM. Algumas diferenças foram verificadas entre os três modelos, a principal é o melhor detalhamento das feições do modelo numérico e dos dados combinados (MERGED), para a topografia dinâmica e as correntes.

A correlação temporal entre TDA e TDH, ambas filtradas com o filtro SSA com $\mathrm{M}=3$, é fraca e moderada, já a correlação entre dos dados TDH e TDC melhora consideravelmente.

Na TDA, foi verificado que as feições foram mantidas, a mais evidente é seu forte gradiente na região de $40^{\circ}$ de latitude, mas os mapas de TDA não apresentaram um bom detalhamento na região da CM. Comparando o verão e inverno, verificou-se que no verão os valores da TDA aumentam e a linha do gradiente é mais evidente do que no inverno. Nesta análise, foram avaliados todos os pontos da grade na região da CBM.

Considerando as correntes geostróficas obtidas com a TDA verificaram-se as 
variabilidades entre verão e inverno, sendo que no verão a CB fica mais intensa, porém não foi possível identificar com precisão o local onde a $\mathrm{CB}$ se separa da costa. Os padrões mostrados no Capítulo 4 (verão e inverno de 2004 e 2005) repetem-se para todos os anos de cobertura do TOPEX/POSEIDON e parte dos dados do Jason 1, com pequenas variações. Assim como nos mapas de TD, as correntes geostróficas do HYCOM e dos dados combinados apresentaram melhor detalhamento na região da CBM.

Comparando os valores médios das correntes geostróficas barotrópicas (altimetriageóide e HYCOM) com as correntes do modelo HYCOM (estas levando em conta as componentes barotrópica e baroclínica), nas latitudes de $38^{\circ} \mathrm{S}, 39^{\circ} \mathrm{S}, 40^{\circ} \mathrm{S}$ e $41^{\circ} \mathrm{S}$, verificouse que os valores do modelo numérico são maiores; e a maior variabilidade encontra-se na região de encontro da $\mathrm{CB}$ com a $\mathrm{CM}$ (longitudes entre $60^{\circ} \mathrm{W}$ e $50^{\circ} \mathrm{W}$ ), principalmente na componente meridional (v) de corrente.

Ao avaliar os resultados, ficou evidente que a combinação de modelos geoidais e altimetria vem evoluindo, possibilitando as primeiras análises das correntes absolutas, entretanto é primordial a utilização de dados de altimetria com melhor resolução espacial. A maior correlação entre os dados combinados e dados do HYCOM evidencia a importância da resolução espacial na utilização de altimetria e de modelos geoidais nos estudos das variabilidades da TDs e correntes geostróficas.

Futuramente, os dados do sistema GOCE deverão preencher as lacunas dos modelos geoidais atuais e, certamente, serão disponibilizados dados de altimetria multisatélites, de modo que poderá ser atingida uma resolução espacial que possibilitará análises mais detalhadas de circulação oceânica, incluindo o estudo de vórtices e meandros. 


\section{6 - CONCLUSÕES}

O objetivo básico deste trabalho consistiu em verificar a hipótese que os atuais modelos geoidais são eficientes no estudo da TDM e respectivas correntes geostróficas médias, bem como no estudo das variações temporais da TD e correntes na região da CBM, que constitui região com uma das mais energéticas dinâmicas do Atlântico Sul.

Considerando as feições médias no Atlântico Sul se pode concluir que:

- A comparação do modelo EGM96 com os modelos geoidais recentes EIGEN-5C e EGM2008 demonstra que estes são mais precisos em temos de coeficientes harmônicos esféricos. Em termos de resolução espacial, o EGM2008 possui uma resolução sem precedentes, pois a mesma está diretamente relacionada com a ordem e grau do modelo ( $l$ $=m=2159)$.

- Os modelos geoidais recentes (EIGEN-5C e EGM2008) apresentaram resultados satisfatórios na determinação da TDM e correntes, com a plena identificação das principais feições de grande e meso escala, o que não ocorre com a TDM-EGM96; este fato comprova as melhorias dos modelos recentes, em especial o modelo EGM2008, que possui grau e ordem superiores aos demais modelos.

- Os problemas referentes aos ruídos foram sanados com a aplicação do filtro SSA, que possui a vantagem de não apresentar problemas nos contornos laterais, podendo ser aplicado de maneira controlada através da matriz $\mathrm{M}$.

- Considerando todo o Atlântico Sul, as correntes geostróficas resultantes dos modelos TDM-EGM08 e TDM-EIGEN-5C apresentaram maior correlação espacial com as correspondentes correntes geostróficas calculas a partir de resultados de elevação do modelo numérico hidrodinâmico HYCOM; as principais correntes ficaram bem caracterizadas em todos os modelos, porém com valores de velocidade resultante distintos.

No estudo da variabilidade da TD e correntes na região da CBM, conclui-se que :

- Apesar de CB, CM e CAS serem identificadas com o método direto, ficou evidente que as feições de TD determinadas por altimetria e modelos geoidais precisam ser aprimoradas em termos de dados com melhor resolução espacial; 
- Considerando as correntes (resultantes do método direto, HYCOM e dados combinados), foi possível identificar as variabilidades nas duas estações (verão e inverno), no entanto o modelo numérico HYCOM e dados combinados da AVISO apresentaram feições mais detalhadas;

- As principais diferenças entre os resultados do método direto e os resultados obtidos a partir do modelo HYCOM e do conjunto de dados combinados da AVISO (MERGED) podem ser atribuídas às diferenças de resoluções espaciais entre os respectivos modelos, e também deve ser levado em conta a imprecisão dos dados de altimetria próximo à costa;

- Apesar da correlação moderada entre dados do HYCOM e os resultados do método direto, utilizando filtragem SSA com $\mathrm{M}=3$, os valores e variabilidades são similares, como pode ser observado nos gráficos de valores e espectros em alguns pontos.

Ficou evidente que o método direto, utilizando apenas altimetria e geóide, possibilita o estudo das variabilidades temporais das correntes, sem detalhamento das feições de pequenas escalas. Em geral, se pode concluir que a evolução dos modelos geoidais é evidente e que a altimetria, bem como os novos modelos do geopotencial, proporcionarão dados com resolução espacial e temporal que possibilitarão o estudo das correntes, vórtices e meandros com grande precisão. Os esforços concentrados em torno da utilização de modelos geoidais no estudo da circulação oceânica de superfície são justificados pela facilidade e vantagens que a tecnologia por satélite oferece (resolução espacial, cobertura, etc.).

O trabalho realizado sugere que o sistema GOCE deverá aprimorar significativamente os estudos de circulação no oceano, principalmente em curtos comprimentos de onda, onde os modelos geoidais atuais ainda carecem de resolução compatível. 


\section{7 - SUGESTÕES PARA TRABALHOS FUTUROS}

Com o conhecimento das vantagens e limitações que o método direto apresentou, e considerando os novos dados que serão brevemente disponibilizados, pode-se sugerir:

- A utilização dos dados do GOCE e dados altimétricos derivados de vários satélites no estudo das variabilidades do nível do mar e correntes;

- Estudo de correntes, vórtices, meandros e outros fenômenos, e suas possíveis relações, em pequena escala;

- Estudo das variações do geóide e suas implicações na dinâmica do oceano;

- $\quad$ Análise da circulação de regiões costeiras em pequena escala, utilizando dados de satélites. 


\section{8 - REFERÊNCIAS.}

Andersen, B. and P. Knudsen (2008), The DNSC08 global Mean sea surface and Bathymetry, Presented EGU-2008, Vienna, Austria.

AVISO (1996), Aviso user handbook merged TOPEX/POSEIDON products AVI-NT- 02101-CN 3.

AVISO (2008), AVISO and PODAAC User Handbook IGDR and GDR Jason Products SMM-MU-M5-OP-13184-CN (AVISO) JPL D-21352 (PODAAC).

AVISO (2010), SSALTO/DUACS User Handbook:(M)SLA and (M)ADT Near-Real Time and Delayed Time Products CLS-DOS-NT-06.034.

Bleck, R. (2002), An oceanic general circulation model framed in hybrid isopycniccartesian coordinates. Ocean Modell., 4, 55-58.

Castruccio, F., J. Verron, L. Gourdeau, J. Brankart, and P. Brasseur, (2008), Joint altimetric and in-situ data assimilation using the GRACE mean dynamic topography: a 1993-1998 hindcast experiment in the Tropical Pacific Ocean, Ocean Dynam., 58, 43-63, 1142

Chambers, D. P., J. Wahr, Nerem, (2004), Preliminary observations of global ocean mass variations with GRACE, Geophys. Res. Lett., 31, L13310.

Desai, S., N. Picot, K. Case, P. Vincent (2003), Aviso and podaac user handbook: IGDR and GDR jason products. Technical report, AVISO-CNES / PODAAC-NASA.

Francisco, C.P.F. (2007) Dinâmica de Meso escala da Confluência Brasil-Malvinas. Tese de Doutorado, IO/USP, 127 pp. 
Förste, C. et al. (2008), EIGEN-GL05C - A new global combined high-resolution GRACEbased gravity field model of the GFZ-GRGS cooperation, Presented EGU-2008, Vienna, Austria.

Garzoli, S.L. (1993) Geostrophic velocity and transport variability in the Brazil-Malvinas Conuence. Deep Sea Res., 40, 1379-1403.

Goni, J. G. and I. Wainer (2001), Investigation of Brazil Current from variability from altimeter data, J. Geophys. Res., 106 (C12), 31.117-31.128.

Goni, J. G. and W.E. Jons (2001), A Census of North Brazil Currents Rings Observed from TOPEX/POSEIDON Altimetry: 1992-1998, Geophysical. Research Letters, 106 (1).

Goni, J. G., S. Garzoli and D. Olson (1996), Dynamics of Brasil Malvinas Confluence based on inverted echo souders and altimetry. J. Geophys. Res., 101(C7), 16,27316,289 .

Gourdeau L., J. M. Lemoine, M.H. Rio, F. Hernandez (2003), Estimating mean dynamic topography in the tropical Pacific ocean from gravity and altimetry satellites. Geophys Res Lett 30(20):2062.

Heck, B. (2004), Problems in the Definition of Vertical Reference Frames. In: V HotineMarussi Synposium on Mathematical Geodesy. IAG Symposia, 127. Ed. Sansò F Springer, Berlin, pp. 164-173.

Heiskanen, W., and H. Moritz. -1967- Physical geodesy. W. H. Freemann, N. York, 364 pp.

Lemoine, F. G., et al. (1998), The development of the joint NASA GSFC and the National Imagery and Mapping Agency (NIMA) Geopotential Model EGM96, Rep. NASA/TP1998-206861, NASA Goddard Space Flight Cent., Greenbelt, Md. 
Lentini, C. A. D., G. J. Goni, and D. B. Olson (2006), Investigation of Brazil Current rings in the confluence region, J. Geophys. Res., 111, C06013, doi:10.1029/2005JC002988.

Matano, R. P. (1993), On the separation of the Brazil Current from the coast, J. Phys. Oceanogr., 23, 79-90,

Nerem, R. S., C. Jekeli and W. M. Kaula, (1995) Gravity field determination and characteristics retrospective and prospective. Journal Geophys. Res. 100 (B8): 1505315074

Olson, D. B., G. P. Podesta, R. H. Evans, and O. B. Brown (1988), Temporal variations in the separation of Brazil and Malvinas currents. Deep-Sea Res., 35(12), 1971-1990.

Parent L, C.E., Testut, J.M. Brankart, J. Verron, P. Brasseur and L. Gourdeau (2003), Comparative assimilation of Topex/Poseidon and ERS altimeter data and of TAO temperature data in the Tropical Pacific Ocean during 1994-1998, and the mean seasurface height Issue. J Mar Syst 40-41:381-401

Pavlis, N.K., S.A. Holmes, S.C. Kenyon and Factor (2008), An Earth Gravitational Model to Degree 2160: EGM2008, presented at the 2008 General Assembly of the European Geosciences Union, Vienna, Austria, April 13-18.

Polito, P. S and O. T. Sato (2004), Oceanografia por satélite. Apostila, IO/USP, São Paulo, $51 \mathrm{pp}$.

Provost, C., and P. Y. Le Traon (1993), Spatial and temporal scale in altimetric variability in the Brazil-Malvinas Current confuence region: Dominance of the semiannual period and large spatial scales, J. Geophys. Res., 98, 18,037-18,052. 
Rapp, R., Y. M. Wang, and N. Pavlis (1991), The Ohio State 1991 geopotential and sea surface topography harmonic coefficient models, Rep 410, Department of Geodetic Science and Surveying, The Ohio State University, Columbus.

Rio, M.-H., and F. Hernandez (2004), A mean dynamic topography computed over the world ocean from altimetry, in situ measurements, and a geoid model, J. Geophys. Res., 109, C12032, doi:10.1029/2003JC002226.

Robinson, A. R. (1985), Satellite Oceanography: an introduction for oceanographers and remote sensing scientists. Jonh Wiley and Sons. 455p

Silveira, I. C. A., A. C. K. Schmidt, E. J. D. Campos, S. S. Godoi, and Y. Ikeda (2000b), A Corrente do Brasil ao largo da costa leste brasileira. Revista. Rrasileira de Oceanografia., 48(2), 171-183.

Smith, W.H.F., and P. Wessel (1990) Gridding with continuous curvature splines in tension, Geophysics, 55, 293-305.

Stammer, D., C. Wunsch, R. Giering, C. Eckert, P. Heimbach, J. Marotzke, A. Adcroft, C. N. Hill, and J. Marshall (2002), Global ocean circulation during 1992 - 1997, estimated from ocean observations and a general circulation model, J. Geophys. Res., 107(C9), 3118.

Stommel, H. (1965), The Gulf Stream: a physical and dynamical description. Berkeley University of California Prees. 248 pp.

Stramma, L. and M. England (1999), On the water masses and mean circulation of the South Atlantic Ocean. J. Geophys. Res., 104(C9), 20.863-20.883.

Swenson, S. and J. Wahr (2002), Methods for inferring regional surface-mass anomalies 
form Gravity Recovery and Climate Experiment (GRACE) measurements of timevariable gravity. Journal of Geophysical Research, 107(B9), 2193.

Tapley, B. D., S. Bettadpur, J. C. Ries, P. F. Thompson, and M.M.Watkins (2004), GRACE measurements of mass variability in the Earth System. Science, 305:5683, 503-505.

Tapley, B.D., D.P. Chambers, B. Bettadpur, J.C. Ries. (2003), Large scale ocean circulation from the GRACE GGM01 Geoid. Geophys Res Lett 30:2163-2166.

Tapley, B. D., J. Ries, S. Bettadpur, D. P. Chamberr, M. Cheng, F. Condi, B. Gunter, Z. Kang, P. Nagel. R. Pastor, T. Pekker, S. Poole and F. Wang (2005), GGM02- An improved Earth gravity field model from GRACE. J. of Geodesy 79, 467-478.

Tapley, B. D., S. Bettadpur, M. Watkins, C. Reigber (2004), The Gravity Recovery and Climate Experiment: Mission overview and early results, Geophys. Res. Lett., 31, L09607, doi:10.1029/2004GL019920.

Tscherning, C. C., (1976), On the chain-rule method for computing potential derivatives, Manuscripta Geodaetica, Vol. 1 pp. 125-141.

Vianna, M. L., V. V. Menezes, and D. P.Chambers (2007), A high resolution satellite-only GRACE-based mean dynamic topography of the South Atlantic Ocean, Geophys. Res. Lett., 34, L24604, doi:10.1029/2007GL031912.

Vianna, M. L., V. V. Menezes (2010), Mean Mesoscale Global Ocean Currents from Geodetic Pre-GOCE MDTs with a Synthesis of the North Pacific Circulation, Journal. Geophysical. Research, 115, C02016, doi:10.1029/2009JC005494

Vossepoel, F. C. (2007), Uncertainties in the mean ocean dynamic topography before the launch of the Gravity Field and Steady-State Ocean Circulation Explorer (GOCE), $J$. 
Geophys. Res., 112, C05010, doi:10.1029/2006JC003891.

Wenzel, G. (1999) Global model of the gravity field of high and ultra- high resolution. Preprint of a paper submited to Buletin of the International Geoid Service, Milan, Italy, 36 pp. 